\title{
Exploring Resettlement Impacts of Hydroelectric Projects
}

\section{A Case Study of Resettlement due to Nam Theun 2 Hydroelectric Project in Lao PDR}

A thesis presented in partial fulfilment of the requirements for the Degree of Master of Philosophy in Development Studies at Victoria University, Wellington, New Zealand 


\section{Abstract}

Over the past five decades, there has been growing awareness of the potential negative effects of development-induced displacement and resettlement. For example, resettlement can threaten people's livelihoods and well-being and sustainable development. In response to this phenomenon, many international financial organisations led by the World Bank have adopted safeguard policies, standards, and guidelines, especially around forced resettlement. These safeguard documents maintain that organisational and financial arrangements - through livelihood restoration programmes - can possibly alleviate displaced people's impoverishment risks if those risks are correctly identified early. This thesis explores claims that such risks in development-caused involuntary population resettlement can be addressed by effective planning processes. Specifically, this thesis examines how resettlement and livelihood restoration programmes related to the Nam Theun 2 hydroelectric project (NT2) in Lao PDR were able (or not) to address the livelihood sustainability of resettled communities.

In conducting fieldwork in Lao PDR, this thesis employed a mixed methods approach using both qualitative and quantitative methods including semi-structured interviews, focus groups, and analysis of quantitative and qualitative secondary data.

The key findings found in this study reflect NT2's mixed performance of resettlement. On the one hand, the project provided enormous advantages to Lao PDR: a) the cooperation between Lao government and international stakeholders including resettled people in the preparation of resettlement strategies; b) introducing the Lao government and resettled people to a new global standard of resettlement practice. On the other hand, this project also caused a number of challenges: a) incomplete preparation of the resettlement strategies; b) unsuccessful implementation of livelihood restoration programmes; and c) the lack of precision in terminology - stipulated in the $\mathrm{CA}$ - to enable the effective establishment of measures, indicators and criteria which could be used to inform objective and fair decision making. These findings seem to hold NT2 back from successfully achieving the sustainable development for resettled people's livelihoods and well-being.

The findings of this study should be of interest to development academics and practitioners working in the fields of energy development and development-induced displacement and resettlement. Specifically, the lessons learned from resettlement and 
livelihood restoration programmes implemented by Nam Theun 2 hydroelectric project are crucial, because it is considered a role model for other hydropower projects in Lao PDR. It is hoped that the results of this study can make a contribution to the on-going improvement of the Lao government's existing policies on resettlement and livelihood restoration strategies in order to fulfil sustainable development goals. 


\section{Acknowledgements}

In recognition of the support and assistance throughout this research, I would like to acknowledge a great number of people, individuals and groups who have contributed to this study and more significantly made this thesis possible.

First and foremost, I would like to show my greatest gratitude to my mother and sister, Mrs Many Chidmany and Mrs Phonethip Chidmany for your warm and unconditional support. Also, my beloved wife and son were always the source of my inspiration and encouragement to complete the programme.

This thesis would not have been possible without the amazing support from NZAID programme and the wonderful assistance from Development Studies Department at Victoria University of Wellington. Particularly, I would like to express my deep appreciation to my amazing supervisor, AProf Sara Kindon, for being an invaluable mentor, support system and friend throughout the entire process. Importantly, your continuous guidance throughout my time in New Zealand and in Laos was priceless.

I would like to extend my greatest gratitude to all of my research participants. Your warmth and sincerity made my fieldwork such an inspiring and rewarding experience. Specifically, a heartfelt thank you goes to my organisation, Department of Environmental and Social Impact Assessment, Ministry of Natural Resources and Environment for your wonderful support and assistance. Friendship and encouragement from my bosses and colleagues have been meaningful and filled with many wonderful memories.

Finally, immense gratitude to my fellow classmates and friends who shared an amazing friendship with me and who also provided comfort to me that have made my time in New Zealand more enjoyable and most memorable. 


\section{Table of Contents}

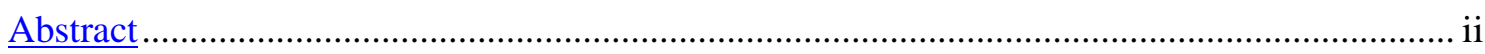

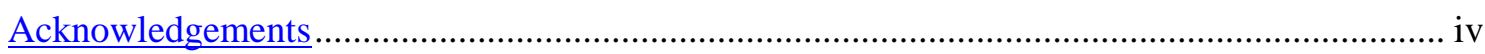

List of Abbreviations ................................................................................................... vii

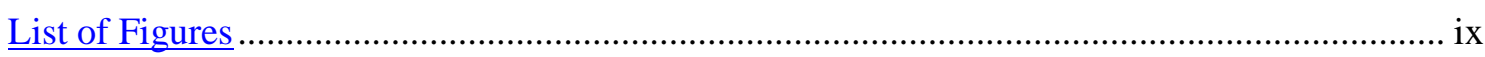

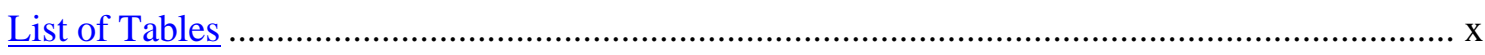

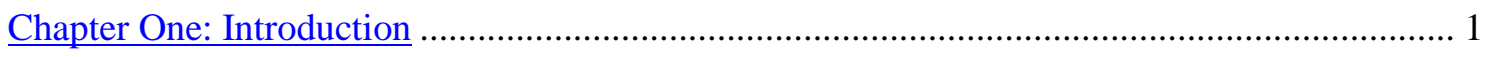

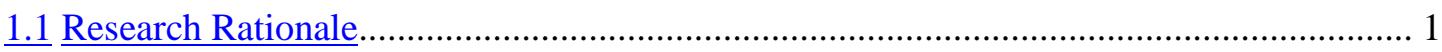

1.2 Research Motivation and Positionality ……............................................................... 2

1.3 The emergence of Nam Theun 2 hydroelectric project in Lao PDR................................... 4

1.4 The Social Impacts and Mitigation Measures of the NT2 Development ............................. 8

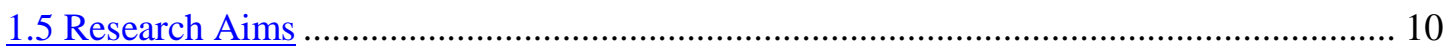

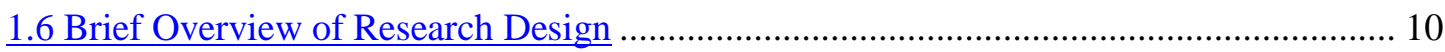

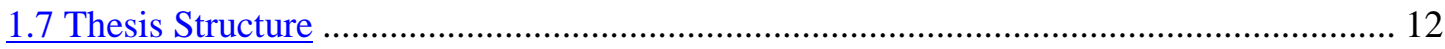

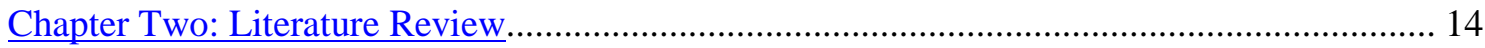

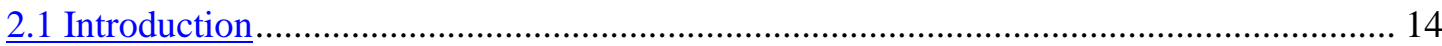

2.2 Development-Induced Displacement and Resettlement (DIDR) ..................................... 14

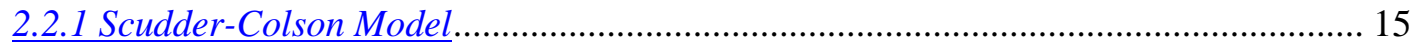

2.2.2 Impoverishment Risk and Reconstruction (IRR) Model............................................ 16

2.3 Compensation, Resettlement and Livelihood Restoration ................................................ 19

2.4 A Brief Overview of Contemporary Resettlement Discourse ............................................. 25

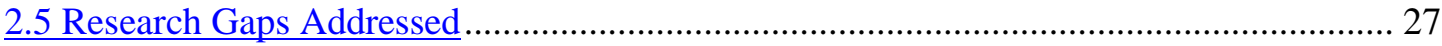

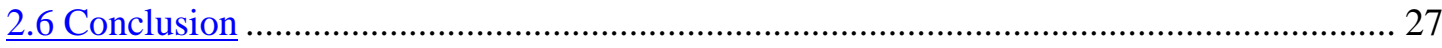

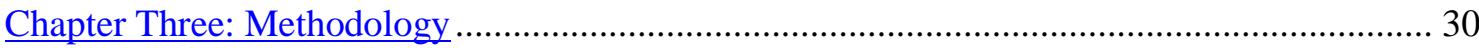

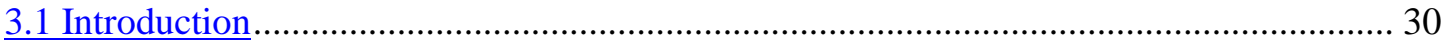

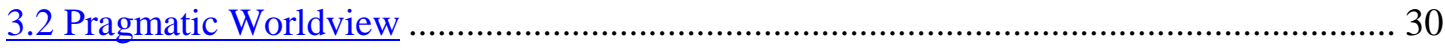

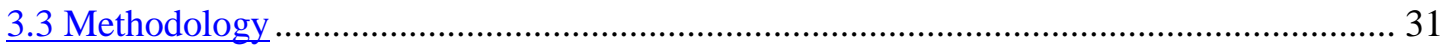

3.4 The Case Study of Nakai Plateau Resettlement Community............................................. 32

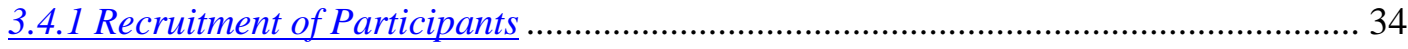

3.4.2 Qualitative Research Methods ............................................................................... 35

3.4.3 Quantitative Research Methods - Numbers and Statistics ...................................... 37

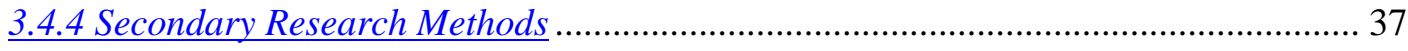

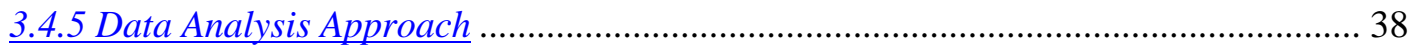

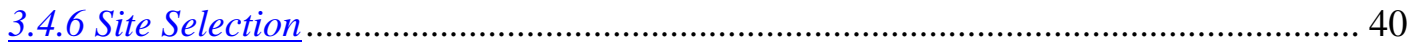

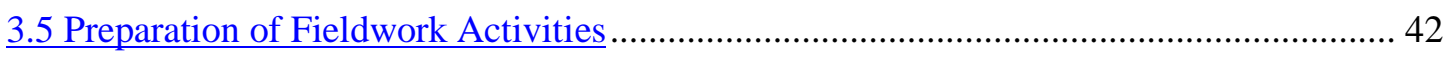

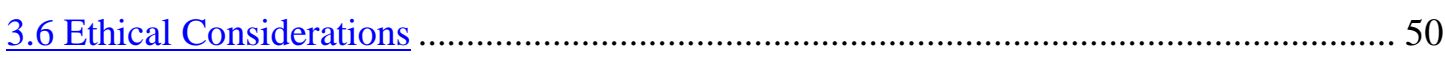

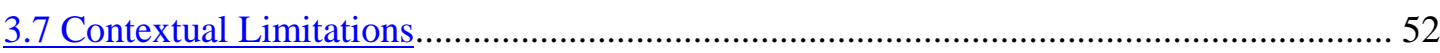




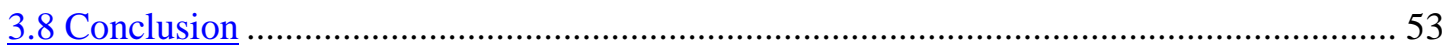

Chapter Four: The Preparation of NT2 Resettlement Strategies ............................................. 55

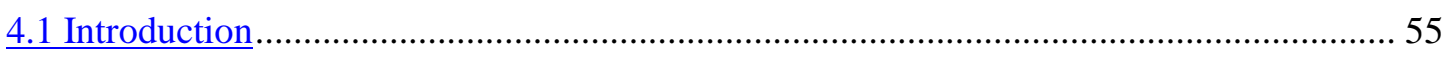

4.2 Introduction to the Nakai Plateau Resettlement Community........................................... 55

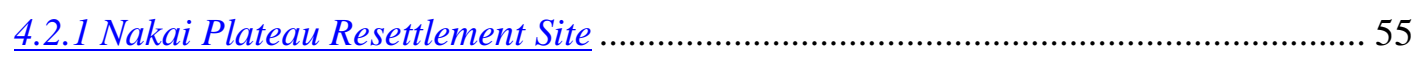

4.2.2 The Two Selected Resettled Villages before Resettlement ........................................ 58

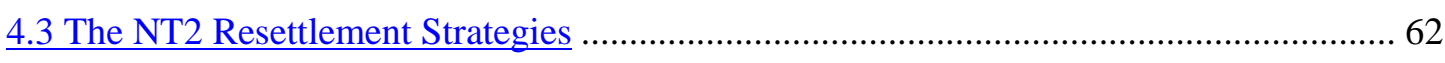

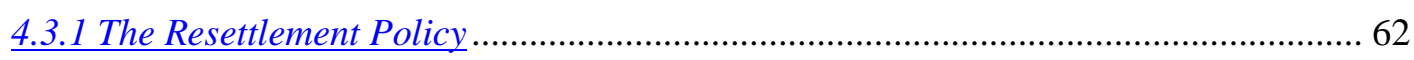

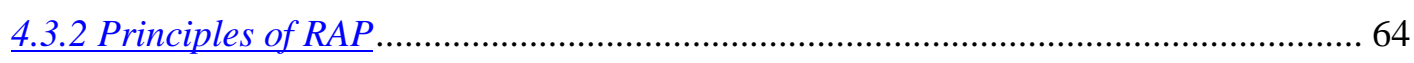

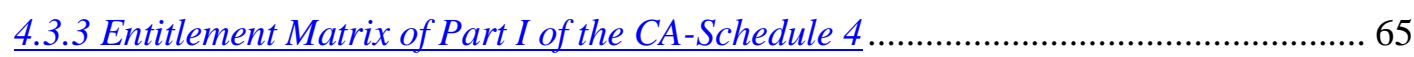

4.3.4 Analysing NT2 Resettlement Strategies through IRR Model ......................................66

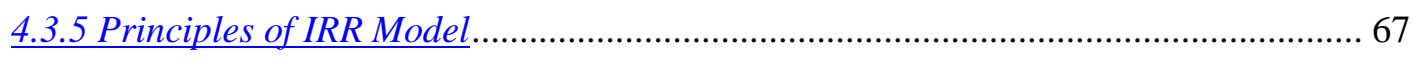

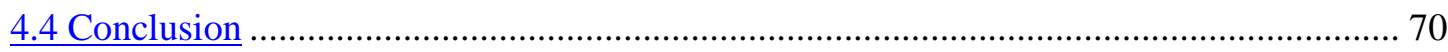

Chapter Five: The Implementation of NT2 Resettlement Strategies ...................................... 71

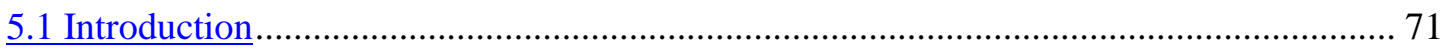

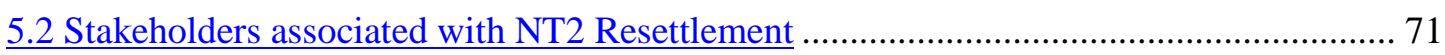

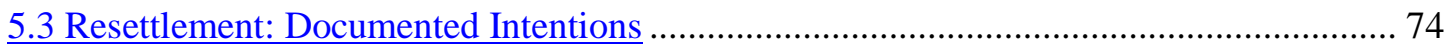

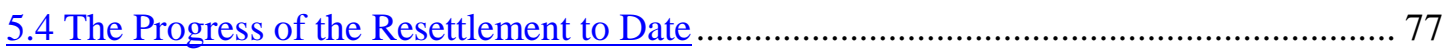

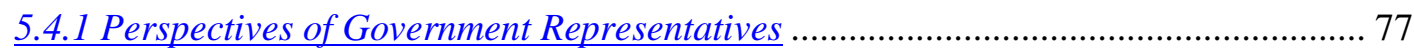

5.4.2 Perspectives from representatives of two resettled villages...................................... 83

5.4.3 Perspective of the Panel of Experts (POE) on the NT2 resettlement programmes.... 86

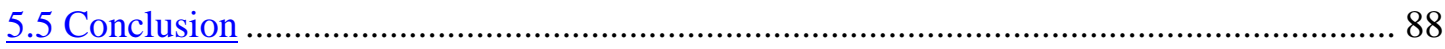

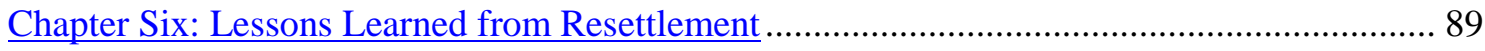

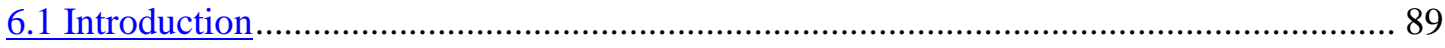

6.2 Benefits gained from NT2 resettlement ………............................................................ 89

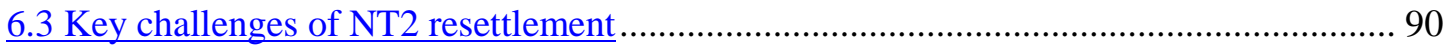

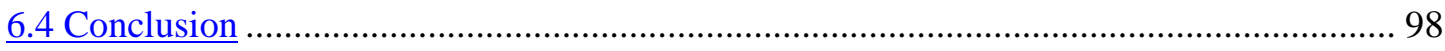

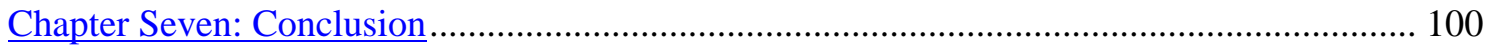

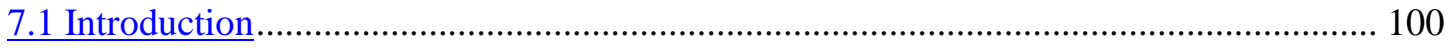

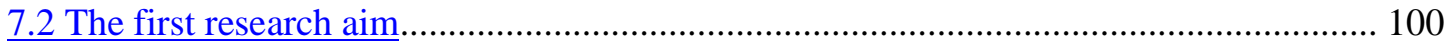

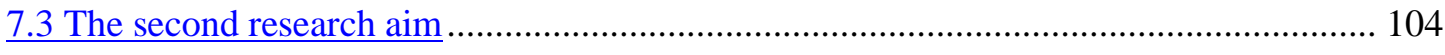

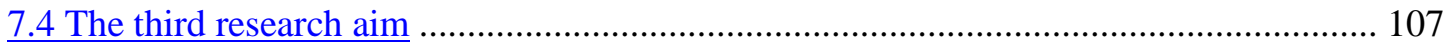

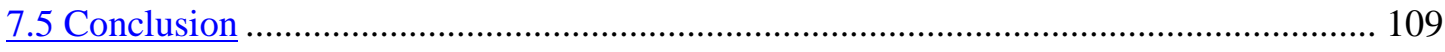

7.5.1 Research recapitulation .................................................................................. 109

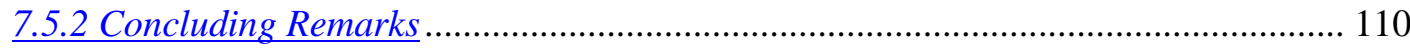

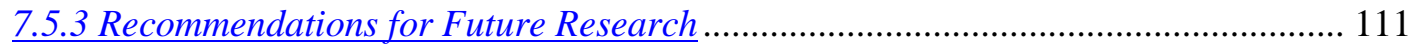

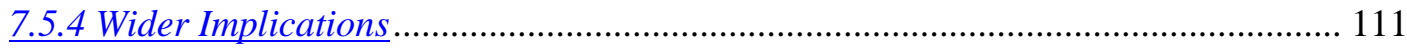


Appendices

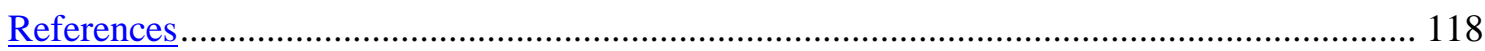

\section{List of Abbreviations}

ADB

CA
Asian Development Bank

Concession Agreement 
DCWGs

DEB

DESIA

DIDR

DRWGs

EMDP

FDI

GDP

GNI

GOL

HIT

IFC

IRR

Lao PDR

LSMS

MDG

MEM

MoNRE

MOU

MW

NRPL

NSEDP

NT2

NTPC

NZAID

PAP

POE
District Compensation Working Groups

Department of Energy Business

Department of Environmental and Social Impact

Assessment

Development-Induced Displacement and Resettlement

District Resettlement Working Groups

Ethnic Minority Development Plan

Foreign Direct Investment

Gross Domestic Product

Gross National Income

Government of Lao PDR

Household Income Target

International Finance Corporation

Impoverishment Risk and Reconstruction

Lao People's Democratic Republic

Living Standards Measurement Survey

Millennium Development Goals

Ministry of Energy and Mines

Ministry of Natural Resources and Environment

Memorandum of Understanding

Megawatt

National Rural Poverty Line

National Socio-Economic Development Plan

Nam Theun 2 Hydroelectric Project

Nam Theun 2 Power Company Limited

New Zealand Agency for International Development

Project-Affected People

Panel of Expert 


\begin{tabular}{ll} 
QSEM & Quarterly Socio Economic Monitoring \\
RAP & Resettlement Action Plan \\
RC & Resettlement Committee \\
RIP & Resettlement Implementation Period \\
RO & Resettlement Office \\
ROs & Resettlement Objectives \\
RMU & Resettlement Management Unit \\
RPF & Resettlement Policy Framework \\
RPs & Resettlement Provisions \\
SESO & Standard Environmental and Social Obligations \\
SDP & Social Development Plan \\
VFA & Village Forest Association \\
VIT & Village Income Target \\
VRCs & Village Resettlement Committees \\
VUW & Victoria University of Wellington \\
WB & World Bank \\
WCD & World Commission on Dams \\
\hline
\end{tabular}

\section{List of Figures}

Figure 1: Map of Lao PDR 
Figure 2: NT2 Project Location and Infrastructure

Figure 3: Thesis Structure Flowchart

Figure 4: Lao PDR

Figure 5: Khammouane Province

Figure 6: The Organisational Responsibilities for Resettlement

\section{List of Tables}


Table 1: The original plan of fieldwork activities concerning interviews and focus groups in resettled communities

Table 2: The adjusted plan of fieldwork activities concerning interviews and focus groups in resettled communities in response to the real changed situations 


\section{Chapter One: Introduction}

\subsection{Research Rationale}

By the mid-twentieth century, dam development and its environmental and social effects were regarded and treated as domestic - rather than international - issues (Fujikura \& Nakayama, 2009). Most large dams were constructed in industrialised countries where only a small number of their citizens were affected. In addition, projectaffected people's (PAP) livelihoods were often restored without significant socioeconomic effects arising, as national economic development combined with relatively high incomes provided the resources to solve most of the problems that arose (Fujikura \& Nakayama, 2009). However, in developing countries, another story emerged. According to Gutman (1994), during the second half of the twentieth century the number of displaced people caused by development projects in developing countries such as China and India, was over 50 million. Within that number, there were initially more than 10 million affected by the construction of hydropower projects.

With an increase in new dam construction projects in developing countries in the latetwentieth century, environmental and social problems associated with these projects have arisen (Fujikura \& Nakayama, 2009). For example, the number of displaced population worldwide caused by the construction of large dams rose to around $40-80$ million (Fujikura \& Nakayama, 2009). Most displaced people were farmers, and they were expected to continue farming after resettlement. Unfortunately, their livelihoods were poorly re-established by hydroelectric project developers in many cases. This failure caused some resettled people to either sell their land and become tenant farmers or move to a city in search of work (Fujikura \& Nakayama, 2009). Consequently, issues associated with dam construction projects became international. Furthermore, environmental and social concerns related to hydroelectric development projects became contextualised within global issues such as human rights and biodiversity (Fujikura \& Nakayama, 2009).

Given these circumstances, involuntary resettlement has become a sizeable societal consequence of many large-scale hydroelectric development projects. Based on insights from many case studies, involuntary resettlement in numerous dam construction projects can generate enormous socio-economic risks for resettled people's lives (Gutman, 1994; Cernea, 1995; Downing, 2002). The risks of involuntary resettlement have been defined by displacement specialists as: the loss of physical and non-physical 
assets which encompass: homes, communities, productive land, income-earning assets and sources, subsistence, resources, cultural sites, social structures, networks and ties, cultural identity and mutual help mechanisms (Downing, 2002).

In the current context in which forced eviction and land-grabbing have become a human rights crisis in the Global South, the World Bank cannot continue its current approach, which treats involuntary resettlement as an acceptable price to be paid by local people, and which assumes that the risks and rights violations can be mitigated by the requirements of the current safeguard policy.

(Bulgalski \& Pred, 2013, p. 1)

As a consequence of these impoverishment risks, the World Bank (WB) has developed safeguard policies on forced resettlement (Bulgalski \& Pred, 2013). It also recognises that without effective planning and implementation of proper measures, the PAP potentially risk facing issues such as homelessness, loss of livelihoods, food insecurity, psychological trauma, negative health impacts, loss of health status, increased morbidity and vulnerability (especially among women and children), economic and cultural marginalisation, and social disintegration (Bulgalski \& Pred, 2013).

The challenges of involuntary resettlement impacts and the risk of displacementinduced impoverishment have intrigued many international financial intermediaries and non-governmental organisations and resulted in international policies, standards and guidelines (Downing, 2002). These policies and standards maintain that organisational and financial arrangements - through livelihood restoration programmes - can possibly alleviate the potential impoverishment risks facing resettled peoples if correctly identified early (Downing, 2002). However, many developing countries, especially in Asia, still have a dearth of formal policies and legal regulations (McDonald, Webber \& Yuefang, 2008). Specifically, the Asian Development Bank (ADB) in their review of resettlement policies and practices, stated that national resettlement policy is absent in the Lao People's Democratic Republic (Lao PDR), Thailand, Malaysia, Pakistan, Nepal, Sri Lanka, Vietnam, Philippines and India (McDonald, Webber \& Yuefang, 2008).

\subsection{Research Motivation and Positionality}

Since my employment at Ministry of Natural Resources and Environment (MoNRE), Lao PDR in 2007, I have been professionally concerned with environmental and social matters caused by hydroelectric projects and these have undoubtedly informed my 
desire to carry out this particular research project. When I was working for the MoNRE, I was a member of a task force in charge of negotiating concession agreements (CA) for the energy sector, particularly the environmental and social obligations with hydroelectric development investors (between 2007 and 2013). This task force was comprised of government officers, international lawyers and technical advisers who represented the MoNRE in determining and agreeing on the specific environmental and social obligations that would govern the investment projects. It was in this capacity that I provided legal, technical and management support to various competent officers within MoNRE and relevant line ministries dedicated to ensuring a high standard of environmental and social safeguards in large hydroelectric development projects.

Specifically, I played a part in achieving the development and application of standard environmental and social obligations (SESO) for energy concession agreements. The SESO is a living document which has been continually evolving throughout numerous implementations of hydropower development projects. It encompasses general obligations applicable to all hydroelectric projects and all types of environmental and social impacts including the issues of resettlement, compensation, livelihood restoration, and so forth.

Through this experience, I discovered that the SESO was initially developed from environmental and social obligations under the CA of Nam Theun 2 hydroelectric project (NT2). NT2 has been widely regarded by WB as a role model of sustainable development for hydropower projects in Lao PDR in terms of socially and environmentally responsible development. (Goldman, 2001; Singh, 2009). Nonetheless, there is no guarantee that well-prepared high level systematised resettlement plans always ensure both effective resettlement practice and outcomes. Hence, in response to this situation, it is crucial to assess the actual performance of NT2 resettlement, compensation, and livelihood restoration programmes. It is this contention that has inspired me to conduct research to examine the implementation of NT2 resettlement, compensation, and livelihood restoration programmes. 


\subsection{The emergence of Nam Theun 2 hydroelectric project in Lao PDR}

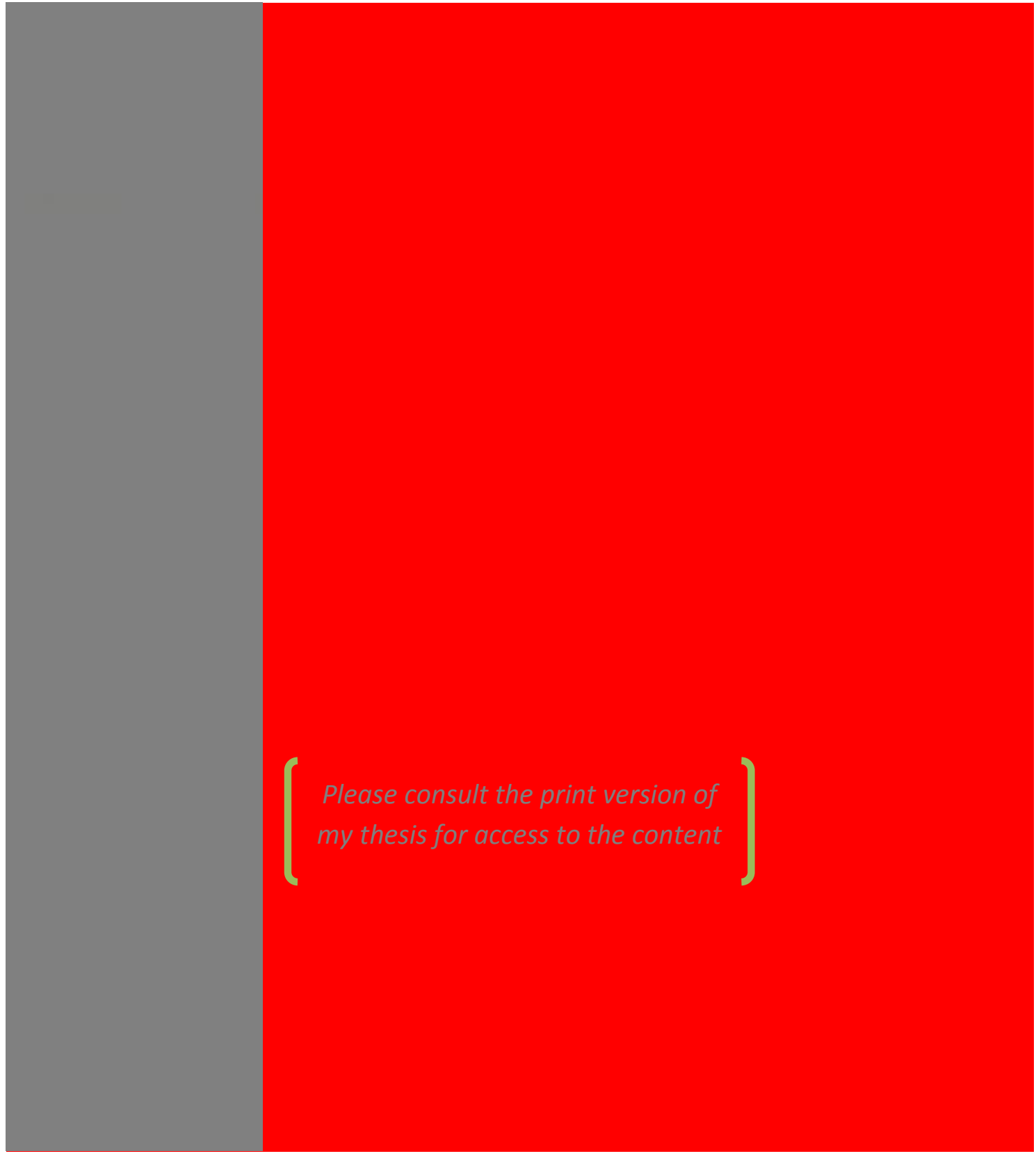

Figure 1: Map of Lao PDR. Image is retrieved from: http://backridetravel.com/about-laos

Lao People's Democratic Republic (Lao PDR) is a one-party state that has been dominated by the Lao People's Revolutionary Party since the 1970s. In the last four decades, it has transitioned from Marxism-Leninism to a more market-oriented economy (Jönsson, 2009). Because Lao PDR remains politically a one-party state with both old-style Soviet-era institutions and free market orientations, it is remarkably stable, politically and economically (Lintner, 2008). In fact, Lao PDR - under a new economic mechanism initiated in the 1980s - aims to escape from its least developed nation status by 2020 (Delang \& Toro, 2011). Indeed, by raising the gross national 
income (GNI) per capita to approximately USD 1,650, Lao PDR should reach this goal (Lintner, 2008; \& World Bank, 2015).

Even though Lao PDR is one of the least developed countries in South East Asia, it has great potential for hydroelectric development (Delang \& Toro, 2011). According to Jusi (2011), Lao PDR has its own determined pathway for development, due to the nation's abundant natural resources. Within these resources, water is fundamental, as it is the key resource for hydroelectric generation which has been identified as the major national development opportunity.

The Lao government considers the exploitation of hydroelectric development as the key to reducing poverty and to fulfil the Millennium Development Goals (MDG) (Jönsson, 2009). Hence, in promoting economic and social development and overcoming the country's comparative disadvantages, hydroelectric development has become the national strategy which aims to expand an affordable, reliable and sustainable electricity supply (Jusi, 2011). In doing so, the Lao government has set up a goal to expand the generation, transmission, distribution and off-grid development to increase the national electrification ratio for the country to a target of above 90 per cent by 2020 (Jusi, 2011). It is significant to note that Lao PDR wants to become the "battery of the region" by increasing the production capacity to 30,000 Megawatt (MW) (Jönsson, 2009, p. 202). Given this intention, the Lao government has emphasised the building of a large number of hydroelectric dams on the tributaries of the Mekong River (Delang \& Toro, 2011).

In fact, according to the Lao government's economic transformation during the five years of the $6^{\text {th }}$ National Socio-Economic Development Plan (NSEDP; 2006-2010), the primary economic success was an increase of foreign direct investment (FDI), particularly in hydropower development (Creak, 2011). Thus, hydroelectric development has played a key role in the recent economic boom of more than seven per cent GDP growth per annum (Lintner, 2008). Given this success, based on the approval of the National Assembly of the $7^{\text {th }}$ NSEDP (2011-2015), the Lao government has intended to continue exploiting these opportunities (Creak, 2011). Hence, the Lao government has been developing a number of hydroelectric projects. For example, there are currently nine dams under construction, nineteen dams in advanced planning, and a further seventy hydropower projects are undertaking preparatory research studies (Jusi, 2011). 
Among these hydropower projects, Nam Theun 2 hydroelectric project (NT2) is the most prominent, and is located in the central part of the country (Erlanger et al., 2008). NT2 is one of the largest infrastructure development projects in South East Asia with a financial investment of over one billion US dollars secured through international loans (Erlanger et al., 2008). In other words, at the time of signing the CA it was the largest ever foreign investment funded project in Lao PDR and the largest internationally financed independent power producer project in South East Asia (Lintner, 2008).

The Lao government has recognised this project as an essential part of the country's development framework to reduce poverty (Jusi, 2011). Specifically, the construction of NT2 adds another 1,070 MW installed capacity which has allowed 95 per cent of its power output to be exported to neighbouring Thailand since late 2009 (Lawrence, 2009; Jusi, 2011). In terms of national revenues gained from NT2, the Lao government is now able to earn royalties, taxes and dividends estimated to be USD 80 million. Importantly, a part of such annual revenues is specifically allocated to poverty alleviation purposes which could help lessen poverty in Lao PDR as well as assist the country to achieve its 2020 development goals (Erlanger et al., 2008; Lintner, 2008).

NT2 was planned in 1995 and implemented over the two decades (Ovenden, 2007). Various stakeholders are involved in the project such as the Lao government, private sector agencies, non-governmental organisations and multilateral financial institutions such as WB (Imhof \& Lawrence, 2005). This multi-stakeholder engagement has led NT2 to be widely recognised as an exemplary example of how the Lao government and various sectors work together. NT2 includes investments for management projects concerning forest and conservation, wildlife and protected areas, and indigenous people's extractive reserves (Goldman, 2001). In addition, it also encompasses irrigated and modernised agriculture with experimental farms, electricity and new roads, megafauna running corridors and eco-tourism, sustainable logging and tree plantations, and new housing settlement (Goldman, 2001). Given this story of its planning and performance, valuable insights and lessons learned from this project can potentially be employed in future projects of similar size, scope, and complexity (Porter \& Shivakumar, 2010). Thus, NT2 has become seemingly WB's flagship project or role model for other fellow hydroelectric development proponents, especially ones under WB's portfolio (Goldman, 2001). 
Overall, the emergence of NT2 as the project boasting the single largest investment status in Lao PDR would suggest that it is of considerable importance for the national economy (Singh, 2009). It also plays a significant role in the broader development of the country by providing capacity building to manage natural resources and develop infrastructure, and to improve the transparency and effectiveness of public expenditure management systems (Jusi, 2011). Furthermore, the preparation of NT2 - through numerous studies and lengthy consultation processes - has enabled the Lao government to pave the way for more participatory, transparent and improved hydropower developments in Lao PDR (Singh, 2009). Hence, it represents a guide for other hydroelectric development proponents nationwide.

NT2 project was carried out under the CA between the Lao government and a project limited company established in Lao PDR. This company is licensed as a foreign investment company under Lao PDR Law called Nam Theun 2 Power Company Limited (NTPC) (Nam Theun 2 hydroelectric project, 2005). The CA granted the NTPC the concession to implement the project on a build, own, operate and transfer basis for a concession period of 25 years following the occurrence of the commercial operations date, subject to certain rights of extension of that term (Nam Theun 2 hydroelectric project, 2005). It is interesting to note that NT2 will be transferred free of charge to Lao PDR after twenty-five years of operation by the NTPC (Lintner, 2008). Thus, NT2 seems to contribute plentiful advantages for the Lao national economy while simultaneously helping to alleviate poverty.

Nevertheless, even though the nature of hydropower development results in generating opportunities for infrastructure development and economic growth, it has potential to cause negative impacts on people's lives and well-being. Particularly, remote rural populations are the most likely to be affected by "the sudden influx of men, materials and money, and associated population mixing that accompany project construction phases" (Erlanger et al., 2008, p. 223). Given this concern, some observers have criticised the Lao government for the exploitation of hydroelectric development as a central strategy. Specifically, concerns have been raised regarding environmental and livelihood issues such as the impact on fisheries and the relocation of farmers caused by the building of dams, and of particular concern is when resettlement is forced or involuntary (Jönsson, 2009). 
Furthermore, the financial benefits from NT2 require big trade-offs. For example, land, river, forest and wildlife habitats are inundated by NT2's 450 square-kilometre reservoir and this has also caused thousands of local people to be displaced (Ovenden, 2007; Lawrence, 2009). Consequently, the impact of the project is considered a high risk in terms of its threats towards the environment and human rights (Hirsch, 2002). Such risks and concerns raise questions about what adverse impacts NT2 has created and how they have been fully addressed so far.

\subsection{The Social Impacts and Mitigation Measures of NT2 Development}

Figure 2: NT2 Project Location and Infrastructure.

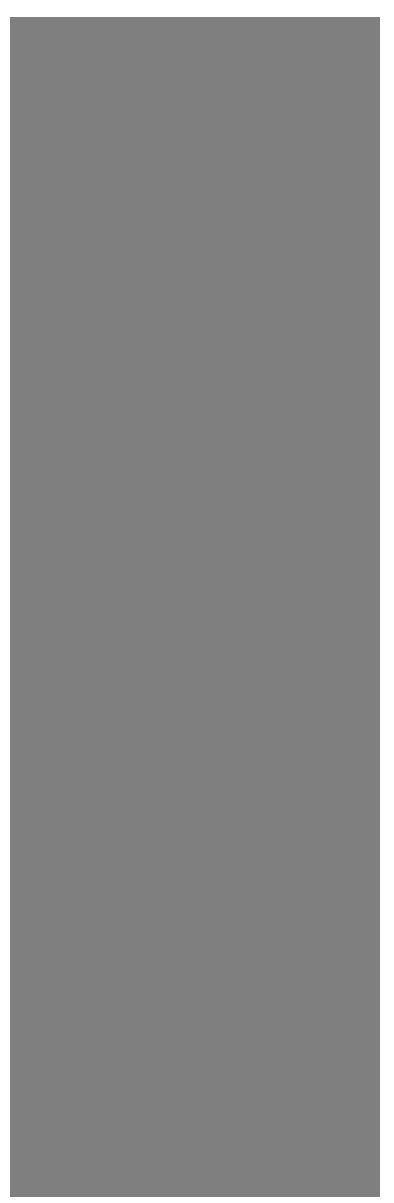

Please consult the print version of my thesis for access to the content

Source: Nam Theun 2 project, 2005, p. 2

NT2 is a mega hydroelectric project which encompasses three provinces: Bolikhamxay (dam area), Khammouane (reservoir power plant, channel, roads), and Savannakhet (transmission line into Thailand) (Lintner, 2008). These three provinces have been mainly affected by NT2's construction of a dam on the Nam Theun River and a 450square-kilometre reservoir (Nam Theun 2 project, 2005). However, Khammouane province has been the relatively most affected area, especially its nine districts: 
Khamkeut, Nakai, Gnommalat, Mahaxai, Xe Bangfai, Thakhek, Nong Bok, Xaibouly and Khanthabouly. Of these, the majority of project activities concerning the construction and operation of NT2 - which potentially result in a range of impacts to the biophysical, socio-economic and cultural environments of the project area - have taken place in the districts of Nakai, Gnommalath and Mahaxai (Ovenden, 2007).

Under NT2 development, over 6,000 indigenous people have been directly affected in the form of resettlement, while more than 100,000 local residents' livelihoods have been indirectly impacted (Delang \& Toro, 2011). According to Phonepraseuth (2012), these impacts have caused damage to local people's traditional lifestyles, cultural identity and living standards, especially for poorer residents who tend to have a stronger cultural attachment to land and other environmentally based resources.

In response to such impacts, NT2 has provided a bundle of mitigation measures (resettlement, compensation, and livelihood restoration programmes) to specifically address the three main project-affected areas. They comprise the reservoir area on Nakai Plateau, NT2's project construction lands, and the downstream areas (Ovenden, 2007). The reservoir area on the Nakai Plateau (in Nakai district) was the first area that all project-affected families are entitled to resettle in. This was the preferred agreed location where new housing was obtained, along with physical and community infrastructure, and the provision of wide-ranging livelihood re-construction programme activities (Ovenden, 2007).

The second area was NT2 project construction lands which were considered to be acquisitioned project land for the construction of NT2 project components. This acquisition of land for project activities has generated wide-ranging effects from disturbance, temporary and permanent land and asset loss requiring compensation to project-affected families as well as restoration of their livelihoods (Ovenden, 2007). The final area was downstream from the power station where the communities along the Xebangfai, Kathang and Gnom Rivers have experienced erratic degrees of impact on their livelihoods and infrastructure. These effects are derived from variations in the hydrological regime, quality of the water and erosion patterns in the receiving water bodies as a result of the construction and new infrastructure (Ovenden, 2007).

Within the three affected areas, the Nakai Plateau (involving over 6,000 families) has received most attention (Imhof \& Lawrence, 2005). The development of the Nakai resettlement and livelihood restoration programmes has become central to NT2's 
resettlement mitigation scheme. Based on NT2's CA, the project is obligated to be responsible for addressing and alleviating or remedying all social impacts resulting from its project activities, especially the sustainable resettlement of the Nakai Plateau population (Nam Theun 2 hydroelectric project, 2005). In translating such social obligations into concrete practicable plans, NT2 has specifically prepared resettlement strategies for all PAP in the Nakai Plateau. These strategies comprise a resettlement action plan (RAP), five pillars of livelihood restoration programmes, a social development plan (SDP), an ethnic minority development plan (EMDP), and so forth (Nam Theun 2 hydroelectric project, 2005; Nam Theun 2 hydroelectric project, n.d.).

\subsection{Research Aims}

Thus, this research will explore the resettlement effects derived from the Nam Theun 2 hydroelectric project. Specifically, the primary aim of this research is to examine the contribution of NT2 resettlement strategies for project-affected populations in the Nakai Plateau. Under this broad objective, three particular aims and sets of research questions are pursued:

Aim 1: Exploring NT2 resettlement strategies preparation.

What social mitigation measures had NT2 prepared in response to resettled people's livelihoods and well-being before resettlement commenced?

Aim 2: Identifying what outcomes were gained from implementation of NT2 resettlement strategies.

How effective have those social mitigation measures been in terms of addressing relevant resettlement challenges throughout the resettlement implementation period?

Aim 3: Examining key lessons learned from NT2 resettlement.

What are the successes and the challenges derived from NT2 resettlement performance?

\subsection{Brief Overview of Research Design}

A mixed methods research approach - qualitative and quantitative - has been employed in this study. According to Leech \& Onwuegbuzie (2009, p. 265), "In general, mixed methods research represents research that involves collecting, analysing, and interpreting quantitative and qualitative data in a single study or in a series of studies 
that investigate the same underlying phenomenon." The goal of mixed methods research is not to replace either of these approaches. Instead, it aims to draw from the strengths and minimise the weaknesses of both in single research studies and across studies (Johnson \& Onwuegbuzie, 2004).

A qualitative approach was applied using semi-structured interviews and focus groups to gain insights into various research participants' experiences concerning their resettlement within NT2 schemes. Research participants mainly consisted of a number of resettled residents in two resettled villages in the Nakai Plateau resettlement community: Nakai and Phon-Sa-On (or Sop On) including their village chiefs. Additionally, some representatives of the Lao governmental agencies who were involved in NT2 resettlement activities were interviewed.

Because the primary aim of this thesis was to assess NT2's capability in terms of improving resettled people's lives and well-being on a sustainable basis, it put emphasis on lived experiences and perspectives of those various research participants.

Importantly, their contributions were expected to help identify potential risks associated with the current situation of NT2's resettlement performance which may have prevented the project from achieving its sustainable development goals. Consequently, the main lessons learned from the performance of the project were also attentively explored so as to provide recommendations for future improvements of resettlement endeavours.

A quantitative approach was employed by integrating data gained from various sources such as Lao government's laws, policy documents and guidelines on NT2, project documents from NT2, and other sources associated with NT2. Employing both secondary sources and interview and focus group data provided an opportunity to integrate and triangulate information increasing the rigour of my work (Sørensen, Sabroe \& Olsen, 1996; Murray \& Overton, 2003). 


\subsection{Thesis Structure}

Figure 3: Thesis Structure Flowchart

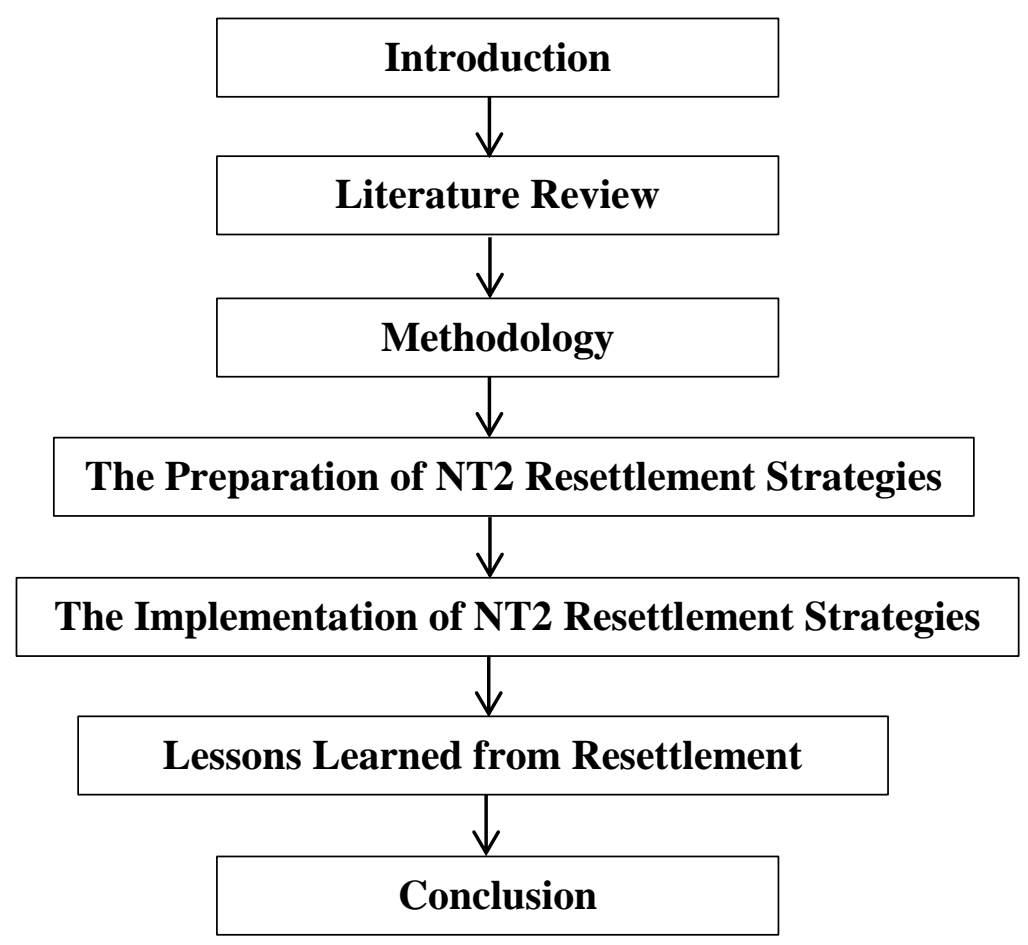

Chapter one provides a description of the research context and the study site, NT2 in Lao PDR. In addition, it also illustrates the research aims and main research questions.

Chapter two provides an overview of resettlement literature. It begins with an introduction of development-induced displacement and provides a background of the two prominent resettlement models, namely the Scudder and Colson (1982) model of resettlement processes and Cernea's impoverishment risks and reconstruction (IRR) model (1997). This chapter also outlines an exploratory discussion about the concepts of resettlement and livelihood restoration in relation to sustainable development.

Chapter three attends to the processes of the fieldwork. It starts with an introduction of a pragmatic worldview as the epistemological lens used in this research. The chapter then continues with a description of the rationale for the adoption of particular research approaches, data collection processes, data analysis techniques, site selection, participant recruitment and fieldwork preparation. Then I will consider ethical considerations that include the concept of positionality, reflexivity, and power relations. Lastly some potential limitations of this study are discussed. 
Chapter four: analyses the preparation of resettlement strategies of NT2 prior to resettlement. It begins with an introduction to the background of the Nakai Plateau resettlement community as well as providing a brief summary of the two selected resettled villages before resettlement.

Chapter five: analyses the implementation of NT2's resettlement strategies during the resettlement implementation period. The chapter begins by introducing an overview of institutional responsibilities of involved stakeholders associated with resettlement works of NT2. It also illustrates the performance of the project in relation to resettlement strategies as well as provides an examination of consequences resulting from the resettlement.

Chapter six: demonstrates general advantages and some significant challenges resulting from the project's resettlement performance. Some highlighted challenges are specifically examined in this chapter as well.

Chapter seven: draws on the ideas gained from Chapters: Four, Five, and Six in conjunction with the theoretical framework of this project to address the three research aims and questions. The chapter explores how the resettlement strategies of NT2 were prepared in response to resettled people's livelihoods and well-being prior to the resettlement. Then, it examines how effective such resettlement strategies have been. The chapter also goes on to illustrate key lessons learned from the project's resettlement performance, especially some challenges that seem likely to prevent the project from achieving sustainable livelihood development of the Nakai Plateau resettlement community. Finally, it provides an overarching conclusion of this research as well as delivers recommendations in relation to future improvements of resettlement endeavours. 


\section{Chapter Two: Literature Review}

\subsection{Introduction}

This chapter provides a general understanding of resettlement using key literature. It begins by introducing what development-induced displacement and resettlement (DIDR) is by providing background into two prominent resettlement models: Scudder and Colson's 1982 model of resettlement processes and Cernea's 1997 impoverishment risks and reconstruction model (IRR model). Later sections, then explore concepts of resettlement and livelihood restoration/rehabilitation. Finally, section 4 distils the key themes of this chapter and identifies the gaps in knowledge that this thesis aims to address.

\subsection{Development-Induced Displacement and Resettlement (DIDR)}

Development-induced displacement and resettlement (DIDR) emerged both as a major concern and as a challenge in sociology and anthropology during the 1990s. This concern arose owing to a dramatic rise in DIDR between the 1970s and 1980s driven predominantly by a global infrastructure boom, and associated with painful and disastrous consequences in relocation experiences (Dwivedi, 2002; Satiroglu \& Choi, 2015). Consequently, DIDR has become an area of interest for the study of policy and academic research, particularly as it represents a kind of forced migration (Cernea \& McDowell, 2000). Many studies have shown that asset and job losses are not the only outcomes of DIDR, but can also include the breakdown of social and food security, credit and labour exchange networks, and social capital and kinship ties (Dwivedi, 2002). In addition, there is also a sense of the affected people's socio-political disempowerment and economic impoverishment as well as their loss of cultural identity and heritage (Dwivedi, 2002).

According to McDonald (2006) the process of displacement and subsequent settlement is called involuntary resettlement. It is involuntary because the process is compulsory, and it is resettlement because the affected people must re-establish their lives in a new location. Involuntary resettlement is also defined as, and intended to be, permanent (Croll, 1999). However, this definition covers a range of resettlement types including only partial asset loss to long distance resettlement in which people are moved into new jurisdictions thousands of miles from their original locale (Croll, 1999).

It is important to note that, even though involuntary resettlement is causes multiple undesirable costs, development economics have traditionally paid little attention to the 
economic and financial underpinnings of such resettlement (Cernea, 1999). There has tended to be an engineering bias as many planners conduct advance studies for the construction of infrastructure projects, which tend to focus on engineering aspects exclusively, leaving the social planning to someone else (Cernea, 1988). Public concern has recently been heightened by involuntary resettlement operations that have run into major problems. As a result, involuntary resettlement is without a doubt a major issue in large development projects (Gutman, 1994).

\subsubsection{Scudder-Colson Model}

An early model of involuntary resettlement was invented by Thayer Scudder and Elizabeth Colson in 1982. The Scudder-Colson model generally illustrates how people and socio-cultural systems respond - through learning about relocation, actual relocation, transition and resettlement - to involuntary resettlement (McDowell, 1996). Specifically, the model outlines impacts on the displaced population during the early stages of resettlement as a source of multidimensional stress, namely "physiological, psychological, and socio-cultural" (Gutman, 1994, pp. 192-193). According to Gutman (1994) the Scudder-Colson model encompasses a five-stage dynamic, starting with: 1.) the recruitment of the population, 2.) resettlement planning, 3.) the actual relocation during transition stage, 4.) economic development, and 5.) incorporation or handing over.

To elaborate, McDonald (2006) states that firstly, the recruitment of the population is where the government and other involved agencies make decisions about the population that will be resettled. Secondly, the resettlement planning is where the people learn of the plans to remove them. Thirdly, the actual relocation during the transition stage is where resettlement commences and displaced people act to reduce related stress. Fourthly, economic development is where there is potential economic and social development. Lastly, incorporation or handing over is where the management of local production systems and the running of the local community are handed over to a second generation that identifies within the community.

As one of the earliest models associated with involuntary resettlement, the ScudderColson model was initially formulated for voluntary settlement processes. Additionally, the model was subsequently extended to some involuntary resettlement processes as well (Cernea, 2000). The model encompasses only those involuntary resettlements which succeed and move through all such five stages, as it was not intended to apply to 
resettlement operations that fail and do not complete the last two stages (Cernea, 2000). In response to such conditions, McDonald-Wilmsen \& Webber (2010) contend that the Scudder-Colson model is an ineffective approach which limits resettled people's rights in decision-making mechanisms determined by state or local level actors. Additionally, resettled people's steady movement through the five stages of the model is the exception rather than the norm (McDonald-Wilmsen \& Webber, 2010).

As a consequence, the Scudder-Colson model was later incorporated into Cernea's (1997) impoverishment risk and reconstruction (IRR) model. With the shift to impoverishment, this model sought to conceptualise and theorise better the experience of displacement (McDowell, 1996). This model or framework has been repeatedly applied in resettlement research, providing important insights and policy recommendations. For example, results have suggested withholding the introduction of economic innovations during the early stages of resettlement, when the displaced population's capacity to absorb additional changes tends to be limited (Gutman, 1994).

\subsubsection{Impoverishment Risk and Reconstruction (IRR) Model}

According to recommendations by the World Commission on Dams (WCD) on development-induced displacement and resettlement (DIDR), dam-induced involuntary resettlement in particular have been underpinned by a key model: the Impoverishment Risks and Reconstruction (IRR) model created by Michael M. Cernea in the early 1990s (McDonald-Wilmsen \& Webber, 2010). Theoretically, the IRR model is applied specifically to recognise the rights of, and risks to, resettled people during resettlement planning, rather than allowing a group of elites to directly control the whole process. Cernea (1997) understood that the impoverishment of displaced people was a central risk in development-caused involuntary population resettlement and could be addressed by effective planning processes.

In response to this central risk, the IRR model has come to be known widely as a contemporary approach which recognises the rights of, and risks, to all relevant stakeholders in the decision-making process from the planning stage onwards (Cernea, 1997). It breaks down the variety of different features of risks which can cause people to become impoverished in eight main ways:

a) Landlessness - the loss of land (the main foundation on which people's livelihoods are constructed); 
b) Joblessness - loss of wage employment;

c) Homelessness - loss of housing or shelter;

d) Marginalisation - displaced people cannot regain previous social standard of living;

e) Food insecurity - calorie-protein intake levels are below the minimum necessary for normal growth and work;

f) Increased morbidity and mortality - (serious declines in health and even death);

g) Loss of access to common property resources - loss of property assets that belong to relocated communities (forested lands, water bodies, grazing lands, burial grounds); and h) Community disarticulation or disruption of social fabric (social organisation, interpersonal ties, kinship groups and informal networks) (Cernea, 1997; Dwivedi, 2002; McDonald-Wilmsen \& Webber, 2010).

The working functions of the IRR model consist of prediction, diagnosis, problemresolution, and research. To elaborate, Cernea \& McDowell (2000) point out that firstly, the predictive function of the model results from in-depth knowledge of past processes stored and synthesised within it. This knowledge helps predict likely problems hidden in the new situations. For example, the predictions are early warnings of major 'social pathologies' likely to occur and such warnings can be issued long before the decision to displace is adopted. Secondly, the diagnostic function is the model's capacity to explain and assess by translating from the general prediction into a specific 'on-the-ground diagnosis' of the project situation at hand (Cernea \& McDowell, 2000, pp. 21-22).

Thirdly, the problem-resolution function is the model's analytical capacity to embrace awareness of the social actors in resettlement, their interaction, communication, and ability to contribute to resolution. Lastly, the research function is the model's 'conceptual scaffolding' for conducting and organising 'theory-led fieldwork' (Cernea $\&$ McDowell, 2000, p. 22). It encourages the creation of hypotheses about relations between main variables in resettlement. It also helps the exploration of mutual linkages of, and the reciprocal reinforcement or weakening effects between, related risks. As a result, these functions help a planning process to anticipate different forms of losses and devise appropriate policies and strategies to prevent them (Dwivedi, 2002).

Furthermore, the functions can produce encompassing and transparent information through the 'computation of losses' associated with both the potential and causes of resettlement impacts (Dwivedi, 2002, p. 718). Thus, the IRR model, through these 
functions, represents a genuine attempt at participation to find an acceptable solution between the planners and displaced people (Dwivedi, 2002).

However, Dwivedi (2002) questions the top-down functional feature of the IRR model which may limit the inclusion of displaced people's intrinsic values such as opinions, beliefs and knowledge that may lead to impoverishment. According to de Wet (2001) the IRR model oversimplifies the argument that well-prepared planning in the early stage can prevent and manage all involuntary resettlement problems. This is because involuntary resettlement involves a higher degree of tension than voluntarily resettlement.

Due to a lack of understanding among scholars and professionals about the social impact of displacement and relocation, collective social impact on the community or other social organisations as a cumulative effect also remains unpredictable (Cernea, 2000). de Wet (2001) claims that recognising the complexities inherent in the involuntary process is absolutely necessary. This claim is reflected in Downing and Garcia-Downing's (2009) notion that it is crucial to consider the psychological, sociological, and cultural disruptions of involuntary resettlement and ways to alleviate them. Moreover, because "the disruption to social life and the chaotic implications for culture which shifts from routine to dissonance" are vitally recognised, such dissonance should be limited while the emergence of a new routine culture should be facilitated as soon as possible after resettlement (McDonald-Wilmsen \& Webber, 2010, p. 148).

Consequently, there is room for the IRR model to be improved by considering another approach which helps make the process of settlement and integration of displaced people into the new or existing host communities last longer (McDonald-Wilmsen \& Webber, 2010). According to Downing and Garcia-Downing (2009), the planning process of the IRR model should embrace displaced people's regular shift between what they call routine and dissonant cultures. It should also recognise the way they convey their inherent values through "codified language, symbols, places endowed with meaning, kinship categories, ritual, dance, music, humour, public works, access rights to certain areas and resources, titles and job descriptions, and other sociocultural expressions" (Oliver-Smith, 2009, p. 228).

Furthermore, McDonald-Wilmsen \& Webber (2010) suggest that dam-induced displacement and resettlement should not stop at a resettlement plan that includes arrangements for the displacement event but should also plan for house and livelihood 
reconstruction. The authors also recognise that longer-term processes of settlement and integration (in addition to original displacement and resettlement) and adaptation and resilience of communities are considered crucial to the success of resettlement (McDonald-Wilmsen \& Webber, 2010). Hence, it may be helpful to learn from wider experiences and models of refugee resettlement cases ${ }^{1}$ whereby when the initial resettlement is finished, the facilitation of settlement is hastily implemented by government and service providers (McDonald-Wilmsen \& Webber, 2010). Both involuntary resettled people caused by development projects and refugees from wars or armed civil conflicts undergo many similar social and economic experiences.

Therefore, it may be of some value to learn from refugee resettlement regarding development-caused involuntary population resettlement (Cernea, 2000).

McDonald-Wilmsen \& Webber (2010) remark that refugee settlement process is conceptualised as a continuum that extending from resettlement to integration in new host societies. Such integration is conceivably an on-going pursuit for emancipation, parity, interdependence and cultural integrity for the purpose of working towards building a socially integrated and stable society (McDonald-Wilmsen \& Webber, 2010). As such, this is a longer-term process underpinned by a number of initiatives which include initial financial assistance and education, enhanced employment opportunities, assistance in securing housing, other social support including community-building services, and even trauma counselling (McDonald-Wilmsen \& Webber, 2010). It is important to note that all these aspects form a holistic approach that encompasses the entire process of social transformation, human agency, community engagement and human development. Particularly, this notion is a matter of ensuring that displaced people are not impoverished (McDonald-Wilmsen \& Webber, 2010). Put simply, these values at work within refugee resettlement contexts could potentially improve the IRR model.

\subsection{Compensation, Resettlement and Livelihood Restoration}

According to Tofail \& Kaidab (2015), many guidelines adopted by international donors such as $\mathrm{WB}$ and $\mathrm{ADB}$ require the provision of financial compensation packages to all those involuntarily resettled. This requirement acknowledges the loss of land and properties as well as people's affected livelihoods. Such requirements have tended to be

\footnotetext{
${ }^{1}$ Even though it could be helpful to learn from the case of refugee resettlement in other contexts, this aspect is beyond the scope of this current thesis
} 
grounded in the core wisdom that if the fundamental material needs of people to be resettled were provided for in cash or in kind, then adequate efforts would have been made (McDonald, 2006). As such, until recently compensation payments have been used as traditional relief for resettled people's dispossession, economic disruption, and income loss due to development projects (Cernea, 2003).

Such financial compensation packages seem appropriate to some extent, but in fact have questionable long term outcomes. For instance, McDonald (2006) claims that resettled people who are given a lump sum of cash usually spiralled into impoverishment. Alternatively, even in the case of land replacement the quality of a replaced land has commonly been insufficient to restore production (McDonald 2006).

To elaborate, a number of case studies undertaken in China, India, and Africa illustrate that resettled people's livelihoods were unable to be re-established through compensation alone (Phonepraseuth, 2012). In China, based on Jing's (1997) review on the practices of three resettlement processes, namely Xin'anjiang, Sanmenxia and Yongjing, he concluded that the resettled people normally were given insufficient compensation and were found to be worse off than their neighbours who were not displaced (Jing, 1997). Webber and McDonald (2004) claim that their study of the Xiaolangdi resettlement in China found the resettled people were dissatisfied with the amount of compensation received. In India, the land offered as compensation was productively inferior (McDonald, 2006). In Africa, McDonald (2006) demonstrated that the insufficient compensation in the Kiambere hydropower project and the Akosomba dam led to widespread social and economic impoverishment. As a result, these studies concluded that the impoverishment risks related to resettlement were not remedied through compensatory means (McDonald, 2006).

In sum, undertaking the restoration of livelihoods associated with involuntary resettlement through compensation alone seems to lead to many unpleasant outcomes (McDonald, Webber \& Yuefang, 2008). Hence, implementing involuntary resettlement by combining 'restoring' and 'improving' components of quality of life to support resettled people's lives in the long run is considered a better solution than mere financial compensation (Tofail \& Kaidab, 2015, p. 204). For this reason, the idea of conducting resettlement as a development project in its own right has emerged (McDonald, Webber \& Yuefang, 2008). Essentially, the concept of 'resettlement with development' is being largely endorsed in academic arena, especially in the field of 
resettlement studies (McDonald, 2006; Tofail \& Kaidab, 2015, p. 204). Additionally, it is also included in the policies of international institutions and increasingly in those of national governments (Cernea, 1995; Muggah, 2000). The concept of resettlement with development is not only compensating loss but also generating benefits to resettled people (Mathur, 2006; Tofail \& Kaidab, 2015).

Accordingly, the concept of resettlement with development claims that many related impoverishment risks of resettled people can be prevented by making those people the first beneficiaries of any proposed development project. In doing so, they no longer bear the cost of development (Wilmsen, Webber \& Yuefang, 2011). In other words, this philosophy suggests that resettled people's lives can be transformed for the better through displacement. For example, Cernea (1997) states that it would be better to treat resettlement operations as opportunities for development, as development projects in their own right, benefitting the resettled people. This embraces risk alleviation but goes on to create a new socioeconomic basis on which resettled people's livelihoods can first be restored and then enduringly improved, so that their incomes could surpass preresettlement levels (Cernea, 1997).

To elaborate, resettlement operations as opportunities for development aim to use reestablishment processes to convert impoverishment risks - identified by the IRR model - into better conditions (Cernea, 1999). Examples of such processes are listed below (Cernea, 1997):

1) Landlessness to land-based re-establishment;

2) Joblessness to reemployment;

3) Homelessness to house reconstruction;

4) Social disarticulation to community reconstruction;

5) Marginalisation to social inclusion;

6) Exploitation to restoration of community assets;

7) Food insecurity to adequate nutrition; and

8) Increased morbidity to better health care. 
However, Koenig (2001, p. 18), for example, questions resettlement as development asking:

(a) What is the development that brings about resettlement in the first place?

(b) Are all resettlement-inducing activities necessarily 'development'?

(c) By what criteria might a project for the resettled people be interpreted as development? And

(d) Does development simply equal rebuilding livelihoods and alleviating impoverishment or is it more than that?

Therefore, the scope of the concept of resettlement with development needs to be further explored, particularly as Mathur (2006) sees resettlement as inevitable in many development projects and thus an enduring problem.

According to Dwivedi (2002), the effectiveness of social performance associated with development-induced displacement is also a significant concern of the World Commission on Dams (WCD). Based on WCD estimates, the physical displacement affects between 40 and 80 million people worldwide, while the livelihood displacement affects other large numbers of communities both upstream and downstream of dams (Dwivedi, 2002). For this reason, WCD raised the issue of how development (as resettlement) was to be defined. Invoking the 1986 United Nation Right to Development, which considered development as a comprehensive process aimed at the constant improvement of the well-being of the entire population (Koenig, 2006). Accordingly, WCD considered that development included five basic aims: 1) equity in resource allocation and benefits; 2) sustainability of the world's resource base; 3) openness and participation in decision making; 4) efficiency in management; and 5) accountability to present and future generations (Koenig, 2006). Thus, in order to succeed in implementing resettlement as development, the resettlement strategies should embrace civil rights, human dignity and economic entitlements of those subject to involuntary resettlement (Dwivedi, 2002).

As a consequence of these working definitions and regarding the framework set in WB and $\mathrm{ADB}$ policies, it has become necessary for development practitioners to have a specific implementation strategy in the form of action plan. Hence, according to Downing (2002), a main organisational step in achieving resettlement goals is a RAP. A RAP is a time-bound action plan including a budget allocated for resettlement strategy, aims, entitlement, actions, responsibilities, monitoring and evaluation. Huggins \& 
Maasdop (2010) suggest that a RAP in accordance with a Resettlement Policy Framework (RPF) - set by the World Bank Operational Policy 4.12 and International Finance Corporation (IFC) Performance Standard 5 - can clarify the principles for social impact mitigation regarding compensation for loss of property, livelihood and resettlement. In addition, the operational objective of the RPF is to provide guidelines to stakeholders participating in the alleviation of negative social effects of the project. In doing so, the PAP is thought to be guaranteed that they will not be impoverished by resettlement (Huggins \& Maasdop, 2010). Nevertheless, such objective set out in a RAP seems to be too narrow as it focuses only on certain economic characteristics of impoverishment such as low income, but does not consider other vital aspects of poverty such as vulnerability and social exclusion (Krantz, 2001).

Such an approach also fails to encompass resettled people's loss of civil and human rights, which can possibly increase impoverishment risks (Downing, 2002). On the other hand, the attempt to rehabilitate people's livelihoods, incomes, and social systems in line with the concept of sustainable development has been enlightening (Downing, 2002). Consequently, more attention has, until currently, been paid to the various factors and processes which either constrain or enhance resettled people's abilities to make a living in an economically, ecologically, and socially sustainable manner (Krantz, 2001). Therefore, the concept of sustainable development has been used to guide livelihood restoration or rehabilitation in resettlement and development discourse (Downing, 2002).

Mahapatra (1999) states that resettlement and rehabilitation are two interrelated processes whereby the former involves relocation after physical displacement from the original habitat and the latter is defined as "grafting a community at a new place and nurturing it to ensure its steady and balanced growth" (Mahapatra, 1999, p. 192). This represents an important measure in terms of assisting resettled people to achieve sustainable development (Mahapatra, 1999).

Scoones (2009) argues that any basic search of literature or development project material, the word livelihoods is generally found as a mobile or flexible term with numerous characteristics: livelihood approaches, livelihood perspectives, livelihood methods and livelihood frameworks. Given this, the word livelihoods can be appended to all types of other words to build entire fields of development enquiry and practice (Scoones, 2009). These aspects are associated with locations (rural or urban 
livelihoods), occupations (farming or fishing livelihoods), social differences (gendered, age-defined livelihoods), directions (livelihood pathways, routes), dynamic patterns (sustainable or resilient livelihoods), and so forth (Scoones, 2009). Importantly, through such various components of a livelihood, the most complex is the range of assets out of which resettled people build their living, which includes both tangible and intangible aspects such as assets, resources, claims, and access (Krantz, 2001). To work towards sustainable development, people's livelihoods must be able to handle with and recover from stresses and shocks, maintain or enhance their competences and assets as well as preventing harm towards natural resources (Krantz, 2001).

Moreover, in order to restore or rehabilitate resettled people's livelihoods in accordance with the principle of sustainable development, having a clear understanding of the concept of sustainable development is equally important. Pearce, (1988, p. 589) states that since the 1980s the ideas of 'sustainable development' and 'sustainability' have been used as the fashionable catchwords. At its simplest, the meaning of sustainability is to make things last, permanent, and endurable (Pearce, 1988). Even though, there has still been no formal agreement about the precise meaning of sustainable development, one idea is that sustainable development requires the stock of capital to be passing on from one generation to the next be maintained or enhanced (Victor, 1991). Such stock of capital consists of several elements: human-made physical capital (infrastructure and technology), natural capital (soil, water, air, and genetic resources), human capital (skills and knowledge), and social capital (networks, social claims, and relationships) (Krantz, 2001; Cernea, 1998, 2003). Thus, it seems to be that in order to restore or rehabilitate livelihoods sustainably, all those resettled people's stocks of capital must be guaranteed to be viable in the long term.

To elaborate, Cernea (1998) notes that people who are affected by forced displacement mostly suffer impoverishment whether their former living standards are above or below poverty line. During such occurrences, affected people often unavoidably lose all forms of aforementioned capital (Gutman, 1994; Cernea, 2003). In other words, the incident threatens those affected people through all forms of capital from the outset when they may be unable to restore their lives and livelihoods (Downing, $2002 \&$ Mathur, 2006). For this reason, reconstructing and maintaining resettled people's types of capital can possibly help address impacts derived from resettlement sustainably (Cernea, 1998; Krantz, $2001 \&$ McDonald, 2006). Therefore, resettlement strategies and action plans 
must include livelihood capital reconstruction to enhance and maintain resettled people's competence to achieve sustainable livelihoods in the long run.

\subsection{A Brief Overview of Contemporary Resettlement Discourse}

There is substantial support from many development-induced displacement and resettlement (DIDR) scholars: Cernea (1998 \& 2000); Mahapatra (1999); Downing (2002); and McDonald (2006) for the application of a resettlement and rehabilitation model (as cited in Phonepraseuth, 2012). However, Satiroglu \& Choi (2015) argue that existing knowledge of DIDR remains limited. They point out that in addition to a lack of knowledge, academic, private, and civil sectors are pulled apart due to different interests and ethical considerations. Such disconnection becomes evident in the knowledge gaps whereby controversies in policy making and implementation remain understudied, and where academic findings have not been incorporated as a basis for practice (Satiroglu \& Choi, 2015). Importantly, they reason that "many questions are yet unanswered: What is 'success' in resettlement? Is development without displacement possible or can resettlement be developmental? Is there a global safeguard policy or do we need an international right 'not to be displaced'?" (Satiroglu \& Choi, 2015, p. 1).

In general, DIDR is perceived as having no limit when it comes to defining a 'development project' and these can range from a small-scale mining project to a hydropower plant construction (Satiroglu \& Choi, 2015). Further, development projects often require land acquisition or changes in existing land use and often cause physical and economic displacement (Satiroglu \& Choi, 2015). Typically, adverse impacts of involuntary resettlement result in loss of livelihoods, loss of land rights and housing, and loss of social networks (Morvaridi, 2004), Furthermore, Koenig (2006) and Phonepraseuth (2012, p. 29) argue that forced resettlement also impoverishes people by taking away their power to make decisions about: "a) where and how they are to live; b) the conditions under which they are to have access to and use productive resources; and c) the autonomy they are to exercise over the running and reproduction of their own socio-political institutions."

This argument highlights on-going ineffective development practice. For example, most DIDR literature seems to promote the importance of lessening economic impoverishment and targeting development to the poorest, which is linked to wider national strategies to relieve poverty and ensure the equity of benefits across society (Phonepraseuth, 2012). Nonetheless, many resettlement scholars argue that there is a 
contradiction between the benefit of increasing 'national welfare' and the consequent poverty of resettled communities, because a resettled population's welfare is commonly 'sacrificed' in the focus on improving national development outcomes (Phonepraseuth, 2012, p. 28). Barutciski (2006) remarks that such a contradiction raises a fundamental question about the relationship between human rights and development.

Barutciski (2006) and Phonepraseuth (2012) state that human rights are defined by many international treaties associated with an individual's right to choice of residence, freedom of movement, and ownership and possession of traditional lands. Yet, even as human rights are recognised by nation states, resettled people seem not to be accorded these rights when they are forced to leave their homelands and suffer socio-economic impoverishment (Phonepraseuth, 2012). Rew et al (2006) and Oliver-Smith \& Sherbinin (2014) note that development often seems to result in systemic failure due to a lack of accountability regarding vulnerability, exposure and the resulting tragic outcomes for resettled communities. A similar sentiment has been expressed by de Wet (2006 in Phonepraseuth, 2012, pp. 28-29) who asserted that "development that comes at the price of a lessening of the human rights of the affected people does not qualify as development."

Moreover, Phonepraseuth (2012) suggests that the dearth of resettled people's involvement in the resettlement mitigation process is one of the problems associated with DIDR. Resettlement planners often attempt to plan and provide mitigation measures for resettled people's livelihoods in the post-resettlement, but overlook the intrinsic complexity of their socio-economic conditions in the pre-resettlement phase (Phonepraseuth, 2012). Koenig (2006) elaborates on this point that socio-economic complexity reflects the connection of social, spatial, economic and political relations, the meaning of using resources, and the various aspects of livelihoods. Given this, ignoring such complexity undermines the basis of both livelihood and community, so that those planners are unable to take all involved factors into consideration, let alone deal with unexpected developments (Koenig, 2006). Consequently, many previous resettlement and livelihood restoration programmes provided for resettled communities have been proven to be ineffective (Phonepraseuth, 2012). Therefore, the limited knowledge concerning resettled people's human rights and their participation in resettlement strategies remains undoubtedly challenging in a development context. 


\subsection{Research Gaps Addressed}

Hydroelectric development is a development activity, that causes physical and livelihood displacement for many people (Satiroglu \& Choi 2015). Even though development planners have paid little attention to the inherent complexity of displaced people's pre-resettlement socio-economic conditions as noted above, they often concentrate on the integration of social, economic, and environmental objectives into management decisions (Hanna, 2000; Phonepraseuth, 2012). In doing so, the challenge of integration is based on taking into account a wide variety of values and demands that are regularly made apparent through public participation (Hanna, 2000). As such, local participation is endorsed in order to decrease any adverse impacts stemming from DIDR on the people involved (Aronsson, 2009). However, while people may participate in local decision-making, their contribution to this process with their existing cultural and other constraints means that they often end up in chronic poverty (Aronsson, 2009).

This paradox links to Hanna's (2000) notion that public participation is generally regarded as a crucial component of the planning or policy process. The degree to which it is included is frequently perceived as a measure of success. Nonetheless, "participation has a relatively complex function within planning and its inclusion, or exclusion, may not always be a good measure of program efficacy" (Hanna, 2000, p. 398). This aspect seems to raise doubts about how effective participation can be to protect people affected by impoverishment (Aronsson, 2009). It also reflects the way development planners oversimplify resettled people's socio-economic complexity down to manageable dimensions that are inspired by outsiders' notions of resettlement (Phonepraseuth, 2012).

Within my research, I will address these gaps by focusing on the experiences of people engaged in the hydropower-induced involuntary resettlement situation through a case study of NT2 in Lao PDR. Specifically, by means of applying the principles of IRR Model as theoretical lens, I will examine NT2 resettlement strategies by analysing project information and the perspectives of some resettled people.

\subsection{Conclusion}

This chapter has provided a brief review of literature concerning resettlement due to development. It introduced conventional approaches to prevent and alleviate risks of impoverishment through compensation, resettlement, and restoration or rehabilitation. Lessons learned through many decades have shown the failure of applying only a single 
means such as compensation payments for both physical and non-physical losses. In response to this failure, the concept of resettlement with development (added emphasis) emerged in order to improve resettlement consequences. The concept of sustainable livelihood restoration or rehabilitation - in addition to resettlement - has increasingly been recognised as valuable.

Consequently, this notion encouraged fruitful discussions in the literature in terms of the evolution of resettlement processes through a number of conceptual frameworks. One prominent issue is the philosophy of sustainable development. In respect to this philosophy, livelihood restoration or rehabilitation is acknowledged as an integral part of resettlement strategies to guarantee the restoration or rehabilitation of resettled people's livelihoods and social systems. Furthermore, writers are increasingly arguing that their intergenerational stocks of access to capital or livelihood capital should be sustainably maintained and enhanced via development.

Among these discussions, a number of concerns associated with resettlement practice were raised within the contemporary development discourse. The most prominent issue is the recognition that forcibly resettled people experience a higher degree of tension than voluntarily displaced people. Involuntarily displaced people mostly suffer impoverishment as losing all forms of livelihood capital whether their former living standards are above or below poverty line. The complexity of involuntarily resettled people's impoverishment is beyond economic loss. Given that, such circumstances have called for the practice of resettlement with development in order to embrace the civil rights, human dignity and economic entitlements of resettled peoples.

The last two sections of this chapter discussed several key development perspectives and concerns within contemporary resettlement discourse. One of these concerns is about the subject of development and resettled people's human rights. Even though citizens' equal rights are recognised at the level of nation state, these people are unlikely to be satisfied with their forcibly displaced situation and are likely to suffer from socioeconomic poverty. Additionally, the other concerns were raised around the issue of resettled people's participation in the resettlement process and the issue of the complexity of local socio-economic conditions frequently overlooked by development planners. These issues reflect an ineffectiveness of current resettlement practice internationally as well as signify how important the recognition of local participation and socio-economic complexity are to improving the resettlement and rehabilitation 
context. As a result, this research project aims to address these gaps by examining the existing development practice associated with hydropower-induced involuntary resettlement in Lao PDR. 


\section{Chapter Three: Methodology}

\subsection{Introduction}

This chapter starts by introducing my epistemological perspective which is based on my personal worldview. Then, I explain the purpose behind my choice of research methods: the process of data collection, the data analysis approach used, the reason for choosing a specific case study including site selection and how I recruited participants. Next, in section 3.6 I illustrate the framework of ethical considerations I employed that encompasses the concepts of positionality, reflexivity, and power relations. Section 3.7 then discloses the limitations of this research including how fieldwork was conducted. Finally, a conclusion is provided in section 3.8.

\subsection{Pragmatic Worldview}

The net that contains the researcher's ontological, epistemological, and methodological assumptions are probably considered a paradigm. Such a paradigm is steered by the researcher's set of beliefs and feelings concerning the world and how it ought to be understood and studied, because all research is interpretive (Cameron, 2011).

Through my own observations in my professional work about resettlement impacts on PAP's lives caused by hydroelectric development projects in Lao PDR, I had noticed challenges concerning these people's livelihoods and well-being. Such challenges potentially encompassed numerous impoverishment risks regarding the PAP's lives ranging from the loss of property and livelihoods to the dismantling of their social fabric. Even though there were a number of social mitigation and livelihood reestablishment measures provided by hydropower project developers to address these challenges, they seemed not to comprehensively rectify all issues. As such, I wanted to more closely examine resettlement strategies and practices of NT2, exploring stakeholders' perspectives, their tangible resettlement experiences, and relevant important project documents.

My concern for the practicalities of resettlement policies and procedures as well as my desire to integrate qualitative and quantitative data reflected pragmatism as an epistemological lens for this research. Creswell (2013) portrays pragmatism as an epistemology with claims for knowledge created by actions, situations, and consequences rather than by antecedent conditions. This links to Wolnicki's (2012, p. 491) notion that "pragmatism theorises that the meaning of any conceptions may be 
sought in their practical bearings; that the function of thought is to guide action; and that truth must be tested by the practical consequences of belief." Importantly, pragmatism philosophically encourages democratic forms of life - through adopting a problem oriented, empirically based experimental form of investigation - where people's demands, needs, and sufferings are embraced (Frega, 2014).

As a result, according to Creswell's (2013) interpretation of pragmatism, pragmatism is not committed to any one system of philosophy and reality. It therefore lends itself well to mixed methods research in that researchers draw freely from both quantitative and qualitative assumptions when they engage in their research. In addition, employing mixed methods research enables the researcher to use both quantitative and qualitative data because they work to provide the best understanding of a research problem. Hence, pragmatism seems to allow the mixed methods researcher to apply numerous methods, different worldviews, and various assumptions including different forms of data collection and analysis (Creswell, 2013). Therefore, I decided that employing mixed methods in my research was likely to be the most suitable research approach to gain insights into the multidimensional resettlement issues of NT2.

\subsection{Methodology}

Cameron (2011) states that mixed methods research is commonly seen as the third methodological movement and has experienced a hasty upsurge in popularity in the last decade. A mixed methods research approach is positioned as the natural complement to traditional qualitative and quantitative research. It does not aim to replace these two important and useful research paradigms but instead tends to draw from the strengths and curtail the weaknesses of both in single studies and across studies (Johnson \& Onwuegbuzie, 2004). Because the mixed methods approach is grounded in pragmatic assumptions: consequence-oriented, problem-centred, and pluralistic, it applies strategies of inquiry that entail collecting data both concurrently and successively to best comprehend research problems (Creswell, 2013). Given this, employing the mixed methods approach for data collection can help generate either numeric information (through instruments) or text information (via interviews), so that the final database signifies both qualitative and quantitative information (Creswell, 2013).

Regarding the use of the mixed methods approach in this research, applying qualitative methods as the main approach for gathering data is considered essential (Creswell, 2013). However, including quantitative methods into this study is considered necessary 
as well. Creswell (2013) states that quantitative research is the methodical inquiry approach, which is empirically used to test a theory. In quantitative studies, the researchers advance the relationship among variables and pose this in terms of questions or hypotheses (Creswell, 2013). He also remarks that "being objective is an essential aspect of competent inquiry, and for this reason researchers must examine methods and conclusions for bias. For example, standards of validity and reliability are important in quantitative research"(Creswell, 2013, p. 8). Hence, these procedures seem to be deductive in nature, contributing to the scientific knowledge base by theory testing (Newman \& Benz, 1998).

On the other hand, the process of qualitative research is largely inductive where qualitative researchers attempt to identify the perspectives of research participants, their interpretations and meanings attached to life events, experiences or objects (Creswell, 2013; Mikene, Gaizauskaite \& Valaviciene, 2013). In other words, according to Carter \& Little (2007), qualitative research commonly represents social research in which the researcher rests upon text data rather than numerical data. The researcher also aims to comprehend the meaning of human action by analysing this data in their textual form instead of converting them to numbers for analysis. Importantly, instead of relying only on participants' perspectives and behaviours as the focus of the research, the researcher - in qualitative research - becomes an active instrument for gathering data as well (Mikene, Gaizauskaite \& Valaviciene, 2013).

Consequently, even though a qualitative research approach is vital, using both quantitative and qualitative research methods are seemingly better by reason of their potential for providing the best understanding of a research problem (Creswell, 2013). Creswell \& Zhang (2009) and Chambers (2012) suggest that a combination of qualitative and quantitative techniques - a mixed methods approach - is able to provide a meaningful and powerful aide to development studies research. Therefore, employing a combination of both qualitative and quantitative research methods in this study is preferable to using only one of them.

\subsection{The Case Study of Nakai Plateau Resettlement Community}

The case study is a 'research strategy' which focuses on understanding the dynamics present within single settings (Eisenhardt, 1989, p. 534). It is one of several forms of social science research such as experiments, surveys, histories, and archival analyses (Yin, 2013). Based on Hays's (2004) notion, even though case study research can 
involve the close examination of people, topics, issues, or programmes, it is unlike ethnographical, biographical, and other historical research approaches. For example, it seeks to discover causal links in settings - where 'cause-and-effect relationships' are complicated and unknown before - so as to answer focused questions in comparatively short period of time (from a few weeks up to a year) (Hays, 2004, p. 218). On the other hand, those three research approaches tend to focus on more complex dimensions: asking broader questions, observing and explaining practices and beliefs and making cultural interpretations in studies that may last for as long as a year or more (Hays, 2004).

Unlike evaluation studies, case study research also typically allows the 'consumer or audience' to determine 'meaning and worth' as well as to form their own 'naturalistic' generalisations by drawing on the information in the case study (Hays, 2004, p. 219). As such, conducting case study research seems to be the relatively favoured technique in situations when: a) the key research questions are 'how' and 'why' questions; b) there is little or no domination by the researcher over behavioural events; and c) the focus of study centres on current (as opposed to entirely historical) phenomenon (Yin, 2013, p. 2).

However, there still are several criticisms of case study research. One such criticism is that the value of its practical knowledge is less than theoretical knowledge as a single case cannot collectively generalise others or cannot contribute to scientific development (Flyvbjerg, 2006). Moreover, the case study can only be useful for creating hypotheses in the first steps of a total research process, while hypotheses testing and theory building are best carried out by other methods later in the process (Flyvbjerg, 2006). In response to those criticisms, Flyvbjerg (2006, pp. 224, $228 \& 229)$ argues that

a) While 'predictive theories and universals' are not found in the study of human affairs, 'concrete context-dependent knowledge' is actively existent. This has proven that the practical knowledge is more valuable than the vain search for the theoretical knowledge in social science.

b) The basis of a single case is able to be generalised as well as the case study is probably central to scientific development through generalisation as supplement or alternative to other methods. However, formal generalisation is overvalued as a source of scientific development, whereas 'the force of example' is underestimated. 
c) "The case study is useful for both generating and testing of hypotheses but is not limited to these research activities alone."

As discussed in Chapter One, the Nakai Plateau resettlement community is the main focus of this research regarding the examination of NT2 resettlement strategies. In other words, I used it as a case study. As Master's degree, this case study research was predetermined to take time within one calendar year. Its selection was based on the contemporary situation of resettled people in the Nakai Plateau (in 2015). The focused research questions were designed to be open-ended questions along with implementing research activities that fostered research participant autonomy.

Subsequently, this research could explore this case study by involving both stakeholders' perspectives and relevant project documents concerning NT2 resettlement strategies. Furthermore, through employing data analysis techniques, I was able to produce thematic findings in response to the three research aims of this study. As a result, I could provide inferences regarding NT2 resettlement performance as well as recommendations for future research.

\subsubsection{Recruitment of Participants}

As discussed in section 3.3, a mixed methods approach was employed in this study including semi-structured interviews and focus groups. For this reason, I selected participants who were the most involved stakeholders and who had relevant experience associated with NT2 resettlement and livelihood restoration operations. These people consisted of representatives from Lao governmental agencies in both central and local governments, representatives from NT2 implementers, and NT2 resettled people. I invited all representatives from the central and local governmental agencies, NT2 project, and some representatives from resettled villagers to participate in semistructured interview sessions. Unfortunately, I did not receive any response from NT2 project regarding research participation (see section 3.5). I also invited all resettled villagers to participate in focus group sessions without representatives from governmental agencies.

The central government representatives were from MoNRE and Ministry of Energy and Mines (MEM) who had policy-making roles regarding the approval of NT2 concession agreement, social obligations, and the processes of NT2 resettlement. The local government representatives were from the resettlement committees (RC) and its secretariat the resettlement management unit (RMU) who acted as the governmental 
implementing body concerning NT2 resettlement processes. These local governmental agencies were the ones who approved and declared the success of NT2 resettlement and livelihood restoration performance in compliance with CA. Apart from governmental agencies, NT2 resettled people were representatives from both Nakai and Phon-Sa-On villages. Specifically, these resettled populations were carefully categorised by their gender, age, ethnicity, and socio-economic status.

\subsubsection{Qualitative Research Methods}

Semi-structured interviews were the primary method used to generate qualitative data. According to Longhurst (2003), semi-structured interviews are considered to be a simple, inoffensive verbal interchange where the interviewer can draw information from the interviewee by asking open-ended questions. The semi-structured interview also allows researchers to elicit more detail about specific issues where information is unavailable within the literature (Davidson \& Tolich, 2003). For example, even though semi-structured interviews involve the preparation of a list of questions, the interviewer may change from the prepared script when new or significant matters arise (Longhurst, 2003). This method undoubtedly enabled me to gain insight into my interviewees' subjective experiences, opinions, and perception concerning my research questions.

In order to understand various issues associated with NT2 resettlement works, semistructured interviews were organised with samples of government officials, project staff and resettled people. I planned to use the official approval from my organisation, the MoNRE to issue an official letter to request cooperation from relevant governmental agencies, NT2, and resettled people through their local authority. In doing so, I expected to be able to have interviews with various stakeholders concerning NT2. For instance, a) interviewing some relevant governmental agencies to understand the policies relating to NT2, namely the CA and social obligations, particularly the resettlement commitment;

b) interviewing NT2 staff to understand the resettlement management and implementation strategies; and c) interviewing a number of resettled people in two resettled villages to gain an insight into their perspectives through the resettlement experience of NT2.

A set of key questions - to be used with those different types of participants - were carefully prepared before the interviews to ensure that main points were not excluded. I recognised that some research questions might be seen as sensitive in some circumstances. I also bore in mind that gathering data and managing interviews in Lao 
PDR could be frustrating because of hierarchy concerns. In fact, Pollard (2009) found that researchers can experience difficulty gathering a certain type of data due to lack of support from informants. For example, some local authorities and project staff might underreport the negative aspects of a situation, but more frequently over report positive sides which could skew research data (Tourangeau \& Yan, 2007). Additionally, resettled villagers might feel uncomfortable when they were asked about their experiences of involuntary resettlement. However, I tried to frame interview questions sensitively and focused more on how their experience could be learned from to improve relevant policies. Moreover, my role as a government official was closely associated within my organisation and its various networks. Using neutral language, I hoped, would also reduce any potential issues for resettled participants.

A focus group was another qualitative method used. According to Morgan (1996), this method collects data through group interaction on a topic determined by the researcher. There are three essential components: a) spending time and effort on data collection, b) locating the interaction in a group discussion as the source of the data, and c) acknowledging the researcher's active role in creating the group discussion for data collection purposes. Additionally, a focus group is generally a discussion among preselected individuals - a group typically consists of six to eight participants - who have similar characteristics or who share some experience of the research topic. It allows participants to influence each other by responding to ideas and comments of others (Hennink, 2007). Furthermore, the focus group does not have to reach consensus on the issues discussed, as its aim is to encourage a range of responses which provide a greater understanding of the participants' attitudes, behaviours, opinions or perceptions on the research issues (Hennink, 2007). Nevertheless, there may be some challenges to this method as some participants may dominate a discussion and hierarchies may develop among the participants. Hence, a skilled moderator is required for this method (Hennink, 2007).

Focus group discussions are not a source of personal information, but they are a source of community-level information that enables the researcher to better understand social behaviour, cultural values or community opinions (Hennink, 2007). Participants in focus group research are also not typically selected randomly but based on certain criteria specific to the research objectives (Hennink, 2007). In this case, certain criteria pertained to participants' involvement within NT2 resettlement programmes. Hence, I held one focus group in each of the two sample resettled villages (see section 3.4.1). I 
selected participants who represented different genders, ages and ethnicities as well as their economic statuses and income generating activities. However, it is significant to note that female and young participants often succumbed to adult males' domination in discussion session of the focus group.

\subsubsection{Quantitative Research Methods - Numbers and Statistics}

\subsubsection{Secondary Research Methods}

Apart from those two qualitative methods, gathering and working with secondary data was another important research method in this study. Sørensen, Sabroe \& Olsen, (1996) suggest that in research, secondary data is not data collected by a particular research purpose. Hence, collecting such data is normally for understanding general concepts in various contexts such as management, claims, planning, evaluation of activities, and surveillance or research. In other words, the technique of acquiring secondary data sources is academically known as secondary research which is not unique to the statistics field. For this research, I analysed the Lao government's laws, policy documents and guidelines on NT2, and project documents from NT2 - to supplement the literature review and the data collected using primary qualitative methods described above.

Employing such secondary data sources along with data sources generated from applied primary methods fostered an opportunity to integrate different information and triangulate some data thereby increasing the rigour of my work (Sørensen, Sabroe \& Olsen, 1996; Murray \& Overton, 2003). In general, there are three different secondary research strategies: a) content analysis which entails the content of various forms of human communication such as newspapers, books, websites; b) secondary analysis which is about using quantitative data that was previously collected by other people for a different purpose; and c) a systematic review that is the combination and investigation of the output of other research concerning the same or a similar phenomenon (Daas \& Arends-Tóth, 2009).

In general, social science data are produced in two main forms: in numbers or in words (Blaikie, 2003). Sandelowski (2000) states that because qualitative and quantitative data sets can be interrelated by maintaining the numbers and words in each data set, these data can be converted to produce one data set with qualitative data transformed into quantitative data, and vice versa. Specifically, 'quantitizing' qualitative data - a process by which qualitative data are treated with quantitative techniques to transform them into 
quantitative data - allows the researcher to produce more meaningful data for a research (Sandelowski, 2000, p. 253). For example, the researcher reduces verbal or visual data (from interviews, observations, or documents) into items or variables that are aimed to mean only a single thing and that can, therefore, be represented numerically (Sandelowski, 2000).

Subsequently, I codified my research questionnaires - used for semi-structured interviews - in a set of numerical items. For an example, based on the eight principles within the impoverishment risks of the IRR Model (as discussed in Chapter Two), I specifically used a series of questionnaires concerning those principles ranging from number one (loss of land) to number eight (disruption of social fabric). Even though the questionnaires were open-ended questions, their answers were used as numerical results in response to such eight categories. These numerical results enabled me to measure how many negative impacts resettled people experienced as well as how comprehensive NT2 resettlement strategies were prepared.

\subsubsection{Data Analysis Approach}

For data analysis, I employed the thematic analysis method. According to Braun \& Clarke (2006), a thematic analysis approach categorises patterned responses or themes from the information gathered and organises it in a meaningful way. It is a flexible method which concentrates more on collective themes from all the informants rather than individual ideas (Miller et al., 2003). Such themes stemmed from the participants' stories and were woven together so as to create a comprehensive picture of their collective experience (Aronson, 1995). It is important to note that "the coherence of ideas rests with the analyst who has rigorously studied how different ideas or components fit together in a meaningful way when linked together" (Aronson, 1995, p. 4).

A content analysis approach was also used in this research. Devi (2009) noted that the content analysis method is the analysis of text documents, which can be quantitative, qualitative or both. This seems to link with Neuendorf's (2002, p. 1) remark that the content analysis approach can be thought of "as the systematic, objective, quantitative analysis of message characteristics.” In general, a number of concurrent steps sampling, unitising, standards of assessment of data and inferential procedures to provide for the conduct of systematic, objective and reliable research - are embraced into content analysis ( $\mathrm{Li}, 2008)$. Additionally, the content analysis method is flexible for 
using text data - verbal, print, or electronic form obtained from open-ended questions of interviews and focus group - coded into explicit categories and then described using statistics. It also concentrates on the characteristics of language as communication, with attention to the contextual meaning of the text (Hsieh \& Shannon, 2005).

As a result of employing these two data analysis techniques, I could pull out themes that arose frequently in the focus group and each interview concerning the informants' NT2 resettlement experience. Particularly, I was able to analyse these variety of data in response to the three research aims of this study. In parallel, the content analysis approach also enabled me to make inferences through communicative channels - semistructured interviews, focus groups, and secondary data collections - about the preexisting content of descriptive context concerning the involuntary resettlement experiences of resettled people caused by NT2. 


\subsubsection{Site Selection}

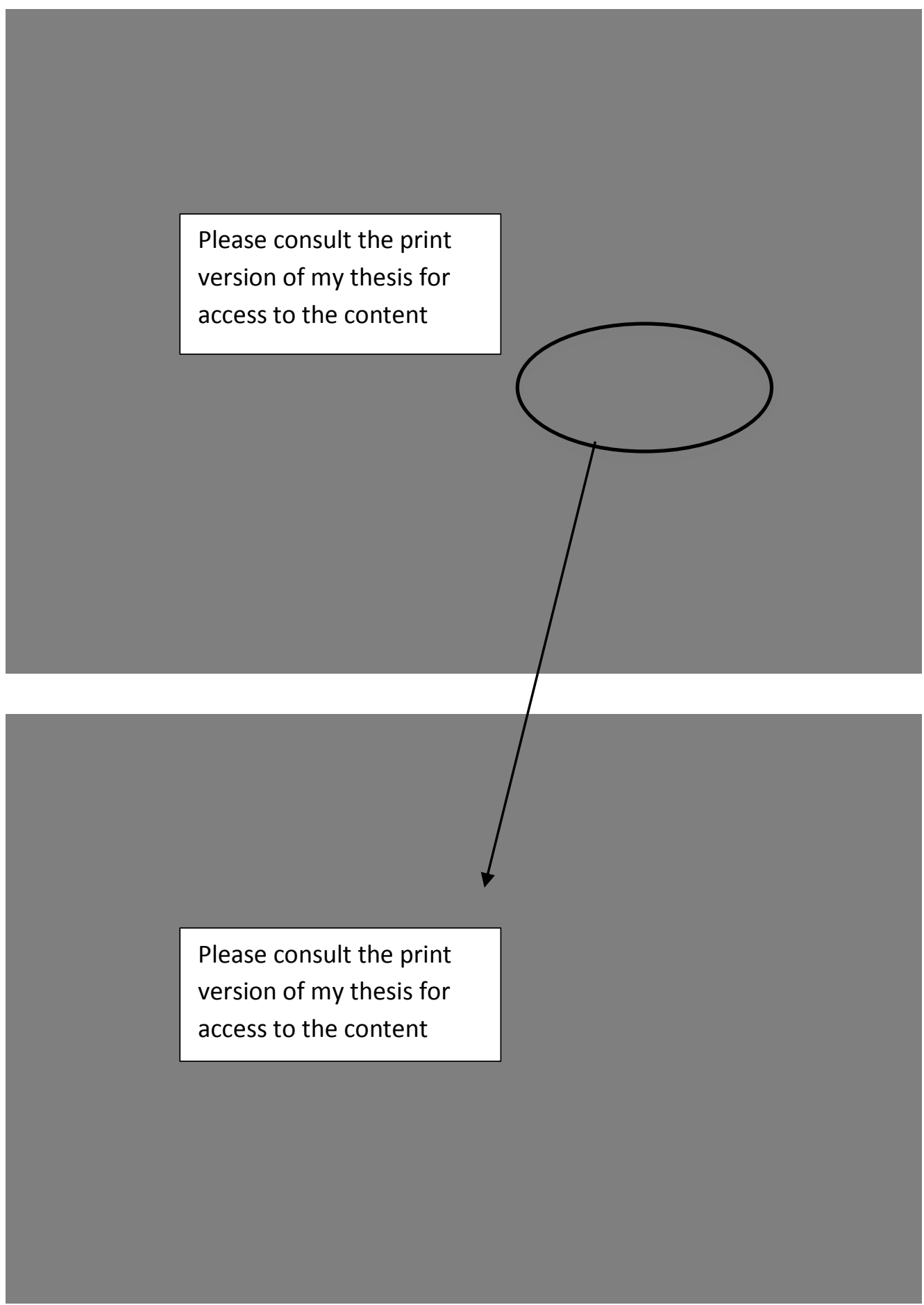

Figure 4: Lao PDR. Source: http://www.themedalhound.com/laos/main.html

Figure 5: Khammouane province. Source:

http://en.wikipedia.org/wiki/Khammouane Province\#mediaviewer/File:Map of Khammouane

Province, Laos.jpg

The primary aim of this research was to examine the impact of NT2 resettlement, compensation and livelihood restoration programmes on the Nakai Plateau resettlement 
community. Originally, there were 17 resettled villages in the Nakai Plateau (Nakai district, Khammouan province): Nong Boua, Sop Hia, Nam Nian, Buoa Ma, Sop Phene, Naong Boua Kham, Sop Ma, Phonsavang, Phon-Sa-On (or Sop On), Thalang, Done, Khonekhen, Ka Oy, Nakai Neua, Nakai Tai, Oudomsouk, and Phonephanbaek (Nam Theun 2 project, 2005b). However, because of an integration of Nakai Neua (Northern Nakai) and Nakai Tai (Southern Nakai) into a new village named Nakai village, the total resettled villages are now understood to be 16 (Nakai village Chief, personal communication, July 2015). According to the Nam Theun 2 hydroelectric project's report (n.d.), all resettled residents who lived on the Nakai Plateau before NT2 dam construction were considered by WB as indigenous people. In other words, under WB's policy those resettled people were also considered to be ethnic minorities (Porter \& Shivakumar, 2010). In addition, many of them were classified as poor or extremely poor, especially ethnic minorities and vulnerable people who were in need of special assistance by the project (Nam Theun 2 hydroelectric project, n.d.).

Given these circumstances, it would have been ideal for me to conduct fieldwork activities in all resettled villages in order to comprehensively explore aspects of these people's livelihoods and well-being as a result of NT2 resettlement. However, due to the limited resources and timeframe of this research, I selected only two villages Nakai village in the north and Phon-Sa-On village in the south on the Nakai Plateau for fieldwork. Even though these two villages seemed to obtain similar resettlement, compensation, and livelihood restoration packages from the project, their different individual characteristics provided some value for comparative exploration.

Nakai village was previously known to be prosperous. It had historical and traditional spiritual significance and its residents' principal occupations were mostly as farmers and cattle raisers (Asian Development Bank, 2004).

Phon-Sa-On village was considered to be a middle-income village where many community facilities were available for the resettled people in the southern zone of the Nakai Plateau resettlement site (Phonepraseuth, 2012). Before resettlement, Phon-SaOn villagers made their living in many ways ranging from farming and raising livestock to handicrafts maker and trading (Nam Theun 2 project, 2005).

The socio-economic diversity of these two selected sites represented some of the key general socio-economic aspects of wider villages. In addition, these locations were conveniently accessible due largely to the improved infrastructure such as access to 
roads. More importantly, they were two of many villages experienced the same fate concerning involuntary resettlement due to NT2 (Erlanger et al., 2008). Given this, local authorities and resettled people were well aware of their issues and they were likely to be able to respond to my intended questions (Souksavath \& Nakayama, 2013).

Therefore, undertaking fieldwork in these two villages potentially enabled this study to create an overview representing resettled people's livelihoods and well-being in the Nakai Plateau as a whole.

\subsection{Preparation of Fieldwork Activities}

According to the Master's thesis policy of Victoria University of Wellington (VUW), Aotearoa New Zealand that I read before undertaking any fieldwork activity, I noted that I must obtain a number of academic approvals. These approvals consisted of confirmation of my Master's thesis research proposal, my research supervisor's letter of reference, an application to undertake research away from VUW, and Human Ethics Approval. Thus, I prepared these documents to submit and they all seemed to progress smoothly. Simultaneously, I intended to undertake fieldwork activities associated with NT2's resettlement programmes in my country, Lao PDR between $24^{\text {th }}$ May 2015 and $22^{\text {nd }}$ August 2015 within a three-month-fieldwork timeframe. Specifically, I originally planned to collect information from my planned research participants through conducting the interview and focus group sessions. My planned research participants consisted of representatives from both central and local governmental agencies, NT2 developers, and two selected resettled villages in Nakai plateau resettlement site (see table 3.1). 
Table 1: The original plan of fieldwork activities concerning interviews and focus groups in resettled communities

\begin{tabular}{|c|c|c|c|c|}
\hline & Week 1 & Week 2 & Week 3 & Week 4 \\
\hline $\begin{array}{l}\text { May } \\
2015\end{array}$ & - & - & - & $\begin{array}{l}\text { Arrive in Vientiane Capital City, } \\
\text { Lao PDR, and start preparing } \\
\text { relevant official request letters } \\
\text { and translate all related research } \\
\text { materials (participant consent } \\
\text { forms, participant information } \\
\text { sheets, research questions, and so } \\
\text { forth) into Lao language, and then } \\
\text { submit them to MoNRE for } \\
\text { approval. }\end{array}$ \\
\hline $\begin{array}{l}\text { June } \\
2015\end{array}$ & $\begin{array}{l}\text { Wait for approval of official request } \\
\text { letters. }\end{array}$ & $\begin{array}{l}\text { Submit all official request letters } \\
\text { including research materials to involved } \\
\text { research targeted participants and ask for } \\
\text { their confirmation. }\end{array}$ & $\begin{array}{l}\text { Conduct interviews with some } \\
\text { interviewees in Vientiane Capital } \\
\text { City such as representatives from } \\
\text { MoNRE, Ministry of Energy and } \\
\text { Mines (MEM), and Nam Theun } 2 \\
\text { hydroelectric project (NT2) } \\
\text { (Transcribe data after finished } \\
\text { interviewing) }\end{array}$ & $\begin{array}{l}\text { Travel to NT2 resettled } \\
\text { communities in Nakai district, } \\
\text { Khammouane province, and } \\
\text { approach relevant local authority } \\
\text { - RC and its secretariat, RMU, } \\
\text { chiefs of two targeted resettled } \\
\text { villages and related } \\
\text { representatives of village women } \\
\text { union - in order to brief them }\end{array}$ \\
\hline
\end{tabular}




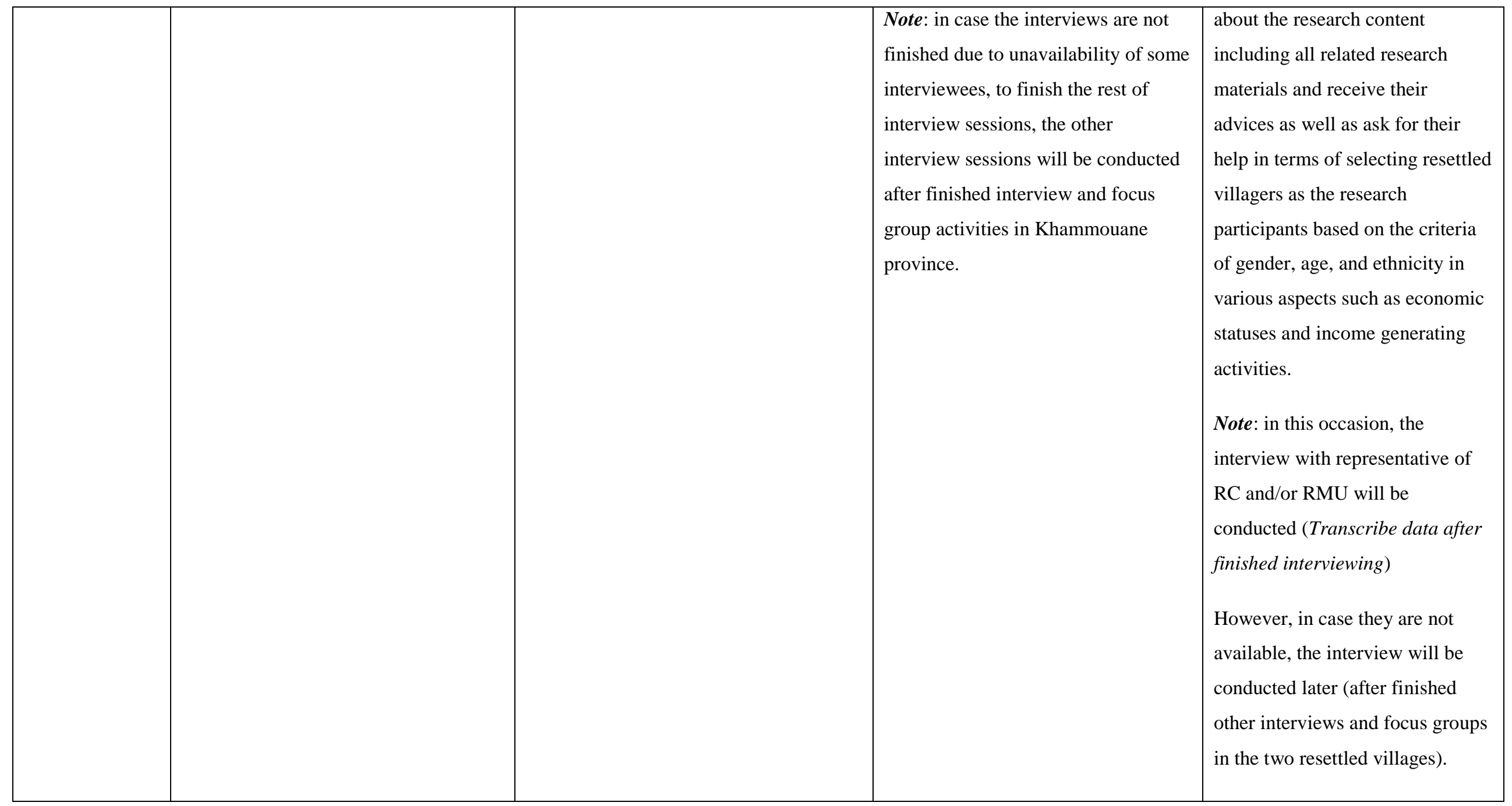




\begin{tabular}{|c|c|c|c|c|}
\hline 2015 & $\begin{array}{l}\text { Prior to conducting interviews and } \\
\text { focus groups in the first resettled } \\
\text { village, one or two days for orientation } \\
\text { reconnaissance is necessary to gain } \\
\text { general understanding of resettled } \\
\text { villagers' life styles as building a good } \\
\text { relationship. After that, the interview } \\
\text { will be conducted with chief of village } \\
\text { and representative of village women } \\
\text { union (Transcribe data after finished } \\
\text { interviewing). } \\
\text { Finally, sub-focus group will be } \\
\text { conducted before the main focus group. } \\
\text { This activity involves women, youth } \\
\text { and ethnic minority people who will be } \\
\text { probably dominated by adult male } \\
\text { when they attend any consultation } \\
\text { session (Transcribe data after finished } \\
\text { interviewing). }\end{array}$ & $\begin{array}{l}\text { Firstly, the main focus group activity } \\
\text { will be conducted by involving all types } \\
\text { of participants (women, adult male, } \\
\text { youth, elder, and ethnic people) } \\
\text { (Transcribe data after finished } \\
\text { interviewing). } \\
\text { Finally, the individual interview will be } \\
\text { conducted with two participants from } \\
\text { sub-focus group and other two } \\
\text { participants from the main focus group } \\
\text { (Transcribe data after finished } \\
\text { interviewing) } \\
\text { Note: after I have finished all research } \\
\text { activities, a small leaving activity } \\
\text { (having a farewell refreshments at the } \\
\text { village hall) will be held. }\end{array}$ & $\begin{array}{l}\text { Prior to conducting interviews and } \\
\text { focus groups in the second resettled } \\
\text { village, one or two days for } \\
\text { orientation reconnaissance is } \\
\text { necessary to gain general } \\
\text { understanding of resettled villagers' } \\
\text { life styles as building a good } \\
\text { relationship. After that, the interview } \\
\text { will be conducted with chief of } \\
\text { village and representative of village } \\
\text { women union (Transcribe data after } \\
\text { finished interviewing). } \\
\text { Finally, sub-focus group will be } \\
\text { conducted before the main focus } \\
\text { group. This activity involves women, } \\
\text { youth and ethnic minority people } \\
\text { who will be probably dominated by } \\
\text { adult male when they attend any } \\
\text { consultation session (Transcribe data } \\
\text { after finished interviewing). }\end{array}$ & $\begin{array}{l}\text { Firstly, the main focus group } \\
\text { activity will be conducted by } \\
\text { involving all types of participants } \\
\text { (women, adult male, youth, elder, } \\
\text { and ethnic people) (Transcribe } \\
\text { data after finished interviewing). } \\
\text { Finally, the individual interview } \\
\text { will be conducted with two } \\
\text { participants from sub-focus group } \\
\text { and other two participants from } \\
\text { the main focus group (Transcribe } \\
\text { data after finished interviewing) } \\
\text { Note: after I have finished all } \\
\text { research activities, a small leaving } \\
\text { activity (having a farewell } \\
\text { refreshments at the village hall) } \\
\text { will be held. }\end{array}$ \\
\hline August & $\begin{array}{l}\text { In case there are any interview delays } \\
\text { due to the unavailability of }\end{array}$ & $\begin{array}{l}\text { Reorganise the transcribed data } \\
\text { collection and translate into English }\end{array}$ & Arrive in Wellington, New Zealand. & - \\
\hline
\end{tabular}




\begin{tabular}{|l|l|l|l|}
\hline 2015 & $\begin{array}{l}\text { representatives of RC and/or RMU at } \\
\text { the last minute, interviews with them } \\
\text { will be conducted before leaving } \\
\text { Khammouane province (Transcribe } \\
\text { data after finished interviewing). }\end{array}$ & $\begin{array}{l}\text { Notering fieldwork in Khammouane } \\
\text { province, using Lao language in } \\
\text { transcribing collected data is convenient } \\
\text { for the researcher. }\end{array}$ & \\
$\begin{array}{l}\text { In addition, in case there are any } \\
\text { interview delays due to unavailability } \\
\text { of representatives of MEM or NT2 at } \\
\text { the last minute, interviews with them } \\
\text { will be conducted when I arrived in } \\
\text { Vientiane Capital City (Transcribe } \\
\text { data after finished interviewing). }\end{array}$ & & \\
\hline
\end{tabular}


Surprisingly, the actual situations - when I got to Lao PDR - did not meet my expectations of fieldwork activities. Due to the fact that there was a delay within the approval process regarding some of the aforementioned documents from VUW, I could not begin my fieldwork activities as planned. Consequently, I needed to readjust my plans. However, I finally obtained approval from VUW by receiving the following documents: confirmed acceptance of Master's thesis research proposal, research supervisor's letter of reference, application to undertake research away from Victoria University, and my Human Ethics Application approval.

I then began preparing and submitting a number of official request letters and their relevant attachments to the Department of Environmental and Social Impact Assessment (DESIA), MoNRE for approval. By July, I received approval of these documents from DESIA. Finally, I submitted these approved official documents to my planned research participants and asked for their confirmation. Unfortunately, at first I could not obtain confirmation from all potential participants for several reasons. For example, there was a mismatch between the available time of some potential participants (especially central governmental agencies' representatives) and my requested date and time. In order to undertake interview and focus group sessions with both local governmental agency's representatives and the two selected resettled villages' representatives I had to wait for those people's confirmation through the local government bureaucracy. However, in the end I obtained confirmation from all my planned research participants, except NT2 developers. It is significant to note that there was no response from NT2 developers, even though I already submitted an official request letter.

Note: As a result of later approvals of VUW and DESIA than expected, I readjusted my fieldwork plan through discussion with my research supervisor (personal communication, July 2015) and implemented it as shown in table 3.2. 
Table 2: The adjusted plan of fieldwork activities concerning interviews and focus groups in resettled communities in response to the real changed situations

\begin{tabular}{|c|c|c|c|c|}
\hline & Week 1 & Week 2 & Week 3 & Week 4 \\
\hline \multirow[t]{2}{*}{ June 2015} & $\begin{array}{l}\text { Waited for approval of the application } \\
\text { to undertake research away from } \\
\text { Victoria University and the Human } \\
\text { Ethics Application. }\end{array}$ & $\begin{array}{l}\text { After obtained approval of the } \\
\text { application to undertake research away } \\
\text { from Victoria University on } 10^{\text {th }} \text { June } \\
2015 \\
\text { Kept waiting for approval of the Human } \\
\text { Ethics Application. }\end{array}$ & $\begin{array}{l}\text { Kept waiting for approval of the } \\
\text { Human Ethics Application. }\end{array}$ & $\begin{array}{l}\text { Obtained the approval of the } \\
\text { Human Ethics Application on } 27^{\text {th }} \\
\text { June } 2015\end{array}$ \\
\hline & $\begin{array}{l}\text { Prepared draft official request letters } \\
\text { and their attachments (waiting for } \\
\text { attaching all approved documents from } \\
\text { VUW) in order to submit to DESIA for } \\
\text { approval }\end{array}$ & Same as week 1 & Same as week 2 & $\begin{array}{l}\text { Submitted all prepared documents } \\
\text { to DESIA for approval }\end{array}$ \\
\hline \multirow[t]{2}{*}{ July 2015} & $\begin{array}{l}\text { Obtained DESIA's approval of all } \\
\text { relevant official request letters and } \\
\text { their attachments on } 1^{\text {st }} \text { July } 2015\end{array}$ & $\begin{array}{l}\text { Conducted interview and focus group } \\
\text { sessions with local governmental } \\
\text { agency's representatives and some } \\
\text { villagers from two selected resettled } \\
\text { villages }\end{array}$ & $\begin{array}{l}\text { Interviewed the representative of } \\
\text { DEB, MEM on } 16^{\text {th }} \text { July } 2015\end{array}$ & $\begin{array}{l}\text { Interviewed the representative of } \\
\text { DESIA on } 23^{\text {rd }} \text { July } 2015\end{array}$ \\
\hline & $\begin{array}{l}\text { Spent whole week to make contacts } \\
\text { with all planned research participants } \\
\text { and obtained confirmations from some } \\
\text { of them only. For example, local } \\
\text { governmental agencies and resettled } \\
\text { people: RMU, the chiefs of the two } \\
\text { selected resettled villages, and some } \\
\text { villagers of the two resettled villages. } \\
\text { However, both central governmental } \\
\text { agencies: Department of Energy } \\
\text { Business (DEB), (MEM) and DESIA } \\
\text { and NT2 developers did not confirm to } \\
\text { me yet }\end{array}$ & $\begin{array}{l}\text { The time spent in this whole week was } \\
\text { for travelling programmes of Vientiane } \\
\text { Capital-Khammouane province- } \\
\text { Vientiane Capital. The distance between } \\
\text { VC-KHM-VC and routes travelled in } \\
\text { different places in Khammouane } \\
\text { province was around } 900-1000 \mathrm{~km} \text { and } \\
\text { undertaking research activities in } \\
\text { resettled community } \\
\text { Kept waiting for confirmations from } \\
\text { DEB, DESIA, and NT2 developers }\end{array}$ & $\begin{array}{l}\text { Transcribed all collected data, while } \\
\text { kept waiting for response from } \\
\text { DESIA and NT2 developers }\end{array}$ & $\begin{array}{l}\text { Transcribed all collected data, } \\
\text { while kept waiting for response } \\
\text { from NT2 developer }\end{array}$ \\
\hline
\end{tabular}




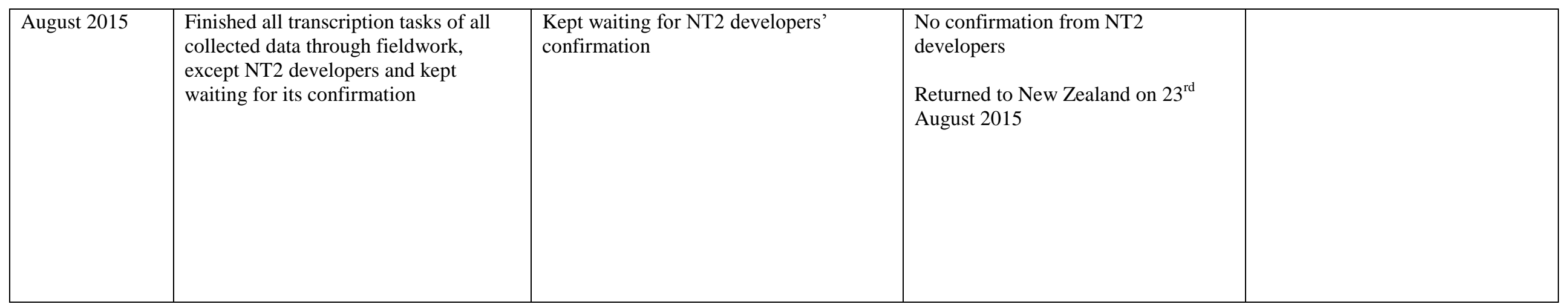




\subsection{Ethical Considerations}

According to Sultana (2007), undertaking research in the fieldwork ethically requires embracing issues of positionality, reflexivity and power relations. Fieldwork is a means of gaining partial representations of people and their actions in tangible space. Hence, it is very important to be aware of the existence of people with a diversity of characteristics and relationships throughout the research endeavour (Chacko, 2004). In addition, reflexive interaction between such positionalities of both parties' personal values in the form of power relations can help to co-produce knowledge as well (Walker et al., 2013). However, power imbalances between the researcher and research participants may cause some methodological and ethical challenges (Smith, 2006). Subsequently, these ethical considerations seem to go beyond the formal VUW approval process as shown through the following details:

Firstly, the notion of positionality embraces attention to characteristics such as race, nationality, and gender which are culturally ascribed. Such attributes require textual disclosure when they affect the information, as they always do to some extent (Chiseri-Strater, 1996). Besides, awareness of positionality can be helpful to shed light on explicit and implicit power structures in the qualitative research process, particularly, an engagement between the researcher and research participants. Also, it includes the way knowledge is transferred through their interaction (Chacko, 2004). Hence, it is significant to recognise the role of the (multiple) "self", showing how the researcher's positionality (in terms of race, nationality, age, gender, social and economic status, sexuality) may influence the "data" collected and thus the information that becomes coded as "knowledge" (Rose, 1997, p. 308).

Nonetheless, inclusion of positionality in the course of conducting fieldwork refers to aspects of identity as aforementioned ethnographical attributes that are markers of relational positions in society, rather than intrinsic qualities. Given that, relations of unequal power may lead to implicit positionality as well as change or produce a diversity of identities. This variously allows for "convergence or divergence" of opinions, behaviours and understandings (Chacko, 2004, p. 52). In addition, the researcher may face problems both of a general nature and specific to the setting in accommodating a range of identities as well as being unable to claim a specific positionality in that moment (Chacko, 2004). As a result, this limits the researcher to 
fully access the lives of those participants, which challenges the researcher to seek out some alternative approaches (Sultana, 2007).

Secondly, due to the fact that reflexivity is an examining process both of oneself as the researcher and the research relationship, it is another important component of doing ethical research (Sultana, 2007). It is often regarded as an effective instrument for ensuring the standard of qualitative research as well as providing transparent information about the positionality and personal values of the researcher. As a result, reflexivity could affect the data collection and analysis obtained from research participants (Walker et al., 2013). Additionally, reflexivity is being supported by many research proponents as a strategy for gaining an insight into knowledge construction. As such, it is a method of avoiding the fabricated 'neutrality and universality' of a large amount of academic knowledge (Rose, 1997, p. 306). Consequently, embracing a reflexive stance is deemed as enhancing confidence in qualitative research and creating researchers' credibility (Walker et al., 2013). Thus, the adoption of reflexivity into qualitative research is sound positive and effective in terms of producing transparent information, gaining insight into knowledge production, and meeting ethical research principles.

Lastly, power relation is another important component of ethical research. "In practice, the power relation plays a vital role functioning as a medium to transfer the representation of the identity by strengthening its type and function which automatically colour the power relation.” (Muqit, 2013, p. 130). Specifically, an interview is the most used method in qualitative research in terms of collecting indepth information. Hence, it is possible to build up power through the interview process and also exercise it via ethnographical attributes of involved participants (Anyan, 2013). For this reason, qualitative research involves both researcher and participants in the 'coproduction of knowledge' so as to avoid the division between researcher and subject as well as share representation between the researcher and participants (Karnieli-Miller, Strier, \& Pessach, 2008; 2009, p. 279). Thus, exercising power relation through interview sessions seems to help both researcher and participants to contribute jointly constructed knowledge effectively within the qualitative research process. 


\subsection{Contextual Limitations}

The research in question took place at a time when NT2 resettlement operation had already been completed. Despite this, obtaining semi-structured interviews and focus groups were challenging. Based on my initial intention to interview experienced individuals concerning NT2 resettlement programmes, I officially submitted invitations to all the targeted research participants: representatives of governmental agencies, NT2 project, and NT2 resettled community. Surprisingly, I obtained cooperation from all of them but NT2 project. Without the presence of representatives from NT2 project creates an absence in this study as data from them was considered to be equally important as the others for this research.

Furthermore, I also encountered some challenges. For example, resettled residents from the two selected villages declined to participate in semi-structured interviews but joined focus group activities. This situation caused concern for me regarding the lack of individual perspective from resettled villagers contributing to the research. Even though they might share their opinions collectively through focus group discussions, these contributions were considered relatively limited. Such occurrences reflected resettled residents' diffident attitude towards having their say in public, which undoubtedly constrained the progress of this study.

However, the chiefs of those two selected villages participated in both research activities. As residents of the two resettled villages, they were considered to be direct experienced individuals as the other resettled villagers. Unfortunately, because of their positions as village chiefs, their answers to my research questionnaires (specifically in semi-structured interviews) were often too general and vague. Moreover, they also made their opinions too broad in focus group discussions. These happenings implied the village chiefs were worried about future consequences arising from contributions made to my fieldwork activities. Since political sensitive issues, in Lao PDR, are highly recognised by government agencies, the way the two village chiefs' concern in respect to politically sensitive place like Nakai resettlement community is not foreign to such recognition.

Lastly, as discussed in section 3.4.6 (Site Selection), because of the limited resources and timeframe of this study, I could not ideally undertake fieldwork activities in all 
the resettled villages. This constrained my capability in terms of generalising the findings as the entire outcomes of the Nakai Plateau resettlement community.

\subsection{Conclusion}

This chapter has provided an overview of the methodology of this research. It introduced my epistemological lens as pragmatism in terms of guiding this study through employing proper research approaches. Additionally, it provided the detail description of the process of fieldwork preparation which included: a) the using of case study of Nakai Plateau resettlement community; b) the recruitment of research participants and site selection; c) the application of qualitative and quantitative research methods as well as the data analysis techniques; and d) the ethical considerations where the concepts of positionality, reflexivity, and power relation were included.

However, there were some challenges during the fieldwork preparation presented in the chapter. Firstly, the delay of academic approvals from VUW and the approval of a number of official request letters from my organisation (DESIA) caused my planned fieldwork activities to be delayed. Secondly, the mismatch between the available time of some research participants and my requested date and time was another cause of fieldwork delay. Lastly, I also faced a delay regarding the local authority's confirmation concerning the participation in my fieldwork activities. As a result, based on a discussion with my research supervisor, initial planned fieldwork activities were re-adjusted.

Furthermore, this chapter provided a reflection associated with limitations of my fieldwork experience. First, it was regrettable that NT2 project representatives were not able to take part in my fieldwork activities, even after my attempts to engage them. Second, resettled villagers and their village chiefs caused challenges to the study. While the former provided limited contribution to the research, the latter caused the researcher to encounter difficulty of deciphering their broad and vague information. Third, the researcher's limited capacity to conduct the fieldwork in all the resettled villages limited his capacity to generalise from the findings to the resettled community as a whole. 
These limitations noted, the research design enabled the researcher to take into account such the challenges and address them through a sound research approach. Finally, the triangulation possible through involvement of different stakeholders means that the perspectives that follow create a clear and compelling picture of lived resettlement experiences. 


\section{Chapter Four: The Preparation of NT2 Resettlement Strategies}

\subsection{Introduction}

This chapter illustrates the findings and analysis associated with the preparation of NT2 resettlement plans prior to resettlement. The chapter begins with an introduction to the background of resettled people's livelihoods in the Nakai Plateau paying attention to those people in the two selected resettled villages and their memories about life before resettlement. Then, I examine the strategies associated with NT2's preparation of resettlement plans by comparing the principles of the IRR Model. Finally, a conclusion is provided in section 4.4.

\subsection{Introduction to the Nakai Plateau Resettlement Community}

\subsubsection{Nakai Plateau Resettlement Site}

Figure 6: Map of the Nakai Plateau resettlement community

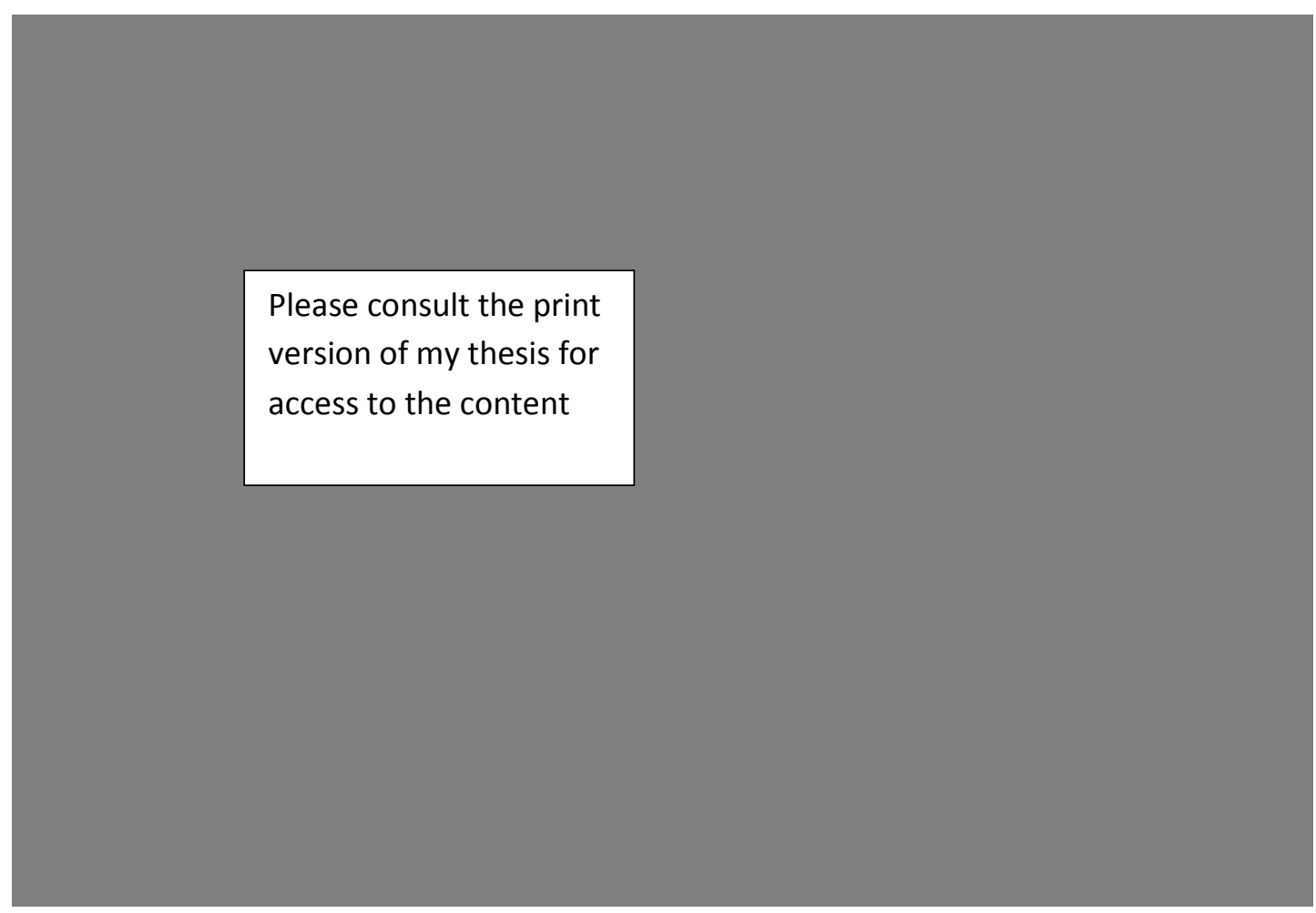

Source: Phonepraseuth, 2012, p. 11

According to the CA signed between Lao government and NT2 developers on $3^{\text {rd }}$ October 2002 including its amended version in March 2005 (Ovenden, 2007), NT2's scheme was to construct a dam on the Nam Theun River to make a 450-squarekilometre reservoir (Nam Theun 2 project, 2005). These project activities would 
affect three central provinces of Laos: Khammouane, Bolikhamxay and Savannakhet (Nam Theun 2 project, 2005). Such a scheme would mostly affect nine districts in Khammouane province - Khamkeut, Nakai, Gnommalat, Mahaxai, Xe Bangfai, Thakhek, Nong Bok, Xaibouly and Khanthabouly - with the majority of project activities taking place in the districts of Nakai, Gnommalath and Mahaxai (Ovenden, 2007). In particular, resettlement activity was identified as impacting mostly the large amount of people living in this province (Ovenden, 2007).

NT2 resettlement area is on the Nakai Plateau which is located between the Annamite mountain range defined as the Lao-Vietnamese border. It also has lowland areas stretching down to the Mekong River and the border with Thailand (Nam Theun 2 hydroelectric project, n.d.). The Plateau is part of the Nakai district, which until very recently has been within one of the group of poorest districts in Lao PDR (Nam Theun 2 hydroelectric project, n.d.). In terms of ethnicity, Khammouane province is populated by a wide range of ethnic groups, which can be divided into four main ethno-linguistic families: Tai-Lao (the majority population), AustroAsiatic, Meo-Yao and Tibeto-Burman (Ovenden, 2007). Given this, there are various ethnic minorities which make most of the population in the Nakai district. In other words, around 50 per cent of the inhabitants in the district centre are ethnic Lao (Singh, 2011).

The Nakai Plateau is also geographically remote (Singh, 2011). Phonepraseuth (2012) describes how, because of the distance and poor conditions of roads between the Nakai district capital, Oudomsouk and Khammouane provincial capital, it took nearly twelve hours to travel to Thakhek in the dry season. Travelling between the two districts, during the wet season, was almost impossible. Phonepraseuth (2012) also illustrated that there were no access roads for more than half of the 16 villages that were going to be resettled by NT2, and only some of them could be reached by using boats.

Additionally, all infrastructural facilities were in very poor condition: no paved road, no access to electricity, and limited access to clean water as well as insecure houses. For example, houses were built by traditional materials of wood, bamboo, and roofed by thatch or shingles (Phonepraseuth, 2012). Furthermore, these residents' social conditions were seemingly insecure, because there were more than 60 per cent of 
them found having limited access to schooling as well as facing difficulty because they had to walk more than 10 kilometres to the nearest health facility (Phonepraseuth, 2012).

NT2's project overview of resettlement programmes made by the Department of Energy Business (n.d.) identified that because the Nakai Plateau was assigned to be NT2's reservoir area, approximately 6,300 residents on the Nakai Plateau area must be resettled. However, even though these inhabitants were to be unavoidably relocated, they would be only relocated from their original locations along the Nam Theun River to the southern edge of the planned reservoir on the Nakai Plateau (Nam Theun 2 hydroelectric project, n.d.). The physical relocation was planned to start with a pilot village in 2004 following with the first group of nine villages and the second group of seven villages in 2006 and 2008 respectively (Nam Theun 2 hydroelectric project, n.d.). Further, before the resettlement process of those populations began many plans associated with resettlement activities were prepared. Thus, the preparation was about recognising resettlement as not only moving people and providing them with shelter and land but also providing support and assistance to help them adapt to a new environment (Nam Theun 2 hydroelectric project, n.d.). For example, assistance was provided for people to identify and pursue new livelihood opportunities as well as to cope with a changing social and economic context. There were improved access roads, telecommunication, electricity and compensation packages. In other words, resettled people would be assisted in adjusting their habits and production/consumption patterns as well as in seizing new opportunities such as enhanced access to services like education and health care (Nam Theun 2 hydroelectric project, n.d.).

Since 1997 there were a number of public consultations concerning RAP held in Vientiane (Capital City of Lao PDR) including many detailed local consultations organised in villages on the Nakai Plateau (Ovenden, 2007). Importantly, a RAP was later drafted and implemented in accordance with NT2's CA, WB and ADB safeguard policies, and NT2 Resettlement Policy (Ovenden, 2007). Therefore, under the principles guided in RAP, the living standards and income earning capacity of residents - who lived in the Nakai Plateau resettlement site - would be improved to 
meet at least the national poverty level including receiving sufficient support during the transition period (Ovenden, 2007).

\subsubsection{The Two Selected Resettled Villages before Resettlement}

\subsubsection{Nakai Village}

As mentioned in Chapter Three, the Southern and the Northern Nakai villages were integrated into one new village: the Nakai village, which is located in the north of Nakai Plateau resettlement community (Nakai village chief, personal communication, July 2015). An Asian Development Bank's report (2004) shows that Nakai village is rich in historical and traditional values as its location is surrounded by numerous sites of spiritual significance, cemeteries, and an abandoned Buddhist temple (believed to be approximately 200 years old). There were also foundations of a royal hunting lodge built in the 1940's on the Nakai Plateau. Before resettlement, residents' principal occupations in the Nakai village were farming and cattle raising. In addition, there were many large paddy field areas available in their old community where they produced plentiful amounts of rice sufficient for their needs, as one Nakai villager shared with me,

When we moved to this resettlement community we received only 0.66 ha of land plot allotted for each household to use for agricultural purposes, which has been insufficient for our subsistence. We think that then, in our old community, we never faced a dearth of foods like we are facing it now.

(Nakai village participant, personal communication, $9^{\text {th }}$ July 2015)

\subsubsection{Nakai Village and The Preparation of NT2 Resettlement Plans}

Findings from my fieldwork illustrate that residents of the Nakai village were well informed by local authorities and NT2 developers about resettlement, compensation, and livelihood restoration strategies before resettlement. These villagers were encouraged to get involved in the preparation of NT2 resettlement plans as they attended the consultation sessions and accompanied the government representatives and NT2 developers to see the actual areas of resettlement. 
The local authority and the project informed us about the preparation of resettlement and livelihoods restoration plans and we were invited to participate in many discussion sessions of the resettlement planning process.

(Nakai village participants, personal communication, $9^{\text {th }}$ July 2015) All villagers were encouragingly mobilized by the local authority to participate in the preparation of resettlement plans. Since they had been informed about their situations in this project, they contributed their time and attentions a lot in preparing the resettlement plans.

(Nakai village chief, personal communication, $9^{\text {th }}$ July 2015)

Significantly, they were informed about the five pillars of livelihood programmes: agriculture development, livestock development, community forestry development, reservoir fisheries development, and off-farm income development. These programmes appeared to be ideal approaches to achieve sustainable livelihoods for the resettled people as planned by NT2.

\subsubsection{Phon-Sa-On Village (Sop On Village)}

Phon-Sa-On village is located in the south of Nakai Plateau resettlement community (Phon-Sa-On village chief, personal communication, July 2015). It is a central service centre where many community facilities (including a healthcare clinic) are available for the resettled people in the southern zone of the Nakai Plateau resettlement site (Phonepraseuth, 2012). Before resettlement most residents of the Phon-Sa-On village were farmers, while the rest were handicrafts makers and traders (Nam Theun 2 project, 2005). Other than this, villagers also made their living by raising a number of livestock such as cattle, pigs, and poultry (Nam Theun 2 project, 2005). In addition, fishing along the Nam Theun River was a livelihood choice as well as collecting natural resources from the forest including slash and burn farming on the mountainous areas.

Apart from such occupational patterns, the welfare of these residents was considered poor at that time. For example, pregnant women were at risk due to the fact there was no hospital in their community and the nearest one was located around 50-60 km away in another district (Phon-Sa-On village chief, personal communication, July 2015). 


\subsubsection{Phon-Sa-On Village and the Preparation of NT2 Resettlement Plans}

Before resettlement, a census was conducted by the Lao government between 1998 and 2004 in Phon-Sa-On village documented 89 affected households or around 420 villagers. One year later, the government and NT2 members held a number of consultation workshops which included various stakeholders in order to come to an agreement with these residents over resettlement. Here, residents were well informed about resettlement, compensation, and livelihood restoration strategies prepared by NT2. In addition, they were involved in every step of the preparation for the resettlement planning process including knowing about the five pillars of livelihood programmes.

During the preparation of resettlement programmes, we invited a small number of villagers (4 - 5 people) from each village including their village chiefs to participate in the session. These people became regular participants who joined us in planning process. For example, they spent many hours during working days at our regular meeting sessions at the RMU office. This showed that the project affected people were always updated for every information and situation.

(RMU representative, personal communication, $8^{\text {th }}$ July 2015) Villagers were involved in every step of preparation of resettlement planning process.

(Phon-Sa-On village chief, personal communication, July 2015)

In summary, before resettlement, residents of both Nakai village and Phon-Sa-On village shared some similar livelihood patterns and pre-resettlement experiences. In terms of livelihood patterns, they were mostly farmers and raised livestock. In terms of pre-resettlement experiences, they were well informed about resettlement, compensation, and livelihood restoration strategies prepared by NT2. Moreover, they were also encouraged to participate in all planning processes. Importantly, they understood about the five pillars of livelihood programmes. 


\subsubsection{Introduction of Five Pillars of Livelihood Restoration Programmes}

NT2 developers prepared livelihood restoration programmes in order to provide resettled people with income generating programmes and to include a diversity of agro-economic activities in the development plans (Nam Theun 2 hydroelectric project, n.d.). As a result, five pillars were established to reconstruct the livelihoods of the Nakai Plateau resettled population - agriculture, livestock, commercial community forestry, fisheries, and non-farm enterprises and employment as follows (Nam Theun 2 project, 2005, p. 1):

1. Agriculture: Wet and dry season cropping, with irrigation water pumped from the Nam Theun 2 Reservoir;

2. Livestock: Livestock raised on a mixture of feed-crops or forages grown on the irrigated areas, and grazing under the forest of the resettlement area and the drawdown zone;

3. Commercial Community Forestry in the resettlement area forests, including management and harvest of the natural forest, reforestation of degraded forests and primary and secondary wood processing providing both employment to some families, and dividends to all;

4. Fisheries: Subsistence and commercial fishing in the newly created Nam Theun 2 Reservoir; and

5. Non-farm enterprises and employment: Waged or self-employment in a range of activities such as small shops, repair and fabrication shops, handicrafts, primary produce trading and construction labour, for example.

According to NT2 Concession Agreement (2005); Nam Theun 2 hydroelectric project (n.d.); and my own observations during the fieldwork, these pillars of livelihood restoration programmes provide many benefits for resettled people. Firstly, the resettled population were supported to optimise their arable lands for the most productive purposes and increase their farming productivity. Secondly, their livestock activities were encouraged. Thirdly, commercial community forestry was seen as a way to help resettled people develop and manage forest resources by and for their community through a village forest association (VFA). The VFA would then ensure sustainable management of more than 17,500 hectares of forest land in the Nakai Plateau. The VFA was thought to provide resettled people with employment 
opportunities and dividends as shareholders. Significantly, strategies aimed to ensure resettled people would protect forest resources.

Fourthly, fisheries were identified as a means for people to generate incomes through the sale of fish or other products like fermented fish or dried fish. Fish could also be a form of subsistence food. Lastly, resettled populations were to be assisted with non-farm enterprises and employment programmes to access optional income sources. For example, many resettled people during the course of the project were employed by NT2 for project construction work as well as for building their own houses or preparing agricultural land. In addition, resettled people were provided with skill training programmes by NT2 so they could run various businesses such as small family shops, guesthouses and restaurants, food processing and service businesses.

\subsection{NT2 Resettlement Strategies}

According to the CA, NT2 was responsible for addressing, alleviating or remedying all social impacts resulted from its project activities especially the resettlement of the Nakai Plateau population (Nam Theun 2 hydroelectric project, 2005). In doing so, NT2 developers were required to prepare certain social action plans such as a RAP and the social and environmental management framework and operational plan (SEMFOP) (Nam Theun 2 hydroelectric project, 2005). All social obligations of NT2 are stipulated in Schedule 4 of the CA, particularly part 1 which deals with the social and resettlement objectives (Nam Theun 2 hydroelectric project, 2005). Given this, all social obligations of NT2 were set out in Schedule 4 of the CA which includes NT2 resettlement strategies for all project-affected populations in the Nakai Plateau (Nam Theun 2 hydroelectric project, 2005). Therefore, an overview of NT2 resettlement strategies is shown in the following section.

\subsubsection{The Resettlement Policy}

The resettlement policy for resettled residents in the Nakai Plateau is specified in part 1 of NT2's CA-Schedule 4 as shown in following objectives:

a) Ensure that all Project Affected Persons promptly receive their entitlements under clause 15 ; 
b) Ensure that Resettlers have their income earning capacity enhanced and achieve the Household Income Target, with adequate support being provided by the parties during the Resettlement Implementation Period;

c) Materially improve Resettler livelihoods on a sustainable basis;

d) Restore livelihoods of Project Affected Persons (other than resettlers who are covered by paragraph (c)) on a sustainable basis;

e) Have the Project Affected Persons participate in the consultation, planning and design process of their new settlement and production areas;

f) Apply special measures as required towards ethnic minorities and vulnerable persons to take care of their needs and foster self-reliance and to improve their socio-economic status;

g) Provide for the construction of infrastructure in the Resettlement Area in accordance with the standards set out in this Part for the best interests of the local population and the population in and around the Resettlement Area;

h) Make replacement land available to all those interested with cash compensation only to be considered for those with specific plans to permanently move out of the district;

i) Conceive and execute resettlement and rehabilitation plans as specific development plans; and

j) Comply with the NT2 Resettlement Policy.

Source: NT2 Concession Agreement, 2005, p. 6

In terms of policy, these objectives seemed to offer an appropriate framework to help meet the goal of sustainable livelihoods development for resettled people. Firstly, they require including the participation of all ethnic characteristics of resettled people in the planning process of resettlement strategies. Secondly, they ensure those people are provided with livelihoods improvement programmes on a sustainable basis regarding the established income target indicators. Lastly, they call for the implementation of resettlement and rehabilitation plans as specific development plans, which is considered crucially important. This action is consistent with Cernea's (1997, p.1570) notion that "socially responsible resettlement - that is resettlement guided by an equity compass - can counteract lasting impoverishment 
and generate benefits for both the regional and local economy". Given that, it seems to relieve resettled people's impoverishment risks and make them as the first benefits recipients of NT2, especially their lives can be transformed for the better (Wilmsen, Webber \& Yuefang, 2011).

\subsubsection{Principles of RAP}

In response to the resettlement policy required by CA, NT2 prepared a set of principles of resettlement identified in RAP as following the guiding assumptions below (Ovenden, 2007, p.9):

a) Funding is assured with all partners agreeing that the RAP is to be fully financed by the NT2 Project.

b) Resettlement planning is to be integrated with the general NT2 Project design from the earliest stages of NT2 Project preparation.

c) The GOL will develop and adopt the appropriate policies to ensure proper and just resettlement, including the development of an applicable Resettlement Policy for the NT2 Project.

d) Nakai Resettled people living standards and income earning capacity will improve to at least the national poverty level, and PAHs will be provided with adequate support during the transition period; resettlement is to be avoided or minimised wherever feasible.

e) Identified gender concerns and specific women's needs and perspectives are to be considered in all components, strategies and planned activities; women and men will have equal opportunity to participate in decision-making, training and the NT2 Project benefits.

f) People to be resettled or directly affected will play an active role in the design, planning, implementation and monitoring of the RAP.

g) Traditional organisational structures, religious beliefs and resource use will be taken into account during resettlement planning and implementation; appropriate consultation and participatory methods are to be used, utilising local knowledge in developing production systems that suit the people's needs and the environment and which avoid dependency on NT2 Project or government agencies.

h) The planning, implementation and compensation processes will be open and transparent but follow prescriptive IFI guidelines. 
These principles are comprehensive and encompass various dimensions for practice. Firstly, they encourage participation of involved stakeholders - the Lao government, NT2, and resettled people - in resettlement planning processes. They attend to gender equality, and cultural or traditional beliefs are highly regarded. Secondly, they embrace resettlement planning into NT2's general project design under financial support from NT2, and they ensure transparency within project implementation. Lastly, they apply the Lao national poverty line as a minimum target for improving resettled population's living standard.

\subsubsection{Entitlement Matrix of Part I of the CA-Schedule 4}

Regarding NT2's social obligations set out in the Part 1 of the CA-Schedule 4, these following details are a summary of the entitlement matrix of resettled residents in the Nakai Plateau resettlement community concerning compensation and rehabilitation packages (NT2 Concession Agreement, 2005, p. 93 - 101):

(a) All people - whose agricultural lands are affected by the NT2 - are compensated with 0.66 ha of cleared and irrigated land per household. They are also eligible to receiving land title;

(b) All people - whose residential land and non-agricultural land are affected by the NT2 are compensated with residential land equivalent to the greater of (1) at least $600 \mathrm{~m}^{2}$ (indicatively $20 \mathrm{~m} \times 30 \mathrm{~m}$ ) plot for the construction of new timber house and surrounding garden, or (2) the area of housing land lost. In addition, households with 7 or more persons containing two families have the option to have two house plots including land title;

(c) All NT2 affected households are entitled to receiving minimum housing area to be the greater of (1) existing area, or (2) $14 \mathrm{~m}^{2}$ of construction area per person; or (3) $42 \mathrm{~m}^{2}$. Households with 7 or more persons containing two families have the option to have two houses. These replaced houses are in good quality of year-round domestic water supply and standard electricity supply;

(d) All households whose business/commercial structure are impacted by the NT2 are entitled to appropriate replacement: obtained assistance for constructing a new one equivalent to the old one and locating at the comparable commercial advantage to the former location; 
(e) All resettled villages - where their physical cultural resources (village monasteries, temples, stupas, spirit houses, and historical artefacts and etc.) are affected by inundation of the Nakai reservoir - are replaced with new buildings of at least similar to dimensions, components and construction materials of the old one;

(f) All households - whose garden and field crops, fruit trees, and timber trees are impacted by the NT2 - are entitled to cash compensation for such loss;

(g) All people whose livelihoods are affected by the NT2 are entitled to re-establishing livelihoods through the five pillars of livelihood restoration programmes provided by the NT2;

(h) All resettled villages - whose common property community infrastructure (electricity, roads, irrigation channels, water source, schools, and etc.) are impacted by the NT2 - are entitled to replacements. It is interesting to note that all resettled villages are provided with nursery school and primary school per village including the school equipment and supplies for each school;

(i) All resettled households are provided with allowances and transitional assistance (food, employment, and etc.);

(j) All resettled people are entitled to use of health facilities and access to health services (access to Nakai district hospital and two newly built integrated community health centres); and

(k) All resettled people access to grievance entitlements if they are unhappy with any of these entitlements above or any NT2 process generally.

These summarised components of the entitlement matrix represent how a bundle of compensation packages for resettled people's losses, provided by NT2 work. They are categorised ranging from compensation for property loss to the loss of livelihoods. This matrix seems to show comprehensive contribution by NT2 to resettled people's living standards. Thus, the entitlement matrix is an integral part of NT2 resettlement strategies to achieve sustainable livelihoods development for resettled people.

\subsubsection{Analysing NT2 Resettlement Strategies through IRR Model}

The function of the IRR model is to help a planning process - associated with involuntary resettlement due to hydroelectric projects - to anticipate different forms 
of losses and devise appropriate policies and strategies to prevent them (Dwivedi, 2002). It can also produce encompassing and transparent information through the 'computation of losses' associated with both the potential and causes of resettlement impacts. It represents a genuine effort at participation to find an acceptable solution between the planners and resettled population (Dwivedi, 2002, p. 718). It is significant to note that, the IRR model has been acknowledged widely as a contemporary approach which recognises the rights of, and risks to, all relevant stakeholders in the decision-making process from the planning stage onwards (Cernea, 1997). Furthermore, NT2 has been regarded by WB as a role model of sustainable development for hydropower projects in Lao PDR (Goldman, 2001). Therefore, using the IRR model as a theoretical lens - in order to analyse NT2 resettlement strategies in pre-resettlement period - seems to be suitable for assessing how comprehensive and effective the strategies were prepared.

\subsubsection{Principles of IRR Model}

According to Cernea (1997); Dwivedi (2002); and McDonald-Wilmsen \& Webber, (2010), the IRR model categorises multidimensional characteristics of risks which can cause resettled populations to become impoverished in the following eight key ways:

a) Landlessness - the loss of land (the main foundation on which people's livelihoods are constructed);

b) Joblessness - loss of wage employment;

c) Homelessness - loss of housing or shelter;

d) Marginalisation - displaced people cannot regain previous social standard of living;

e) Food insecurity - calorie-protein intake levels are below the minimum necessary for normal growth and work;

f) Increased morbidity and mortality - serious declines in health and even death;

g) Loss of access to common property resources - loss of property assets that belong to relocated communities (forested lands, water bodies, grazing lands, burial grounds); and

h) Community disarticulation - disruption of social fabric (social organisation, interpersonal ties, kinship groups and informal networks) 
Because the IRR model is a mixture of impoverishment risk diagnosis and reestablishment of impoverishment (Cernea, 1999), it provides a conceptual reconstruction pattern for those aforementioned risks of impoverishment as follows (Cernea, 1997, pp. 1580-1582):

a) From landlessness to land-based re-establishment;

b) From joblessness to reemployment;

c) From homelessness to house reconstruction;

d) From marginalisation to social inclusion;

e) From food insecurity to adequate nutrition;

f) From increased morbidity to better health care;

g) From exploitation to restoration of community assets; and

h) From social disarticulation to community reconstruction

When comparing NT2 resettlement strategies and the IRR model's principles, the former seems to be consistent with principles of the latter. NT2 resettlement strategies addressed all concerns associated with potential impoverishment risks and provided various interesting mitigation measures for such risks, which were also consistent with the IRR model. However, even though NT2 resettlement strategies seem to be complete and effective, some challenges occurred during their preparation period raise doubts about how they were produced.

The following quotes expressed by my research participants imply that NT2 resettlement strategies were probably not as well prepared as it first appeared:

At the time when NT2 resettlement strategies were being prepared, then my organisation, Department of Energy Business (DEB), MEM was - on behalf of Lao government - responsible for reviewing them. We did not only review but also translated them into Lao language, because they all were English. For the preparation process of NT2 resettlement strategies, we had the RC that took a leading position in consultation workshops with the PAP. At this point, we (DEB) acted as a facilitator of the session. However, all 
consultation agendas were based on NT2 project documents prepared by consulting firms.

(DEB, MEM representative, personal communication, $16^{\text {th }}$ July 2015) We, project-affected villagers, were involved in the resettlement planning process as participants in each consultation workshop. We contributed many opinions to each discussion session in what we were mostly concerned. For example, we worried that after relocation we might not receive any replacement and compensation as the local authority and the project promised to provide us. Anyway, we had no choice and had to give in to all of their requirements undeniably.

(Phon-Sa-On village female participant, personal communication, $10^{\text {th }}$ July 2015)

Communication was the most challenging issue when we (government representatives and NT2 project implementers) worked with project-affected residents, because they used basic Lao language.

(DEB, MEM representative, personal communication, $16^{\text {th }}$ July 2015) When we discussed with project-affected villagers in many sessions, they seemed to understand about NT2 resettlement strategies. However, they were often unsure about what would be the actual compensation of their own lost properties and livelihoods.

(RMU representative, personal communication, $8^{\text {th }}$ July 2015).

These quotes illustrate that NT2 resettlement strategies were predominantly prepared by NT2 developers and all discussed agendas were likely influenced by them. Kapoor (2005) suggests that the participatory development conceptually implies that the participants are never fully liberated from the domination of the facilitator. Even though a facilitator behaves as a neutral convenor in cross-cultural practice and empowers all participants to contribute to a project agenda, such an agenda is designed, planned, and controlled by the facilitator (Kapoor, 2005). As a result, power is tilted decidedly in favour of the convenor, and, while it may well be used accountably and democratically, it can just as easily be abused (Kapoor, 2005). This 
phenomenon is linked to a criticism of the IRR Model made by Dwivedi (2002) that such a model - through its top-down functional feature - seems to limit the inclusion of displaced people's inherent opinions, beliefs and knowledge, which may lead to impoverishment.

In terms of preparing NT2 resettlement strategies, despite the full participation of project-affected residents, their contributions seemed not to serve their own needs but to support the predetermined agendas of the project. This reflects an unequal power aspect between the facilitator (NT2 developers) and the participants (projectaffected villagers) (Pieterse, 1998). Importantly, these people did not only deal with the difficulty of understanding about such strategies due to their limited linguistic abilities but also seemed to be cunningly exploited by NT2 developers (Kapoor, 2005). Therefore, even though NT2 resettlement strategies are impressive, especially as they meet the principles of the IRR Model, their preparation is questionable.

\subsection{Conclusion}

This chapter has presented the findings of my field research associated with the preparation of NT2 resettlement strategies prior to actual resettlement. It introduced background information of the Nakai Plateau resettlement community, particularly the two selected resettled villages: Nakai and Phon-Sa-On villages. Following this introduction, a brief overview of the preparation of NT2 resettlement strategies as well as their relevant policy and technical documents were provided: a) the five pillars of livelihood restoration programmes; b) the resettlement policy; c) the principles of RAP; and d) the entitlement matrix.

NT2 resettlement strategies were consistent with the principles of the IRR Model the contemporary resettlement approach - which seemed to be sound resettlement strategies. However, a drawback of the top-down functional feature of the IRR Model and a loophole of the participatory approach have raised doubts about how appropriate and ethical NT2 resettlement strategies were prepared. Other findings gained from the actual implementation of NT2 resettlement strategies in the next chapter will provide a clearer picture about the capacity of such strategies and whether they were able to address all resettled people's impoverishment risks or not. 


\section{Chapter Five: The Implementation of NT2 Resettlement Strategies}

\subsection{Introduction}

This chapter discusses fieldwork findings related to resettlement activities during the Resettlement Implementation Period (RIP) of NT2. First, it introduces the institutional responsibilities of the stakeholders concerning NT2 resettlement programmes. Then it illustrates the performance of NT2 in relation to the resettlement strategies. Next, I present an analysis of the consequences of resettlement. Finally, I conclude noting the central concern associated with the existing ineffective livelihood improvement strategies of NT2 as well as interest in future improvement.

\subsection{Stakeholders associated with NT2 Resettlement}

NT2 was carried out under the CA between the Lao government and NTPC (Nam Theun 2 hydroelectric project, 2005). Both parties acknowledged and agreed that any social impacts caused from NT2 activities must be addressed, alleviated or remedied by the NTPC to reasonable satisfaction of the government in accordance with the CA (Nam Theun 2 hydroelectric project, 2005). Specifically, the institutional responsibilities of the government and the NTPC for resettlement are briefly shown through the following: 
Figure 6: The Organisational Responsibilities for Resettlement

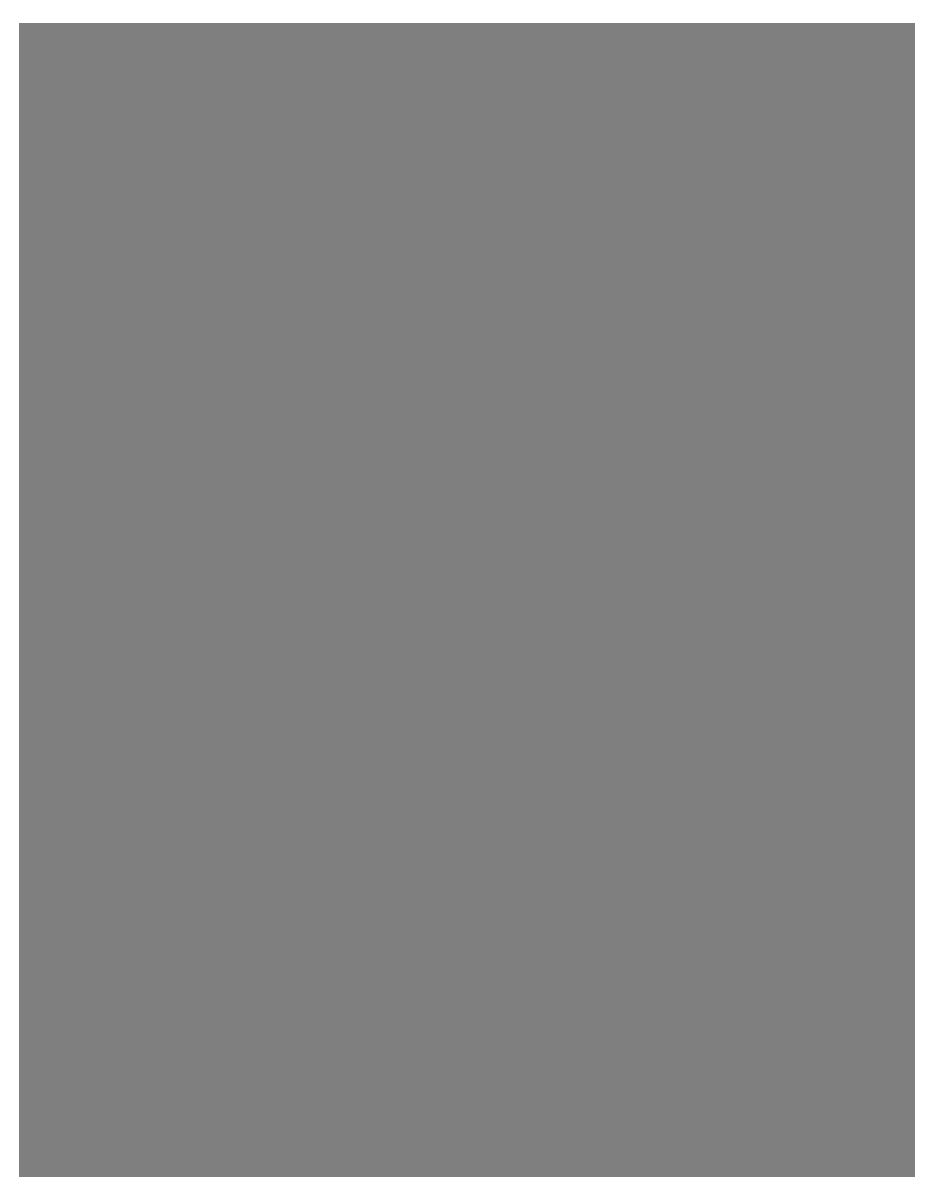

Please consult the print version of
my thesis for access to the content

Source: Nam Theun 2 hydropower project, 2005, p. 11 
The RC was established by the government to have joint overall responsibility with the NTPC for guiding and overseeing the resettlement process. The RC was organised with the Governor and Vice-Governor of Khammouane Province as chair and vice-chair so as to better reflect provincial, district and village planning and implementation responsibilities. Members from fellow project-affected provinces of Bolikhamxay and Savannakhet were included. Additionally, the $\mathrm{RC}$ had the right to review and approve all resettlement works as part of a quarterly, six monthly, and annual or ad hoc plans. Furthermore, the RC through its secretariat, RMU, has jointly worked with the Resettlement Office (RO) established by the NTPC in guiding, implementing, and monitoring the resettlement process to achieve its objectives and outcomes ${ }^{2}$.

Apart from these key implementing bodies associated with resettlement works, there were a number of District Resettlement Working Groups (DRWGs) established by the government in the Nakai, Gnommalath, and Khamkeut districts. There were also District Compensation Working Groups (DCWGs) set up in Mahaxai, Xebangfai, Nongbok and Xaibouly districts. These working groups were responsible, under the direction of the RMU and with assistance from the NTPC through the RO, for implementing the relocation, compensation, rehabilitation and development activities specific to their districts. The government also appointed Village Resettlement Committees (VRCs) in each project-affected village to be responsible for the following duties under the direction of the DRWGs: a) representing the interests of the village; b) holding public consultation with their villages and coordinating with mass organisations at village level concerning the resettlement process; c) developing village development plans and monitoring and evaluating the resettlement process in their village; and d) participating in the Grievance Procedures as specified in the CA.

The CA required the Lao government and the NTPC to establish a panel of experts (POE) with up to three expert members as the body of resettlement process responsible for facilitating the on-going independent review and guidance. Its review and guidance encompassed a) mitigation and remedying of project impacts; b) implementation of each party's obligations under the environmental and social objectives (ESOs); c) amelioration and remedying of unanticipated project impacts; and d) appropriateness and relevance of the ESOs. POE's procedures - including the extent to which its comments and recommendations

\footnotetext{
${ }^{2}$ The information in this section is largely drawn from the following documents: Nam Theun 2 hydroelectric project (2005); NT2 Concession Agreement (CA) (2005); Background project overview (n.d.); Scudder, Talbot $\&$ Whitmore (1999); and Nam Theun 2: Independent Assessments (n.d.).
} 
are binding in the NTPC - are set out in the CA. POE played a main role in providing advice to the RC through consultation in relation to the resettlement process, especially before RIP was terminated. RIP is the period from commencement of implementation of the resettlement process $^{3}$, and ends when the RC is satisfied, on advice from POE, that the Resettlement Objectives (RO) and Resettlement Provisions (RP) have been achieved.

It is important to note that, POE had full rights in terms of reviewing and analysing the resettlement component of ESOs, particularly the activities performed during RIP such as resettlement objectives and resettlement provisions. In case the NTPC was unable to demonstrate to POE that the resettlement objectives and the resettlement provisions had been achieved, RIP would be extended for a period as recommended by POE.

\subsection{Resettlement: Documented Intentions}

As discussed in Chapter Four, the physical relocation of people living in the Nakai Plateau was started with a pilot village in 2004 (Nam Theun 2 hydroelectric project, n.d.). An initial group of nine villages was then relocated in 2006 into temporary settlements for safety reasons to protect villages from possible backwater effects generated by the coffer dam (Nam Theun 2 hydroelectric project, n.d.). A second group of seven villages was moved in the dry season of 2007/2008 and all 17 villages were relocated by May 2008 into their new houses (Nam Theun 2 hydroelectric project, n.d.). According to NT2 resettlement strategies, the PAP to be resettled were to be materially compensated for all of their physical loss in accordance with the principle of replacement costs. Such replacement costs included recompense of agricultural lands, gardens, houses, schools, hospitals and dispensaries, temples, cemeteries, markets, buildings, fruit trees, etc (GOL Resettlement Principles, n.d.). Food subsidies and food for work should have also been provided during the resettlement transitional period for clearing new lands and building new infrastructures (Nam Theun 2 hydroelectric project, n.d.).

Apart from such compensation for physical loss, the aim was for these populations to improve their living standards. This links to Cernea's (1997) notion that resettlement operations should be treated as developmental opportunities, as development projects in their own right, benefitting the resettled people. In particular, individual household incomes should

\footnotetext{
${ }^{3}$ Resettlement Process means the planning and implementation of entitlements and measures to mitigate and/or compensate the Project Impacts, including but not limited to compensation, relocation and rehabilitation of Project-Affected Persons (NT2 Concession Agreement (CA), 2005).
} 
have risen above the National Rural Poverty Line (NRPL) within four years after physical relocation (GOL Resettlement Principles, n.d.). In order to improve such living standards, the Household Income Target (HIT) was set up as one of the resettlement objectives to be achieved before the RC declared the closing of RIP (Nam Theun 2 hydroelectric project, n.d.).

HIT was defined in the CA as the yearly target for the income of resettled households to above the NRPL at year five of RIP (NT2 Concession Agreement (CA), 2005). The target for each Resettled household in the resettlement area should have been greater of:

a) The then current National Rural Poverty Line, multiplied by the number of persons in the household; and

b) Lao PDR Kip 1,420,800 per person, multiplied by the number of persons in the household (this being the equivalent to USD 800 per average household in June 2002, using the exchange rate of Lao PDR Kip 9,800 = USD 1 and average household size being 5.518 persons)

(NT2 Concession Agreement (CA), 2005, p. 2)

The Village Income Target (VIT) ${ }^{4}$ was also established in order to measure the resettled villagers' incomes at the end of RIP (NT2 Concession Agreement (CA), 2005). In other words, HIT measurement was agreed by stakeholders to be consumption based and to be undertaken by early 2013 (Nam Theun 2 hydroelectric project, n.d.), while VIT measurement was conducted at the end of RIP (NT2 Concession Agreement (CA), 2005). In addition, it is interesting to note that there was an application of special measures for ethnic minority groups and vulnerable persons. In a nutshell, all people to be resettled were to be compensated for their physical losses and also supported to improve their lives and to ensure opportunities for sustainable livelihoods (GOL Resettlement Principles, n.d.). Based on

\footnotetext{
${ }^{4}$ Village Income Target means the yearly target for the income of resettled villages, including income in cash and in kind, to be reached at the end of the Resettlement Implementation Period, being for each village in the Resettlement Area, the greater of:
}

(a) The then current Average Rural Income Per Person, multiplied by the number of persons in the village; and (b) Lao PDR Kip 2,131,200 per person, multiplied by the number of persons in the village (this being the equivalent of USD 1200 per average household in June 2002, using the exchange rate of Lao PDR Kip 9,800= USD 1 and the average household size being 5.518 persons). 
information in the Nam Theun 2 hydroelectric (n.d.) documentation, the following were the outcomes noted for each of the 1,310 resettled households between 2006 and 2013:

Community infrastructure: each resettled village received a new access road, a meeting hall, a village office, a warehouse and a covered market, a primary school (combined with a nursery school) and a teacher's house including complete school equipment and supplies for the classrooms. Additionally, all resettled villages obtained seed processing and storage facilities, an organic fertiliser factory, an electricity distribution system with wiring and appropriate safety devices in each community building. They also gained access to a good quality year-round domestic water supply with adequate drainage facilities and trading places to allow easy boat and road access to each relocated village.

Household infrastructure and assets: all resettled people obtained residential land and a house where the title was registered with both husband and wife. If there was any household with seven or more people living there, people were given the option to have two houses. Apart from such accommodation, each resettled household received a flush toilet with a suitable septic tank, standard electricity supply, 0,66 hectare of land for agricultural purposes including partial irrigation, and compensation for lost paddy and fruit trees.

Livelihood programme: all resettled residents were entitled to attend all the five pillars of the livelihood programmes: a) an agricultural development programme including clearing land from unexploded ordnance as well as obtaining seeds and seedlings, fertiliser, compost bins, various agricultural tools, demonstration and extension activities; b) a community forestry programme including a 70 year 23,400 hectares forestry concession in the area surrounding resettlement villages, household membership in the Village Forestry Association (VFA), which could be inherited and passed on to future generations, and forestry equipment to be used by the VFA such as sawmills, logging trucks, carpentry tools, and so forth; c) a fisheries programme including full access to fisheries in the reservoir for subsistence and commercial purposes in respects to Reservoir Fisheries Management Programme (RFMP); d) an off-farm marketing programme including access to skills training for off-farm employment: tailoring, weaving, small shop keeping, processing and marketing of locallyproduced goods, and services concerning construction and tourism for developing unskilled and semi-skilled labour. 
Transitional support ${ }^{5}$ : each resettled household was entitled to receive monthly rice support of $18 \mathrm{~kg}$ per adult and $12 \mathrm{~kg}$ per child during the transitional period. It was noted that as most of households have been able to access new income sources through consumption and trade of forest products which have long been important for livelihoods (e.g. wildlife, rattan, Agar wood, timber), since October 2008 the rice support was targeted to provide to around 35 vulnerable households only. Apart from the rice support, all vulnerable families also obtained monthly protein support in the form of $8 \mathrm{eggs}, 800 \mathrm{~g}$ of dried meat and $800 \mathrm{~g}$ of fresh meat per person. They also received wages for clearing land and constructing houses during the transitional period.

\subsection{The Progress of The Resettlement to Date}

The above resettlement provisions were implemented between 2006 and 2013. My fieldwork data generated in 2015 updated the progress of the current NT2 resettlement works. The data generated information focused on both the contemporary NT2 resettlement issues and also portrayed something of the previous circumstances before NT2 resettlement programmes were implemented. In what follows I discuss the perspectives of research participants and some relevant project documents. Various aspects associated with NT2 resettlement works are detailed in turn.

\subsubsection{Perspectives of Government Representatives}

According to the data primarily collected from the government representatives' responses to semi-structured interviews, the NTPC through NT2 resettlement strategies identified impoverishment risks and provided multiple mitigation measures to address such potential impoverishments. The impoverishment risks - landlessness, joblessness, homelessness, marginalisation, food insecurity, increased morbidity and mortality, loss of access to common property resources, and community disarticulation - have been addressed well (McDonaldWilmsen \& Webber, 2010). Nonetheless, while the physical impact (loss of properties) seems to have been well addressed, dealing with the non-physical impact (loss of livelihoods) through the livelihood restoration performance of the NTPC is still questionable. A

\footnotetext{
${ }^{5}$ The resettlement transitional period (from relocation to self-sufficiency) will be minimised and adequate social, economic and environmental support will be provided during this period. Transitional support and a phased exit strategy, including a package of livelihood activities that are similar to pre-project livelihood activities with the project providing inputs, initially fully subsidised but gradually phased out as families become able to support themselves (Nam Theun 2 hydropower project, 2005).
} 
representative of DEB, MEM (personal communication, $16^{\text {th }}$ July 2015) pointed out that there are a few obstacles that prevented NT2 from achieving sustainable livelihoods ${ }^{6}$.

The first issue concerned the indecisiveness of resettled people towards several livelihood programmes. For instance, in consultation workshops the resettled villagers often requested to do fishing, plant a village forest, and sell natural products, but they later changed their minds saying that they lacked the labour power to do these activities. In another example, the NTPC supported the PAP by providing them with fishing nets and boats to do fishing in NT2 reservoir. Even though there were a lot of fish when the reservoir was filled by water, such a large number exceeded many resettled people's needs (supply was higher than demand) which made fishing as an income generating activity economically unviable. As a result, those people did not want to do fishing any longer.

The second issue was the failure of some components of the livelihood restoration programmes due to their ineffective planning. The village forest programme was a good example as it was iteratively adjusted or modified several times to meet all stakeholders' needs, but still did not work. This failure raised question about the programme's design. For example, (as discussed regarding the village forestry association, VFA in Chapter Four), after logging timbers and putting them into a furniture factory to transform them into finished products for selling, it turned out that there was not enough money from sales to cover administrative costs or to pay a dividend distributed to the resettled villagers.

The third factor concerned the agricultural land plots (0,66 hectare) provided to resettled people. The assigned parcels of land were mostly in an unproductive condition, so the resettled villagers struggled to plant some vegetables and crops there. Initially, small amounts of agricultural products were sold successfully due to the influx of a large number of people associated with NT2 such as construction workers. However, this did not last for long, because when the project construction was completed, those workers left.

These accounts reflect how challenging it was to plan for such complex issues. Some of the livelihood restoration programmes seemed not to permeate the fundamental interests of the

\footnotetext{
${ }^{6}$ A representative of DEB, MEM said that: "DEB was the standing office belonged to the National Power Committees who were the predecessor of MEM. Our main mandate was the focal point for dealing with all NT2 project documents such as Feasibility Study (FS), Environmental and Social obligations (E\&S obligations) of NT2's CA. The reason why we took over such E \& S obligations - which nowadays have been responsible by MoNRE - because MoNRE then was Science, Technology, and Environment Agency (STEA) had not embraced such E\&S obligations into its mandate yet." (personal communication, 16th July 2015).
} 
PAP. Additionally, the allotted pieces of mostly unproductive agricultural land were unable to sustainably restore the PAP's livelihoods. Even though these people enjoyed selling small amounts of agricultural products during the project construction period, it was inevitably unsustainable. As such, both limited productive land plots and inaccessibility to an optional market seemed to be a big challenge for the PAP. A representative of the RMU (personal communication, $8^{\text {th }}$ July 2015) remarked that the number of people in the resettled community had been increasing, while the provision of replaced/compensated agricultural land plots had not. Consequently, the growing resettled population will undoubtedly face insufficient agricultural land plots for generating a living in the future.

A representative from the DESIA, MoNRE claimed that the good progress of the implementation of NT2 resettlement works resulted from the government's recognition, and the NTPC's intention, of fully engaging all stakeholders in preparing NT2 resettlement strategies, particularly the PAP (personal communication, $23^{\text {rd }}$ July 2015) ${ }^{7}$. In parallel, the establishment of a Public Information Centre (PIC) by the government was evidently a great facilitator for the government and the NTPC to ensure they conveyed relevant information concerning NT2 to all stakeholders (DESIA, MoNRE representative, personal communication, 23rd July 2015). Consequently, it seems that NTPC made efforts to inform stakeholders with knowledge, particularly the PAP to meet their own needs as much as possible. Thus, most of NT2 resettlement programmes were successfully implemented (DESIA, MoNRE representative, personal communication, 23rd July 2015).

Despite these official points of view, to understand all the information in the form of both technical and legal content associated with NT2 resettlement strategies would have been difficult for the PAP, because they used a basic form of the Lao language (DEB, MEM representative, personal communication, $16^{\text {th }}$ July 2015). For instance, they understood Lao language only in the form of a few words or a word such as house, school, playing radio, and so forth, but did not understand words in long and complex sentences, particularly in legal and official terms (DEB, MEM representative, personal communication, $16^{\text {th }}$ July 2015).

\footnotetext{
${ }^{7}$ A representative of DESIA, MoNRE said that: "During the preparation period of NT2 resettlement plans my organization then was Department of Environment (DOE), Science, Technology, and Environment Agency (STEA) almost did not get involved in the planning processes. We indirectly engaged in reviewing and approving a number of NT2 project's relevant documents, especially Environmental and Social Obligations (E\&S Obligations) of NT2's CA as it was so-called then 'Schedule 4'." (personal communication, 23rd July 2015)
} 
It is therefore questionable whether the PAP fully understood all the dimensions of NT2 resettlement process, compensation, and livelihood restoration programmes. As a result, their doubts about entitlements to those programmes once caused them to avoid giving cooperation in the project activities (RMU representative, personal communication, $8^{\text {th }}$ July 2015). In addition, some resettled villagers even insisted on not moving at all. They had strong beliefs in river spirits, forest spirits, and ancestral spirits which provided the government and the NTPC with a difficult situation as they had to convince these people to move (DEB, MEM representative, personal communication, $16^{\text {th }}$ July 2015). Despite the fact that all the PAP were often involved in long-lasting consultation workshops associated with NT2 resettlement strategies, they were still unclear about their entitlements within the programmes. To this end, it is possible that the resettled people understood NT2 resettlement strategies only worked at a superficial level.

The government and the NTPC tried to devise a solution through suitable communicative approach to deal with such challenges. One of the respondents described how they dealt with language barriers:

We adapted ourselves in terms of improvising appropriate language (communicative types) and attitudes to be used with those affected people who were local people. For example, we tried to calm them down when some conflicts happened, even though their reactions were very aggressive or belligerent. They sometimes held knives to threaten us where we had to put ourselves into their shoes and tried to ensure them that we were their friends who were there in order to solve their problems.

(RMU presentative, personal communication, $8^{\text {th }}$ July 2015)

Such an orientation gradually diluted the intense responses of some PAP by building mutual trust. In addition, the strategy of involving many resettled people in the construction of their new houses encouraged them through work as employees of NT2. Under the supervision of contractors engaged by NT2, these people earned wages and became skilful house builders (DEB, MEM representative, personal communication, $16^{\text {th }}$ July 2015).

DEB, MEM representative added that:

In response to such linguistic limitations, the government, with assistance of the NTPC, used pictures to demonstrate resettlement activities to the resettled people. 
For example, a picture of an old house and a new house, a picture of an old rice field and new 0.66 hectare of agricultural land plots, a picture of the distance from one place to another place, etc. However, even though the government and the NTPC used pictures in demonstrating resettlement activities to the resettled people, it was a challenge to ensure the resettled population understood complex resettlement strategies

(personal communication, 16th July 2015)

Further, there was a big effort by the government to use pictures when addressing the PAP's limited linguistic ability. This seemed to be a good strategy, but it was not a complete solution as the complex resettlement strategies were unlikely to be understood by pictures alone.

Even with such challenges, when these respondents were asked if the resettlement operation of NT2 has successfully achieved the sustainable development of resettled people's livelihoods and well-being, their answers were mostly positive. With its success, it could be replicable to other hydroelectric projects both in Lao PDR and other countries. However, NT2 still has to adjust some minor components of its resettlement programmes in order for it to be an effective role model for others. The responses of the government representatives about the current situation are shown in the following passages:

NT2 has massively achieved the sustainable development of resettled people's livelihoods and well-being. However, there are still some minor tricky issues have been challenging its capability to address them. By this success, the performance of NT2 can be replicable to other nations or even other hydroelectric projects in Lao PDR as a good model. It surely seems to me that many hydroelectric project documents as well as laws, decrees, regulations, and technical guidelines prepared and improved by the government nowadays have been developed by NT2. To the extent if it could be the role model for other hydroelectric projects, it should adjust some components in order to make it more effective in terms of achieving the goal of sustainable livelihood development.

(DEB, MEM representative, personal communication, $16^{\text {th }}$ July 2015) 
NT2 is highly valued as an internationally recognised model in Lao PDR. For example, it introduced the government to the systematised resettlement, compensation, and livelihood restoration processes: setting up goals to achieve livelihood restoration tasks, implementation mechanisms, monitoring programmes, and other measures. In comparison with many hydroelectric projects implemented in other countries, NT2 is an outstanding project in terms of effectively performing environmental and social obligations. In particular, its efforts and colossal resources technically and financially contributed in implementing social obligations.

Regarding lessons learned from NT2, many legal and technical documents associated with resettlement issues have been dramatically improved. They are the Prime Minister's decree on resettlement and compensation, the standard on environmental and social obligations, public involvement guidelines, and so forth. It was the best model in the past but for the future it needs improvement for it to remain a role model. However, if many new coming hydroelectric projects could perform at least at the same level of NT2, they could be considered effective projects.

(DESIA, MoNRE representative, personal communication, 23rd July 2015)

NT2 seems to have found it difficult to achieve sustainable goals. For this project I can say that some succeeded and some did not succeed, because the coming future will be the challenging factor. For example, a number of resettled populations are rising, while the replaced/compensated pieces of agricultural land are as the same. Thus, the growing population in future will undoubtedly confront insufficient agricultural land plots for making a living. In addition, the fishing activity in NT2 reservoir in future may face insufficient fish population to serve resettled villagers, because of the increasing number of their population has been so dramatic.

With lessons learned from NT2, the content of the concession agreement of other hydropower projects in Lao PDR have been improved a lot. Many guidelines concerning public involvement have been highly improved as well. To this extent, it could be the role model for other hydroelectric projects, because this project has applied international systematised resettlement, compensation, and livelihood restoration processes. Even though there are still some minor defective issues in the 
implementation of NT2 resettlement programmes, the immensity of its successful performance is undeniably a great achievement.

(RMU representative, personal communication, 8th July 2015)

As explored several perspectives of the government representatives on NT2 resettlement performance, can be summarised as some respondents (DEB and RMU) - who had much experience in preparing NT2 resettlement strategies - provide information in depth, while general information is delivered by a less experienced authority (DESIA). The former implies some ineffective performance of NT2, particularly its livelihood improvement programmes as well as several challenges which both the government and the project had to address. The latter tends to appreciate the good progress of NT2 resettlement performance. However, their opinions are similar in response to the same question asked if the resettlement operation of NT2 has successfully achieved the sustainable development for resettled people's livelihoods and well-being. They agree that NT2 can be an effective role model for other projects resulting from its numerous contributions to Lao PDR, even though there are still some minor issues to address.

\subsubsection{Perspectives from representatives of two resettled villages}

Based on data primarily collected from representatives of the two case study resettled villages through interviews and focus group discussions, it would seem that both communities were well informed about NT2 resettlement programmes including the five pillars of livelihood restoration programmes.

We knew that after our houses were inundated we would be going to move to the resettlement site. Additionally, we were also informed about five pillars of livelihood programmes (agriculture development, livestock development, community forestry development, reservoir fisheries development, and off-farm income development).

(Nakai village chief, personal communication, $9^{\text {th }}$ July 2015)

We were well informed by the authority and the project about resettlement, compensation, and livelihood restoration strategies and were highly encouraged to get involved in the preparation of NT2 resettlement plans as we attended the consultation sessions and were accompanied with the authority and the project to go to see the actual location of the resettlement site. 
(Nakai village female participant, personal communication, $9^{\text {th }}$ July 2015)

We were informed that all kinds of our losses would be compensated as from the loss of fruits to the loss of agricultural lands. All those losses were compensated in cash, except houses.

(Phon-Sa-On village chief, personal communication, $10^{\text {th }}$ July 2015)

The authority and the project then made all project information available at the suitable and understandable level to us, so I can say that there were regular discussion sessions where we always continuously participated.

(Phon-Sa-On village male participant, personal communication, $10^{\text {th }}$ July 2015)

Because these resettled villagers were fully involved in the preparation of NT2 resettlement programmes, they concluded that all resettlement, compensation, and livelihood restoration strategies had well implemented during the RP. Nevertheless, even though NT2 resettlement performance was highly appreciated by the representatives of these case-study resettled populations, some outcomes resulting from its implementation, especially with respect to the livelihood restoration programmes have not satisfied many of those people.

Some participants remarked that the replaced/compensated 0.66 hectare of agricultural land plot was inferior compared with the farm land they had in the past, both in terms of quality and size. For example, previously most villagers carried out farming on any size of land on the plain and productive area in their old community, and can no longer do this in their present resettlement community. A reason for this was that the replacement pieces of agricultural land were in poor condition: dry, sloped, and unproductive (Phon-Sa-On village participants, personal communication, $10^{\text {th }}$ July 2015). As one Nakai villager told me:

When we moved in to this resettlement community we received only the allotted 0.66 hectare of agricultural land plot for each household to be used for agricultural purposes which has been insufficient for our subsistence. I think that in our old community then we never faced a dearth of foods like we have been facing here so far.

(Nakai village female participant, personal communication, $9^{\text {th }}$ July 2015).

Other participants added that the NTPC has, to date, successfully implemented resettlement programmes. However, the remaining issue was challenging to address. For instance, even 
though the livelihood restoration programmes were planned to be finished in 2015, some issues were unaddressed at this time (Phon-Sa-On village participants, personal communication, $10^{\text {th }}$ July 2015). Some participants expressed their feelings about some failed components of livelihood restoration programmes in the following way:

The project trained us to be fishermen, but the amount of fish we caught was insufficient for our subsistence needs, especially if our family consisted of many members. Also, we were trained to do gardening where we grew crops and vegetables, but we did not have a market space for selling our garden products.

(Nakai village participants, personal communication, $9^{\text {th }}$ July 2015).

Also:

There have been many frequent vocational training programmes provided to us. Anyway, even though all training programmes seem to be effective, after we finished such programmes we cannot use them to do for a living. For example, we are trained to be cassava planters, but we do not have resources to do this such as lack of money, productive land plots, and tools.

(Phon-Sa-On village male participant, personal communication, $10^{\text {th }}$ July 2015).

When representatives of both resettled villages were asked if the resettlement operation of NT2 has successfully achieved the sustainable development of resettled people's livelihoods and well-being, their answers came with mixed views:

Yes, it can. Even though it is not $100 \%$ perfect for being a role model, there is only very minor issue considered as $1 \%$ obstructs its complete performance to be the role model for other projects in Laos

Yes, it could. In comparing to some projects both happened and happening in this province, NT2 project is the best in terms of no serious problems happened like they usually happened/happening in those projects

(Nakai village participants, personal communication, $9^{\text {th }}$ July 2015).

NT2 can achieve such goal, because many countries came to our community to have a look at the real circumstance and learned many things from this project resettlement implementation 
No, we do not think so. Even though NT2 project implemented most resettlement programmes very well, the dearth of effective livelihood restoration strategies has held it back from the achievement of sustainable livelihood development of resettled population

(Phon-Sa-On village participants, personal communication, $10^{\text {th }}$ July 2015).

These stories from participants reflected to me how some aspects of the livelihood restoration programmes planned by the NTPC had not been particularly effective and were likely to hold NT2 back from achieving its goals of sustainable livelihood development. The poor quality of the 0.66 hectare agricultural land plots seems to be the central challenge along with the remaining unsuccessful issue of programme activities as yet incomplete. These aspects probably affect the level of trust felt by the resettled populations towards NT2 as well as their curiosity about the RP period, particularly the livelihood restoration programmes as they did not know whether it was to be terminated in 2015 or extended.

\subsubsection{Perspective of the Panel of Experts (POE) on NT2 resettlement programmes}

As discussed in section 5.2, POE was established by the government and the NTPC under the requirement of CA. Based on its mandate, POE - during RIP - produced over twenty reports on the international environmental and social panel of experts associated with NT2 between 1997 and 2014 (Nam Theun 2: Independent Assessments, n.d). These documents provided independent assessments on NT2 project throughout its preparation and implementation, which encompassed environmental and social obligations of the project (Nam Theun 2: Independent Assessments, n.d). McDowell, Scudder \& Talbot (2014) and McDowell \& Talbot (2014) analyse the current five pillars of NT2 livelihood restoration programmes as follows:

Fisheries: This pillar seemed to be the most successful and significant of the five pillars, because it provided the highest consistent income and was an important food source to resettled people. However, fish catches had been declining due to illegal fishing by resettled people in protected areas where were reserved for reproduction of the reservoir fish and outsiders as well as the lack of law enforcement that was supposed to ensure that the resettled people were the ones to benefit from the reservoir fishery. 
Forestry: This was not proving to be very effective. There had been no dividends paid to resettled people since 2012 and the inventorying, protection and management of the forest resource had been minimal. In addition, the harvesting and utilisation of the timber had been deficient and produced serious waste. Also, the marketing was inadequate and the endeavours to meet market demands was seriously flawed. As a result, McDowell, Scudder \& Talbot (2014) recommended that RIP not be closed without addressing these issues.

Agriculture: Even though there was a huge investment of energy and time by the government and the NTPC, agriculture remains a disappointing pillar. For example, there has been low utilisation of the 0.66 agricultural land plots, because resettled people did not have resources and idea about what kind of work to do with the household garden areas and the irrigation systems. There were many reasons for this: the soils were seldom fertile in the resettlement area, the plots could not always be protected from human and animal intruders, and the pumped irrigation and intensive farming practices systems were a wholly new technology on the Nakai Plateau resettlement site. Lastly, many resettled villagers were preoccupied with more remunerative and usually less labour-intensive pursuits like fishing.

Livestock and Off-Farm pillars: There was not a lot of substantial progress to date but lots of future potential. Livestock has been one of the more successful components but the number of livestock is already close to the carrying capacity of the Nakai Plateau resettlement area. So it would seem there is limited potential for this pillar to compensate for the disasters of the other failing pillars. There was also little measurable progress on off-farm employment activities.

Apart from such analysed livelihood restoration pillars, VIT is another significant point that needs to be analysed as well. One government respondent (DEB, MEM representative, personal communication, $16^{\text {th }}$ July 2015) noted that the Nakai district, Khammouane province was officially declared to no longer be of one of the poorest districts in Lao PDR as a result of NT2 and the resettlement process. However, WB and POE disagreed on that declaration, because they invoked the obligation of NT2 CA which required the NTPC to achieve VIT after closing RIP in order to meet the concept of sustainable livelihood development (DEB, MEM representative, personal communication, $16^{\text {th }}$ July 2015). Thus, due to the fact that the NTPC has not achieved VIT by the end of 2015, POE would require NT2 to extend the period of livelihood restoration programmes to 2017 (DEB, MEM representative, personal communication, $16^{\text {th }}$ July 2015). 
These analytical outcomes are likely to be an indicator of incomplete activities as well as the ineffective performance of the NTPC in terms of achieving sustainable livelihood development for the resettled populations. To conclude, the NTPC needs more time in order to accomplish such goals.

\subsection{Conclusion}

This chapter has illustrated the results of the field research concerning the implementation of NT2 resettlement programmes. It introduced the institutional arrangements of the stakeholders associated with NT2 resettlement programmes. Additionally, the consequences of the implementation of the actual resettlement were illustrated in two different periods: the previous practice and the existing performance. They were interrelated and interwoven through various perspectives of the involved stakeholders who experienced NT2 resettlement performance.

The outcomes of the actual resettlement showed that the physical relocation of people living in the Nakai Plateau was conducted between 2004 and 2008. Even though these resettled people's physical loss (properties) ranging from the loss of agricultural lands to the loss of houses were generally well replaced and compensated, their non-physical loss (living standards) remained challenging. Based on various perspectives gained from the research participants (the government representatives and resettled residents) and POE's reports, the issue of NT2's livelihood improvement strategies was the central concern among them.

Specifically, the five pillars of the livelihood restoration programmes have not satisfied these people. Moreover, they tended to believe that some incomplete or unsuccessful jobs performed by the project concerning such programmes might prevent the project from achieving sustainable livelihood development for the Nakai Plateau resettled populations in the future. It will be interesting to observe what the next step of NT2 will be and how resettled people's livelihoods will be improved to meet the sustainable livelihood development goal.

Despite this dissatisfaction, most research respondents supported NT2 and promoted it as the role model for other similar projects, despite there have been remaining challenges to address. Such apparent contradictions prompted me to further inquire in the next chapter the lessons learned, where I will also distil key findings from this research. 


\section{Chapter Six: Lessons Learned from Resettlement}

\subsection{Introduction}

This chapter distils key lessons learned from the preparation and implementation of NT2 resettlement strategies as explored through fieldwork. It begins with an illustration of the general advantages and also some of the significant challenges that arose from NT2 resettlement performance. Section 3 then, proceeds with an examination of some highlighted challenges. Finally, a conclusion of these challenges is provided in section 4 .

\subsection{Benefits gained from NT2 resettlement}

Based on the lessons learned from both the planning phase and the implementation phase of NT2 resettlement programmes, I have observed a number of benefits. Firstly, NT2 is the first project in Lao PDR that engaged both Lao national and international stakeholders in the preparation of resettlement plans (DEB, MEM representative, personal communication, $16^{\text {th }}$ July 2015). Additionally, it introduced these stakeholders to the recognition of internationally systematised resettlement, compensation, and livelihood restoration processes. For example, it set up goals and indicators to achieve the restoration of resettled people's livelihoods on a sustainable basis. Also, it devised implementation mechanisms, monitoring programmes, and measures to accomplish such goals. With this attention to quality, NT2 has been outstanding among other hydropower projects both in Lao PDR and neighbouring countries (DESIA, MoNRE representative, personal communication, $23^{\text {rd }}$ July 2015).

Furthermore, based on information documented in the Nam Theun 2 hydroelectric project's report (n.d.), there have been many advantages from the actual implementation of NT2 resettlement programmes, especially for resettled people and their communities. In brief, compensation was provided for lost properties and entitlements to build new livelihoods. Main private and public infrastructures were built for new houses including water supply and sanitation systems, schools, health centres, community buildings, roads and the electricity supply. Resettled households also received agricultural land plots and entitlements to much beneficial assistance such as technical assistance to develop existing and new livelihood restoration pillars. Moreover, they were provided employment opportunities and food subsidies to maintain living standards during the resettlement transitional period as well.

It is important to note that two health centres were built on the Nakai Plateau. They helped strengthen public health services with a special focus on preventive, maternal and child 
health. These programmes contributed significantly to lowering childhood mortality rates and the overall health status of resettled populations.

With the project's healthcare support, pregnant women are entitled to antenatal and postnatal care with free of charge service which helps women a lot in terms of taking no risk of infant and maternal mortality as happened in the past.

(Phon-Sa-On village chief, personal communication, July 2015)

\subsection{Key challenges of NT2 resettlement}

Even though NT2 resettlement performance contains a large number of benefits, there still are some challenges which seem to prevent it from achieving sustainable development. Regarding the lessons learned from the previous chapter, such challenges mainly include the poor quality of agricultural land plots provided to resettled households, the unsuccessful performance of the five livelihood restoration pillars and the failure of reaching VIT in compliance with the CA. Given these aspects, in this section I examine some key challenges in more depth to try to identify what some of the relevant issues might be that are preventing NT2 from accomplishing the aforementioned sustainable livelihood development goals. I draw on international literature to help me do this. Furthermore, from my assessment of both secondary and primary data, there are a number of implications found in various forms that could be the cause of ineffectual practice by NT2. Some are found from terminology used and unclear obligations specified in the CA, while some are found from ineffective social requirements under the $\mathrm{CA}$. To elaborate:

Sustainability: in respect to the third objective of the resettlement policy imposed by Schedule 4 of the CA, the aim was for resettled people's livelihoods to be materially improved on a sustainable basis (NT2 Concession Agreement, 2005). This provision conforms to Krantz' (2001) recommendation that ensuring resettled people's livelihoods on a sustainable basis can enable them to cope with and recuperate from strain and shock, retain or improve their competences and assets including avoid damaging natural resource base. However, the terms sustainable development and sustainability have contested meanings over the past decades (Wals \& Jickling, 2002). Consequently, the meaning of sustainable development is ambiguous and still lacks precision (Santillo, 2007). Within NT2 project, there was no definition of the term sustainability specified in the CA (DEB, MEM representative, personal communication, $16^{\text {th }}$ July 2015). As a result, this missing definition 
no doubt contributed to the unclear goal of NT2 resettlement strategies for achieving sustainable livelihood development of resettled people.

However, despite the CA being silent about the definition of sustainability, NTPC's social obligations remain committed to development on a sustainable basis in accordance with the CA. According to McDowell \& Talbot (2014), a primary principle of the CA was to build into all aspects of NT2 a high level of sustainability. For example, the meaning of sustainability in this project was not about what has actually happened: a few years of high consumption based on two or three years of large fish catches in the initial years after the reservoir was filled. Moreover, sustainability was not about relying on illegal harvesting of wildlife and high value hardwoods like rosewood. Unfortunately, notwithstanding the fact that the CA principle sounded very convincing, the NTPC's ineffectiveness within the five livelihood restoration pillars programmes has revealed limitations around the conception and implementation of sustainability.

Despite this lack of progress by the NTPC, any serious measures to address such issues seem unlikely. Because there is no definition of sustainability in the CA and no corresponding framework for assessment, accomplishing the five livelihood restoration pillars on sustainable basis seems to be aimless. Given this, the only way to justify the success of the project's livelihood restoration programmes is likely to depend on some measures such as the government's satisfaction, the achievement of any agreed livelihood improvement indicator, and so forth. Nonetheless, no matter what existing measures are used for justifying success or not within this project, it still may not lead to sustainable livelihoods development of resettled people.

Reasonable satisfaction of the government: the government and the NTPC acknowledged and agreed that any social impacts caused from NT2 activities must be addressed and alleviated or remedied by the NTPC to the reasonable satisfaction of the government in accordance with the CA (Nam Theun 2 hydroelectric project, 2005). Also, in respect to the Schedule 4 of the CA, resettlement objectives (ROs) and resettlement provisions (RPs) through the NTPC's implementation of the resettlement process were to be considered successfully achieved when the government - based on advice from POE - was satisfied (NT2 Concession Agreement (CA), 2005). These requirements seem to conceptually work well in terms of setting up a goal for accomplishing NT2 resettlement programmes, but what and how effective are criteria used by the government in their decision making process? It is 
significant to note that there is no definition or detailed explanation associated with such requirements specified in the $\mathrm{CA}$.

One respondent from the DEB, MEM stated that:

After an assessment of incompleteness of NT2 livelihood restoration programmes by $P O E$, it recommended the government considers extending the livelihood restoration period to 2017 where the initial planned period was 2015. POE argued based on the unfulfilled commitments of the project in terms of achieving VIT. This commitment required the NTPC to ensure improving resettled villagers' annual average household income to reach USD 1,200 before closing RIP. Nonetheless, the government seemed not to agree with extending RIP as recommended by POE, because the government declared NT2 to be the role model project in line with the World Bank's support already. The government also reasoned that many countries had visited NT2 and appreciated it as the role model for their nations as well. This showed that the contemporary existence of NT2 seemed to be good enough to merit an appreciation of being an excellent archetype in terms of socially and environmentally responsible development project. Thus, it might not be a good idea to extend the livelihood restoration period, because it would seem to hold the project back from being the role model project.

(DEB, MEM representative, personal communication, $16^{\text {th }}$ July 2015).

This issue relates to McDowell, Scudder \& Talbot's (2014) statement that the government, in January 2014, declared that the resettlement household income target had been achieved in accordance with the CA. This was despite the fact that many incomes have fallen below the CA requirements to date, and there continues to be problems remaining with each of the five pillars of livelihood restoration programmes. As a result, this issue is a good example to indicate that even though POE's recommendation has a valid point about the NTPC's inability to achieve its social obligation under the CA, its recommendation seemed not to convince the government to take into account such unfulfilled commitments. Therefore, the evaluation criterion of reasonable satisfaction of the government is unclear and likely to be indefensible, which may lead to contractually illogical results.

Household income target (HIT) and village income target (VIT): in pursuant to article 1.2 of the Schedule 4 of the CA, HIT and VIT were established to indicate any improvements to 
resettled people's living standards after being restored by NT2 livelihood restoration programmes (NT2 Concession Agreement (CA), 2005). In parallel, based on the Lao Prime Minister's decree 201 promulgated in April 2012, HIT was defined as the national rural poverty line (NRPL) which was set at 180,000 kip per capita per month for rural areas in Lao PDR. Additionally, raising the NRPL by the Lao consumer price index in April 2013 - the time when consumption was measured - set the income target at 186,000 kip or USD 18.97 per capita per month (35.29 NZD calculated by [186,000 Lao kip divided by 5,269.50 \{current rate NZD $1=5,269.50$ Lao kip on $18^{\text {th }}$ Jan 2016 $\}$ ) in regard to an exchange rate required by the CA as 9,800 kip equal USD 1 (Nam Theun 2 hydroelectric project, n.d.; NT2 Concession Agreement (CA), 2005).

Consequently, HIT was designed to improve resettled people's annual average household income to USD 800 by year five of RIP, while VIT was required to increase resettled people's annual average household income to USD 1,200 at the end of RIP (NT2 Concession Agreement (CA), 2005). In short, HIT sought to enable resettled people to reach the NRPL and VIT sought to increase resettled people's incomes above the NRPL. Both HIT and VIT seemed to be tangible goals for NT2 to achieve.

However, there were problems with the accurate measurement of income. NT2 analysed seven rounds of the living standards measurement survey (LSMS) conducted between 2006 and 2013, and three phases were surveyed: the pre-resettlement, the transitional period, and the post-resettlement (Nam Theun 2 hydroelectric project, n.d.). Through surveying of these three phases, the recorded per capita of monthly income and consumption of resettled peoples fluctuated. The latest results obtained from the seventh round of the LSMS showed that the declared average income in 2013 was 228,000 kip per capita per month, while the monthly per capita consumption for the same time period was 622,000 kip (Nam Theun 2 hydroelectric project, n.d.).

A reason for the under-declared income may have been that there were only three sources of income declared in 2013 such as fishing, forest, and crops, while other sources such as employment, livestock, and other relevant sources were undisclosed (Nam Theun 2 hydroelectric project, n.d.). Specifically, the fishing income - the major income source - was considered a windfall income gained from the first two years after the impoundment of the reservoir (Nam Theun 2 hydroelectric project, n.d.). However, resettled people seemed to conceal another source of their income derived from illegal fishing in protected areas 
(McDowell \& Talbot, 2014). In addition, they also probably covered up their illegal income derived from rosewood (McDowell, Scudder \& Talbot, 2014). Given these aspects, the declared incomes appeared far below expenditure levels confirmed that incomes had been systematically under-declared and that consumption was a more reliable indicator for measuring living standards. As a result, the project opted to use consumption in place of the income in terms of measuring resettled people's living standards (Nam Theun 2 hydroelectric project, n.d.).

Nonetheless, it would have been better if total income was able to be identified to ensure greater accuracy and certainty that HIT and VIT had been improved and met targets at year five and at the end of RIP respectively as required by the CA (Nam Theun 2 hydroelectric project, n.d.). Without such accurate measures, the project claims that the poverty rate dropped significantly due to the sum of all mitigation and support programmes to restore livelihoods of all resettled people is questionable (Nam Theun 2 hydroelectric project, n.d.).

In addition to the problems with definition and measurement of income, I also wish to call attention to the fact that living standards encompass much more than income. As such, the existing five livelihood restoration pillars have been considered ineffective, todate by POE, so the stability of resettled people's incomes and improved living standards over the long term remain of concern. Living standards comprise of a wide range of fundamental aspects such as life expectancy, infant survival, educational enrolment, literacy, and so forth. Therefore focusing only on income as an indicator of improved living standards would seem to be ineffective (Neumayer, 2003) and not followed international best practice.

Integrated social plans: according to Ovenden (2007), the government and the NTPC under the CA - jointly developed compensation and livelihood restoration guidelines. These social documents were based on the government's available legislation and policies in conjunction with World Bank and the Asian Development Bank safeguard policies. Given that, SDP, EMDP and RAP are prepared and have been implemented accordingly. In general, the objective of SDP was to counteract, reduce and alleviate social impacts of NT2 through resettlement, compensation and development plans. Besides, it was also to ensure that the project benefitted the PAP as well as the people of Lao PDR in general by generating revenue for poverty reduction programmes (Nam Theun 2 hydropower project, 2005). Thus, because SDP was prepared to ensure the integration of ethnic minority issues, gender strategies and action plans, it embraced both EMDP and RAP (Nam Theun 2 hydropower project, 2005). 
EMDP focused on identifying and addressing the special needs of ethnic minority communities in all project areas. With this concentration, it defined these ethnic minority populations' socio-economic background including their feedback and recommendations for NTPC to incorporate them in the project design. In doing so, NTPC was enabled to deal with specific issues concerning ethnic minorities during project implementation and monitoring (Nam Theun 2 hydropower project, 2005). RAP emphasised the necessity of identifying project's impacts on resettled people based on an inventory of losses and socio-economic surveys. It reflected a process of consultation with the PAP and defined their entitlement packages. It also covered the participatory process to enable detailed design as well as the livelihood development programmes. It included public health and community development programmes, grievance mechanisms, and institutional monitoring and implementation arrangements during project implementation. Lastly, it contained summarised budgets and detailed implementation schedules (Nam Theun 2 hydropower project, 2005).

Despite this thoroughness, it is questionable whether these integrated social plans became living documents throughout the resettlement process, even though they followed both national and international policies. According to NT2 Concession Agreement (CA) (2005), the NTPC was obligated to prepare updated integrated social plans - in accordance with WB and ADB safeguard policies - and submit to the RC for approval at least fifteen days prior to the proposed commencement of implementation. The RC was responsible for reviewing and approving each plan based on any input from WB and ADB. The RC then had to provide a no-objection notification on these plans to the NTPC within thirty days. If the consideration went beyond such time, the plans were deemed as having no-objection from the RC (NT2 Concession Agreement (CA), 2005).

In reality, the NTPC only prepared the updated integrated social plans and submitted them to the RC for approval once throughout the entire resettlement process. For me, this raises concerns about how effective the plans were, particularly when there may have been uncertainty during the course of resettlement. I base my concerns on some valid points taken from the Standard Environmental and Social Obligations (SESO) for Energy Concession Agreements developed by MoNRE (Ministry of Natural Resources and Environment, n.d.) in response to such uncertainty that what if:

a) Measures of resettlement and compensation are insufficient to mitigate actual or likely adverse impacts of the project; 
b) New information becomes known about how harmful the adverse impacts are or likely to be;

c) The project experienced adverse impacts which were unforeseen at the time when all relevant assessments and plans were approved;

d) The adverse impacts are greater than the anticipated impacts that formed the basis for preparation of the relevant assessments and plans; and

e) Measures of resettlement and compensation are unnecessary or ineffective in mitigating the adverse impacts.

In addition, an international consultant who has been working for MoNRE expressed to me that:

In terms of being a model project, there should have been a requirement stipulated in the CA on the project to have information sharing which is much more publically disclosed without keeping the data with itself only, but NT2 does not have such requirements. It is very difficult to access certain data from NT2, because it does not share them with others. In addition, all social plans have to be regularly updated and approved by concerned governmental agencies such as the $R C$.

(An international consultant of MoNRE, personal communication, July 2015)

This opinion seems to reflect the fact that there was no requirement of the NTPC to regularly update its integrated social plans and submit them to the RC for approval throughout the resettlement process. This may be a factor that caused the NTPC to fail in effectively implementing the five livelihood restoration pillars, because many uncertain issues have probably not been carefully addressed. Therefore, it would be better if all relevant integrated social plans had been made living documents and had been periodically updated and approved throughout the resettlement process.

Natural growth of resettled population: households included in the August 2003 census carried out by Nakai District administration were the original generation of families to be resettled. Once the original generation of families were resettled, there has been natural growth resulting in a second generation of households including children in registered households who may have formed new families after the initial registration process (NT2 Concession Agreement (CA), 2005). According to McDowell, Scudder \& Talbot (2014), 
resettled people's socio-economic status were ineffectively surveyed by both the Living Standards Measurement Survey (LSMS) and Quarterly Socio Economic Monitoring (QSEM) process. Both LSMS and QSEM surveys excluded the natural growth of second generation households and only reflected the experiences of the original resettled families. The second generation households were included in an extended QSEM survey later in the fourth quarter of 2012. But this inclusion was too late, because all relevant integrated social plans had been already approved.

During the time the second generation were excluded from both LSMS and QSEM surveys, there was growing pressure - observed in 2010 - on natural resources as well as from outside interests (Nam Theun 2 hydroelectric project, n.d.). Even though the outside interests were intended to be prevented by legal measures in order to preserve livelihood opportunities for resettled people (Nam Theun 2 hydroelectric project, n.d.), it was questionable whether the livelihood opportunities available were sufficient to sustain and meet the needs of the natural growth of the resettled population. According to McDowell, Scudder \& Talbot (2010), the original resettled people's livelihood restoration process should have been well implemented before the second generation problem emerged. Inopportunely, not only did the second generation problem already exist within NT2, but the various project agencies appeared to be unaware of its threat to achieving livelihood development, especially that of achieving better living standards and livelihoods for both first and second generation people.

This challenge seems to reflect NT2's ineffective planning and strategies for realistic resettlement, compensation and livelihood restoration, because such strategies seemed to focus only on the original generation resettled people. A representative from RMU reinforced this point when he said,

The number of resettled population has been increasing, while the size of their allotted agricultural land plots by NT2 is still as the same. Sadly, such allotted pieces of agricultural land are mixed up with slope, potholes, and unproductive conditions. This phenomenon will surely affect resettled people and their natural growth in the future, especially facing a lack of sufficient agricultural land plots for making a living.

(RMU representative, personal communication, $8^{\text {th }}$ July 2015). 
In light of this statement, I reiterate my central argument that NT2 missed the critical definition and ability to effectively implement sustainable development. As MacPherson (2012, p. 5) states "sustainable development is development that meets the needs of the present without compromising the ability of future generations to meet their own needs." Hence, to achieve the goal of sustainable livelihood development, it was incumbent upon NT2 to ensure that the needs of successive generations of resettled populations were not impeded by the resettlement strategies.

\subsection{Conclusion}

NT2 has generated enormous advantages from its implementation of resettlement, compensation and livelihood restoration programmes to the Lao government and resettled people's lives. Of benefit has been the introduction of the government to internationally recognise systematised resettlement processes in line with WB and ADB safeguards. These provisions have enabled the Lao government to illustrate a new global standard of resettlement practice. In addition, resettled people have gained benefits from new housing with necessary public utilities, entitlements to compensation packages of agricultural land plots as well as access to livelihood restoration programmes, and access to employment opportunities and food subsidies during the resettlement transitional period. These programmes have improved living standards in relation to their old lives.

However, there are still a number of challenges preventing NT2 from achieving sustainable livelihood development for its resettled people. The challenges encompass issues of NT2's unsuccessful resettlement and rehabilitation performance ranging from the poor compensation of unproductive agricultural land plots to the ineffective livelihood reconstruction programmes for resettled households. For example, the biggest issue is the lack of precision in terminology - stipulated in the CA - to enable the effective establishment of measures, indicators and criteria which could be used to inform objective and fair decision making.

The outcomes demonstrate that the challenges that potentially hold NT2 back from achieving sustainable livelihood development goal are caused by: a) an unclear framework concerning sustainable development identified in the CA; b) an ambiguous authority of the government's approving process associated with the success or the failure of NT2 resettlement performance; c) an unclear indicator used for measuring resettled households' living standard such as both HIT and VIT; d) an ineffective approving procedure of NT2's integrated social 
plans; and e) an incomprehensive planning process on dealing with sustainable livelihood development of resettled people including their natural growth in long term. The next chapter returns to the central aims of this research and seeks to put these findings into a wider context. 


\section{Chapter Seven: Conclusion}

\subsection{Introduction}

This study examined existing NT2 resettlement strategies. Specifically, I addressed the resettlement-induced effects on the PAP in Nakai Plateau and the sustainability of their livelihoods. In addressing the primary purpose of this study, three main research aims and questions were discussed. This chapter attempts to bring these aims and questions into a discussion with my research analysis from previous chapters.

This chapter begins by exploring how NT2 resettlement strategies were prepared to address challenges of resettled people's livelihood and well-being in the Nakai Plateau. Specifically, it aims to assess how comprehensively the resettlement, compensation and livelihood restoration arrangements were carried out. Then, section 3 explores how NT2 resettlement strategies have been implemented in terms of addressing relevant resettlement concerns throughout RIP. Particularly, it aims to observe how effective the resettlement, compensation and livelihood restoration programmes have been.

Section 4 will then seek to understand main lessons learned from NT2's resettlement performance. In particular, it aims to explore both successes and challenges concerning NT2 resettlement strategies. It also highlights the challenges which may prevent the project from accomplishing sustainable livelihood development of the Nakai Plateau resettled community. Finally, Section 5 will provide a conclusion of this research as well as deliver recommendations in relations to future improvements of resettlement endeavours.

\subsection{The first research aim}

Exploring NT2 resettlement strategies preparation

What social mitigation measures had NT2 prepared in response to resettled people's livelihoods and well-being before resettlement commenced?

As explored in Chapter Two, Cernea (1997) believes that the impoverishment of resettled people - which was central to risk in development-caused involuntary population resettlement - could be addressed through effective planning processes from an early stage. This issue ignited several criticisms from some scholars. Particularly, de Wet (2001) argues that the nature of involuntary resettlement involved a higher degree of tension of displaced people's disadvantages than voluntarily resettled people. Hence, the idea that well-prepared 
planning in the early stages could prevent and manage all involuntary resettlement problems was an oversimplification. Correspondingly, Downing (2002) adds that the risks of involuntary resettlement were not only physical loss (houses, productive land, etc.) but also non-physical loss (cultural identity, kinship, network, etc.). Given this, McDonald-Wilmsen \& Webber (2010) suggest that development-caused involuntary population resettlement should not only require a resettlement plan that included arrangements for the resettlement event but it should also require a plan for further livelihood reconstruction. This idea recognised the longer-term processes of settlement and integration - in addition to displacement and resettlement - where the adaptation and resilience of communities were considered as crucial to its success (McDonald-Wilmsen \& Webber, 2010).

These discussions conform to the findings of this research as presented in Chapters Four and Six. NT2 prepared the resettlement strategies for resettled people in the Nakai Plateau in compliance with its social obligations under the CA. In terms of resettlement policy required by the CA, NT2 resettlement strategies embraced: a) all ethnic characteristics of the PAP's participation into planning processes of resettlement; b) a number of livelihood restoration measures in sustainable basis for resettled residents and the establishment of income target indicators (HIT and VIT); and c) implementing resettlement and rehabilitation plans as specific development (NT2 Concession Agreement, 2005).

In addition, NT2 resettlement strategies incorporated resettlement principles in response to the resettlement policy. Based on Ovenden (2007), the resettlement principles encompassed: a) involving main stakeholders (the Lao government, NT2, and resettled people) in the participation of resettlement planning processes where gender equality and cultural or traditional beliefs were respected; b) incorporating the resettlement planning processes into NT2's general project design under financial support from the project as well as ensuring transparency of project implementation; and c) applying Lao National Poverty Line to be a minimum target for improving resettled population's living standard including NT2's support during the transition period.

Thus, both resettlement policy and resettlement principles are the likely factors to form a comprehensive framework for guiding NT2 in performing resettlement and rehabilitation programmes on a sustainable basis. Importantly, these findings support Cernea's (1997, p.1570) statement that "socially responsible resettlement - that is resettlement guided by an equity compass - can counteract lasting impoverishment and generate benefits for both the 
regional and local economy." Hence, they seem to potentially address impoverishment risks of resettled people as well as transform these people to become the first benefits recipients of the project where their livelihoods can be improved.

To achieve this framework, NT2's social obligations under the CA were translated into a wide range of socially differentiated rights and entitlements of resettled people contained in a matrix and integrated social plans. On the one hand, the former was the entitlement matrix, which delineated the entitlements of resettled residents in the Nakai Plateau resettlement community to compensation and rehabilitation packages (Concession Agreement, 2005). On the other hand, the latter were various social action plans including, but not limited to: SDP, EMDP and RAP (Ovenden, 2007). Both of them were prepared in accordance with the government's available legislation and policies including World Bank and the Asian Development Bank safeguard policies (Ovenden, 2007).

To further understand the entitlement matrix, all compensation and rehabilitation packages for resettled residents in the Nakai Plateau were allocated into different categories in response to various types of loss. According to NT2 Concession Agreement (2005), the matrix covered resettled people's entitlements for: a) compensation for loss of agricultural and nonagricultural lands, agricultural products, residential lands and houses, commercial structure, and physical cultural resources; b) restoration for loss of livelihoods, allowances of transitional assistance (food, employment, and so forth) as well as access to grievance redress mechanisms; and c) compensation for loss of common property community infrastructure (electricity, roads, irrigation channels, water source, schools, and etc.) and access to health facilities and services.

For a deeper understanding about integrated social plans, SDP, EMDP, and RAP were designed and planned to address a multiplicity of different social impacts stemming from NT2 development. Firstly, SDP was projected to counteract, reduce and alleviate the social impacts of NT2 through resettlement, compensation and development plans. Additionally, it was also planned to ensure that this project benefited the PAP as well as the people of the Lao PDR in general by generating revenue for poverty reduction programmes (Nam Theun 2 hydropower project, 2005). Secondly, EMDP was aimed to identify and address the special needs of ethnic minority communities in project areas. With this focus, it defined their socioeconomic background, the construction process, including their feedback and recommendations for NTPC to incorporate them in the project design. In doing so, NTPC 
was enabled to deal with specific issues concerning ethnic minorities during project implementation and monitoring (Nam Theun 2 hydropower project, 2005).

Thirdly, RAP attempted to emphasise the necessity of identifying the PAP's impact based on inventory of losses and socio-economic surveys. Because of this, such identification encompassed a reflective consultation with the PAP and defined their entitlement packages (Nam Theun 2 hydropower project, 2005). It also covered the participatory process for detailed design as well as the livelihood development programmes. Moreover, it included public health and community development programmes, grievance mechanisms, and institutional monitoring and implementation arrangements during project implementation (Nam Theun 2 hydropower project, 2005). Crucially, it contained summarised budgets and detailed implementation schedules as well (Nam Theun 2 hydropower project, 2005).

However, even though these integrated social plans contained wide-ranging social measures for addressing PAP's impacts, in practice they simply mitigated physical losses. To address non-physical losses (livelihoods and well-being of resettled people), specific livelihood restoration measures such as the five pillars of livelihood restoration programmes were prepared in addition to such integrated social plans. Regarding Nam Theun 2 hydroelectric project (n.d.) and NT2 Concession Agreement (2005), the five livelihood restoration pillars paid close attention to reconstructing livelihoods and well-being of the Nakai Plateau resettled population. These five pillars comprised of agriculture, livestock, commercial community forestry, fisheries, and non-farm enterprises and employment.

The objective of the five livelihood restoration pillars was to encourage resettled people to generate incomes through: a) optimising arable lands for the most productive purposes and increasing farming productivity; b) raising livestock activities to develop productive livestock production; c) developing and managing forest resources by and for the community through village forest association (VFA) and then gaining employment opportunities and dividends as shareholders; d) generating incomes through fisheries by selling caught fishes or transforming them into other products: fermented fishes or dried fishes; and e) exploiting non-farm enterprises and employment programmes to access to optional income sources. For example, people employed by NT2 project for construction works can also learn relevant skills through training programmes provided by NT2 to prepare them for businesses ownership. 
Through exploration of the framework, the entitlement matrix, and the integrated social plans, NT2 resettlement strategies seem to be comprehensively prepared in terms of addressing all concerns associated with the PAP's livelihoods and well-being caused by this development. Significantly, they are far more likely that all involved impoverishment risks identified by Impoverishment Risk and Reconstruction Model (as illustrated in Chapter Two) are seemingly recognised and included in the strategies. This may indicate that NT2 resettlement strategies are consistent with the international resettlement standards, which means they will probably achieve sustainable livelihood development for resettled people in the Nakai Plateau.

\subsection{The second research aim}

Identifying what outcomes were gained from implementation of NT2 resettlement strategies.

How effective have those social mitigation measures been in terms of addressing relevant resettlement challenges throughout the resettlement implementation period?

As explored in Chapter Two, Cernea (1997); Wilmsen, Webber \& Yuefang, (2011) and Tofail \& Kaidab (2015) remarked that embracing the concept of resettlement with development was very important for development practice. This would encourage operations of involuntary resettlement not only for compensating loss but also generating benefits to resettled people. In other words, making these resettled populations as the first beneficiaries of a development project was to prevent them from bearing the cost of development and the related risks of impoverishment. This embraced risk alleviation but went on to create a new socioeconomic basis on which resettled people's livelihoods could first be restored and then enduringly improved, so that their incomes could surpass pre-resettlement levels (Cernea, 1997). In a nutshell, this concept aims to provide resettled people with improved livelihoods, despite the fact that they have to undergo involuntary resettlement resulting from development projects.

According to Cernea (1997, 1999), operating resettlement as development opportunities was to analytically place re-establishment processes under the same analytical lens as the risks of impoverishment identified in the IRR model as following aspects: 1) from landlessness to land-based re-establishment; 2) from joblessness to reemployment; 3) from homelessness to house reconstruction; 4) from social disarticulation to community reconstruction; 5) from marginalisation to social inclusion; 6) from exploitation to restoration of community assets; 
7) from food insecurity to adequate nutrition; and 8) from increased morbidity to better health care. Thus, the concept of resettlement with development became largely endorsed in the field of resettlement studies. Particularly, it was included in the policies of international institutions and increasingly in those of national governments (Cernea, 1995 \& Muggah, 2000).

The above discussions meet multidimensional aspects of the findings in this research as explored in Chapter Five and Six. After physical relocation of approximately 1,310 resettled households of 17 villages in the Nakai Plateau from 2004 to 2008, NT2 provided each of these households with a resettlement package which had been implemented between 2006 and 2013 (Nam Theun 2 hydroelectric project, n.d.). Based on NT2 resettlement strategies, resettled people were entitled to material compensation for all of their physical losses in accordance with the principle of replacement cost. The replacement cost included agricultural lands, gardens, houses, schools, hospitals and dispensaries, temples, cemeteries, markets, buildings, fruit trees, and so forth (GOL Resettlement Principles, n.d.). Also, food subsidies and food for work was provided during the resettlement transitional period for clearing new lands and building new infrastructures (Nam Theun 2 hydroelectric project, n.d.). Moreover, these populations' living standard should be materially improved after relocation. Particularly, individual household incomes should be above the National Rural Poverty Line (NRPL) within four years after physical relocation (GOL Resettlement Principles, n.d.).

Special measures were specifically provided towards groups of ethnic minorities and vulnerable persons. In short, all people to be resettled should not only be compensated for their physical losses but be also assured that their livelihoods will be improved and sustained (GOL Resettlement Principles, n.d.). As a result, Nam Theun 2 hydroelectric project (n.d.) claimed that the outcomes derived from implementation of the resettlement package encompassed these following components: a) Community Infrastructure - where each resettled village received a number of basic infrastructures ranging from road, market, and primary school to electricity distribution system, water supply, and seed processing and storage facilities; b) Household Infrastructure and Assets - where all resettled people obtained residential lands, houses and flush toilet with suitable septic tank, standard electricity supply, 0.66 hectare of land plots for agricultural purposes including partial irrigation; c) Livelihood Programmes - where all resettled residents were entitled to attend all five pillars of livelihood restoration programmes; and d) Transitional Period - where each 
resettled household was entitled to receiving monthly rice support, monthly protein support, and wages for clearing land and constructing houses during the transitional period.

On the face of it, this looks impressive. Nonetheless, these outcomes show only NT2's resettlement performance at a certain time (2006 - 2013). Hence, the present-day data collected from my fieldwork in 2015 is crucial in terms of updating the progress of the current NT2 resettlement. The data was gained from many perspectives of research participants and some relevant project documents in the fieldwork. Thus, through these data, various aspects associated with the recent resettlement and livelihood restoration works of NT2 are shown through the following details:

In general, the impoverishment risks - landlessness, joblessness, homelessness, marginalisation, food insecurity, increased morbidity and mortality, loss of access to common property resources, and community disarticulation - have been addressed well so far in planning (McDonald-Wilmsen \& Webber, 2010). Nevertheless, while material physical impacts (loss of properties) seem to be addressed, dealing with the non-material impacts (loss of livelihoods) through livelihood restoration performance of NT2 has been more fraught. According to McDowell, Scudder \& Talbot (2014) and McDowell \& Talbot (2014), the five pillars of NT2 livelihood restoration programmes have not appeared to achieve sustainable livelihood development of resettled people as planned. Firstly, the fisheries pillar is encountering a decline in fish catches due to illegal fishing occurring by resettled people in protected areas and outsiders, even though presently it is the most successful and significant pillar as it generates high incomes and is reliable food source for resettled people.

Secondly, the forestry pillar is facing problems of: a) no dividends have been paid through the VFA to resettled households since 2012; b) the harvesting and utilisation of the timber have been deficient to a level which has produced serious waste; and c) the marketing has been inadequate and the endeavours to meet market demands seriously flawed. Thirdly, the agriculture pillar is confronting ineffective utilisation of the 0.66 hectare of land plots for agricultural purposes including partial irrigation: a) the soils are seldom fertile in the resettlement area; b) the plots cannot always be protected from human and animal intruders; and c) the pumped irrigation and intensive farming practices systems are a wholly new technology on the Nakai Plateau resettlement site. Fourthly, the livestock pillar seems to be adequate, but it is not successful enough to drive the whole economy. Lastly, the off-farm pillar has made little measurable progress regarding off-farm employment activities. 
In addition to these challenges, NT2 has also not achieved VIT for 2015 (DEB, MEM representative, personal communication, $16^{\text {th }}$ July 2015). In terms of income target indicators used for measuring resettled people's living standard, VIT - under the requirement of the CA - represents resettled people's incomes as better than the NRPL (NT2 Concession Agreement (CA), 2005). This means NT2 has not contractually fulfilled its social obligations in compliance with the CA yet. Therefore, POE has recommended that the Lao government should extend RIP to 2017 so as to address the defective issues concerning the five livelihood restoration pillars and VIT (one respondent from DEB, MEM, personal communication on $16^{\text {th }}$ July 2015).

Unfortunately, this lack of performance has been obscured by the project's aforementioned success. Based on a number of perspectives of some representatives from the Lao governmental agencies and resettled communities, NT2 has mostly achieved its social obligations under the CA despite some existing minor issues remaining (representatives from DEB, MEM; DESIA, MoNRE; RMU; and Nakai \& Phon-Sa-On (or Sop On) villages, personal communication, $8^{\text {th }}, 9^{\text {th }}, 10^{\text {th }}, 16^{\text {th }} \& 23^{\text {rd }}$ July 2015). It is interesting to note that the Lao government seems not to agree with POE's advice on extending RIP (DEB, MEM representative, personal communication, $16^{\text {th }}$ July 2015).

This seems to illustrate that these involved stakeholders have mostly been satisfied with the current NT2 resettlement performance, despite the incompleteness of both the five livelihood restoration pillars and VIT. Particularly, under the name of the role model project in Lao PDR, NT2 should strive to address such pending issues in order to prove its potential for achieving its sustainable livelihood development goals. However, based on research participants' perspectives, it can be recapitulated that the actual implementation of NT2 resettlement strategies has to date effectively accomplished a large number of positive outcomes. Specifically, these outcomes extend beyond economic benefits: increased income or access to employment including better healthcare and education and so forth. Hence, even though, there still are some issues that need addressing, these accomplishments are essential regarding the resettled populations and their livelihood goals.

\subsection{The third research aim}

Examining key lessons learned from NT2 resettlement. 
What are the successes and the challenges derived from NT2 resettlement performance?

As explored in Chapter Two, resettlement and rehabilitation are two interrelated processes that play an important role concerning the enhancement of resettled people's livelihoods on a sustainable basis (Mahapatra, 1999). Importantly, the objective of rehabilitation is to reach a point where resettled people's livelihoods are better off than or not worse off than they were before resettlement (Mahapatra, 1999). This concept mirrors the findings of this research as explored in Chapter Six, because there have been a number of key successes stemming from NT2 resettlement performance so far. In broad terms, NT2 resettlement performance succeeded in engaging both Lao national and international stakeholders in the preparation of resettlement plans, particularly resettled populations (DEB, MEM representative, personal communication, $16^{\text {th }}$ July 2015). With this engagement, these stakeholders were introduced to the international recognised systematised resettlement, compensation, and livelihood restoration processes on a sustainable basis (DESIA, MoNRE representative, personal communication, $23^{\text {rd }}$ July 2015).

Specifically there have been numerous advantages gained from the actual implementation of NT2 resettlement strategies, especially resettled people and their community (Nam Theun 2 hydroelectric project, n.d.). For example, resettled residents obtained house replacements that were connected to the electricity grid. They also received land plots for agricultural purposes. Furthermore, they were entitled to much beneficial assistance such as technical assistance to develop existing and new livelihood restoration pillars. Moreover, they were provided employment opportunities and food subsidies to maintain living standard during the resettlement transitional period (Nam Theun 2 hydroelectric project, n.d.).

Nevertheless, there are still some challenges along with numerous positive outcomes of the project which they may prevent the project back from accomplishing sustainable livelihood development goals. As demonstrated in the previous section, NT2's unsuccessful performance of the five livelihood restoration pillars and its unfulfilled contractually social obligations (VIT) under the CA are, among other, the key defective issues. In examining these issues, it is necessary to explore some possibilities of the causes of such ineffectual practice of the project. For example as outlined in Chapter Six:

a) An unclear framework concerning sustainable development identified in the CA; 
b) An ambiguous authority of the government's approving process associated with the success or the failure of NT2 resettlement performance;

c) An unclear indicator used for measuring resettled households' living standard such as the VIT;

d) An ineffective approving procedure of the NT2's integrated social plans; and

e) An incomprehensive planning process on dealing with sustainable livelihood development of resettled people including their natural growth in long term.

Thus, even though the key lessons learned from NT2 resettlement performance appeared to contain a large number of benefits, these challenges are significant enough to prevent the project from accomplishing sustainable development within the Nakai Plateau resettlement community.

\subsection{Conclusion}

\subsubsection{Research recapitulation}

The purpose of this research was to explore resettlement impacts of hydroelectric projects through a case study in Lao PDR. Specifically, it intended to examine the contribution of NT2 resettlement strategies for project-affected populations in the Nakai Plateau. In order to fulfil the primary aim for this research, three main research conclusions can be discerned:

Firstly, NT2 resettlement strategies presented wide-ranging social mitigation approaches that had been prepared before resettlement commenced. The strategies were consistent with international resettlement standards and the IRR Model. Significantly, they were strictly prepared in compliance with the $\mathrm{CA}$, which has been to date the governing body for developing this project. Thus, NT2 resettlement strategies seemed to comprehensively address all relevant resettlement impacts related to the Nakai Plateau resettled populations' livelihoods and well-being in a sustainable pathway.

Secondly, through the implementation of NT2 resettlement strategies, the Nakai Plateau resettled community's capabilities and livelihoods have been strengthened. The outcomes illustrate the Nakai Plateau resettled community have gained many benefits from the project. Such benefits range from increased income or employment opportunities to better healthcare and education. Nonetheless, there have been some challenges: the ineffective performance of the five livelihood restoration pillars and the unaccomplished VIT. These challenges seem to 
indicate an obstacle concerning the achievement of sustainable livelihoods. Therefore, in terms of NT2 acting as a role model, it needs to address such challenges.

Lastly, the ineffective performance of the five livelihood restoration pillars and the unaccomplished VIT required critical investigation. This investigation indicated various possible causes hidden in terminology and unclear obligations specified in the CA. Ineffective social requirements within the CA were also found. The results show the aforementioned five implications (a-e) of ineffectual practice of the project. Thus, these implications undoubtedly prevent the project from achieving sustainable development of the Nakai Plateau resettlement community.

\subsubsection{Concluding Remarks}

Even though this research was undertaken in 2015 which was expected to be the final year of NT2's RIP, incomplete works of the project have caused doubt as to whether NT2's RIP will be extended or not. In light of this situation, while the implementation of NT2 resettlement strategies has to date contributed a large number of advantages to the Nakai Plateau resettled community, the project's success remains uncertain. If RIP is extended, NT2 may face some unexpected challenges. Therefore, the project will need to keep on developing adaptive mitigation measures in response to such challenges. Particularly, these measures will be a responsive action in order to achieve sustainable livelihood development goals.

However, if RIP is not extended, it will probably be a responsibility of the Lao government to address such future challenges. Thus, this will raise doubts about NT2's capacity to fulfil its social obligations under the CA. Moreover, its competence - as the role model for other hydroelectric projects in Lao PDR - may also be called into question. Apart from these issues, as the investments of hydropower sector have continuously been promoted by the Lao government, more and more local people have been or will be resettled as a consequence. Therefore, it is crucial for the Lao government and hydroelectric proponents to jointly keep developing all relevant resettlement strategies and policies to address resettlement effects in a more sustainable manner.

Based on lessons learned from this case study, this thesis proposes that future mitigation and rehabilitation measures concerning dam-caused population resettlement should take into account: a) a clear framework stipulated in the CA associated with the definition of terminology or measuring indicators, and social obligations and requirements on the Lao government, hydropower project developers and any concerned parties; b) more meaningful 
participation of the PAP throughout the resettlement planning and implementation processes; and c) strict implementation of all relevant integrated social action plans in compliance with the CA. If these conditions are taken into account, future resettlement and rehabilitation initiatives in Lao PDR will probably be more successful and bring more positive results to resettled populations and their communities.

\subsubsection{Recommendations for Future Research}

Due to the uncertainty surrounding the extension of RIP, the current findings of this research cannot definitively determine the success or failure of the project, especially concerning the sustainable development of the Nakai Plateau resettled community. In addition, because there is no contribution from NT2 developers in this research, the study may lack insight in this regard.

Nonetheless, a large amount of evidence found during the course of this study suggests that NT2 resettlement strategies were planned and implemented in accordance with both international and national recognised standards. In addition, NT2 resettlement strategies seemed to be consistent with the principles of the IRR Model. These facts portray the reliable aspects of the project in terms of addressing impacts associated with dam-caused population resettlement. Therefore, generating a deeper and more critical understanding of internationally recognised resettlement standards, particularly the framework for improving resettled people's living standards and quality of life, might be a crucially significant subject for future examination.

\subsubsection{Wider Implications}

There are currently over 60 tributary and mainstream dams planned or under construction in Lao PDR with 95 per cent of the electricity from these dams scheduled to be exported to neighbouring countries (Matthews, 2012). Because Thailand is South-East Asia's largest energy consumer (Middleton, 2012), it becomes one of the key investors in hydroelectric development in Lao PDR (Matthews, 2012). With this connection, Thailand and Lao PDR mobilise power to control the benefits from hydropower while the social impacts are largely ignored (Matthews, 2012). Due to weak rule of law associated with social matters (Middleton, 2012), it seems to cause local livelihoods in Lao PDR to be negatively impacted (Matthews, 2012).

However, regarding lessons learned from NT2 case study, especially the international recognised systematised resettlement, compensation, and livelihood restoration processes on 
a sustainable basis are likely to be the solution for Lao PDR. With this contribution of the project, it seems to enable the Lao government to improve and strengthen the existing legal and technical documents concerning such social matters. Additionally, as a flagship project with performance bonds, trust funds, and insurance underpinned by WB and international financial institutions (Goodland, 2010; Matthews, 2012), NT2 is potentially a role model for hydropower proponents in Lao PDR and perhaps even in other region. As a result, if hydroelectric development projects perform their social obligations in compliance with all strengthened legal and technical requirements, all relevant social impacts will hopefully be addressed.

Nevertheless, lessons can be learned from the implementation of the project, particularly the contractual issue (the CA) and the social impact mitigation and rehabilitation issue (the resettlement strategies). While the former deals with the legal aspects, the latter deals with relevant technical aspects of social matters. On the one hand, some gaps (unclear frameworks, undefined terminology) found in NT2's CA imply how challenging they are for the project to achieve sustainable livelihood development goals. On the other hand, some ineffective components of the resettlement strategies (the five livelihood restoration pillars, integrated social plans) seem to obstruct NT2 to fulfil its social obligations in accordance with the CA.

Consequently, these challenges open up room for hydropower proponents and the Lao government to draw on these unsuccessful components of NT2 to improve their approaches in the future.

Recommendation 1: In preparing the CA, all parties (the Lao government and hydroelectric project investors or any third party) should jointly ensure that terminology and any specific framework must be clearly defined and clarified.

Recommendation 2: In preparing resettlement strategies, the hydropower proponents should learn from refugee resettlement in other contexts. Refugee resettlement (as briefly explored in Chapter Two) requires more comprehensive components than the development-caused involuntary population resettlement. Hence, incorporating it into resettlement strategies may lead to higher living standards regarding resettled people.

Recommendation 3: In preparing the resettlement strategies, the hydropower project developers should ensure that all resettlement plans are prepared transparently and ethically 
by engaging all stakeholders, particularly the PAP, in the entire process of resettlement planning.

To conclude, if these recommended approaches were used, NT2 would possibly become a better role model for other hydropower proponents, especially regarding resettlement endeavours. 


\section{Appendices}

\section{Appendix 1: Support Letter from School Department}

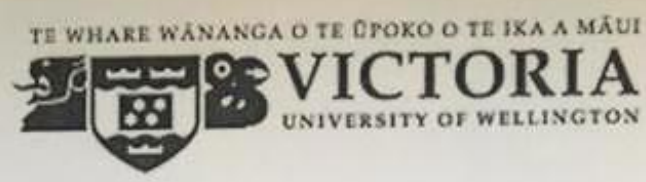

AProf. Sara Kindon

School of Geography, Environment and Earth Sciences

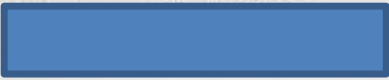

20 May 2015

To Whom It May Concern

Re: Somsanid CHIDMANY

This letter is to confirm that Mr. Somsanid Chidmany is fully registered as a Masters student in the Development Studies programme at the School of Geography, Environment and Earth Sciences (SGEES) at Victoria University of Wellington. As a part of this degree, Somsanid is currently undertaking a research project leading to a thesis. The working title of his thesis is: "Exploring resettlement impacts of hydroelectric projects in Lao PDR: A case study of resettlement due to Nam Theun 2 hydroelectric project".

I am Somsanid's academic supervisor and fully support his proposal. We feel that this research is both important and interesting. It has much potential not only as an academic exercise but also it promises to be able to inform development policy and practice, particularly in the area of livelihood sustainability of hydroelectric development-induced displaced communities which is crucial for Lao PDR.

If you have any further questions or would like to receive further information about the research project, you can contact me as Somsanid's academic supervisor, AProf. Sara Kindon at and Sara.Kindon@vuw.ac.nz. Somsanid's contact details are: +856 2059535837 or +64 0221346717 and tivictorianz@gmail.com and chidmasoms@myvuw.ac.nz.

We would be most grateful if you could offer any assistance you can to Somsanid and his research.

Yours faithfully,

Associate Professor Sara Kindon

Programme Director Geography 


\section{Appendix 2: Victoria University Human Ethics Low Risk Notification}

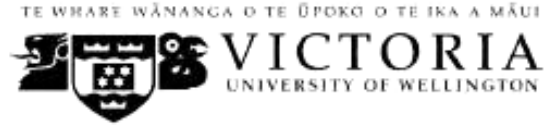

MEMORANDUM
Phone

Email

susan corbettivuw.acn=

\begin{tabular}{l|l}
\hline TO & Somsanid Chidmany \\
\hline COPY TO & Sara Kindon \\
\hline FROM & AProf Susan Corbett, Convener, Human Ethics Committee \\
\hline DATE & 27 June 2015 \\
\hline PAGES & 1 \\
\hline SUBJECT & $\begin{array}{l}\text { Ethics Approval: 21868 } \\
\text { Exploring resettlement impacts of hydroelectric projects in Lao } \\
\text { PDR. A case study of resettlement due to Nam Theun 2 } \\
\text { hydroelectric project in Lao PDR }\end{array}$ \\
\hline
\end{tabular}

Thank you for your application for ethical approval, which has now been considered by the Standing Committee of the Human Ethics Committee.

Your application has been approved from the above date and this approval continues until 26 February 2016. If your data collection is not completed by this date you should apply to the Human Ethics Committee for an extension to this approval.

Best wishes with the research.

Kind regards

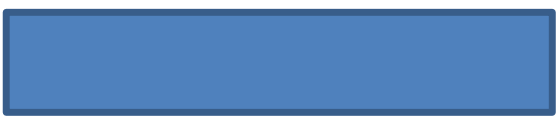

Susan Corbett

Convener, Victoria University Human Ethics Committee 


\section{Appendix 3: Participant Information Sheet for Focus Group Activities}
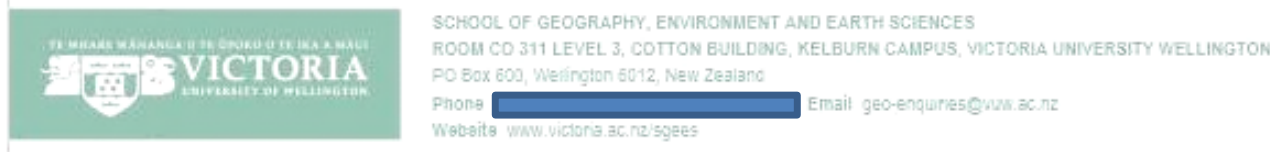

\section{Participant Information Sheet}

Research Project Title: Exploring resettlement impacts of hydroelectric projects in Lao PDR: A case study of resettlement due to Nam Theun 2 hydroelectric project.

My name is Somsanid CHIDMANY, a Master's student in Development Studies at School of Geography, Environment and Earth Sciences, Victoria University of Wellington in New Zealand. I am also an officer who has been working for Ministry of Natural Resources and Environment so far. I am currently doing a thesis research in order to fulfil the requirement of my Master's degree. This research has been approved by the University Human Ethics Committee. The main purpose of my research is to examine the potential of resettlement and livelihood restoration arrangements provided by Nam Theun 2 hydroelectric project - as it has been recognized as a role model for many hydroelectric projects in Lao PDR - in addressing livelihood sustainability of the project-affected communities. It is significant to note that, during my study period at the Victoria University between March 2014 and March 2016 I have taken an education leave. Hence, all activities associated with this research are only for my educational purpose and they have nothing concerned with my organization.

Using a specific case study from Nam Theun 2 hydroelectric project, this research aims to explore how the resettlement and livelihood restoration programmes of this project were employed, to identify what measures were applied for addressing relevant resettlement challenges throughout resettlement implementation period, and to identify what further lessons learned from such project for future hydroelectric projects in Lao PDR and elsewhere.

This research will apply focus group approach. Hence, if you are willing to be involved in the research I would like to carry out a focus group discussion with you and some of your fellow resettled villagers which will be taken time around 1 hour. Additionally, the focus group discussion will be conducted at the meeting hall of the village office or a temple or a school within your village. The focus group discussion will be audio taped if you are comfortable with it and information recorded will be kept confidential through uploading to my computer and external hard disk. It depends on your decision in terms of whether you wish to be named in publishable material or not. If it is the latter, your identity will be kept confidential. Importantly, because this research is based on your voluntary participation, you can withdraw from the study before the start date of the focus group activity, 
All materials collected will be kept confidential and will be viewed only by myself and my supervisor (AProf Sara Kindon). For example, during the study, all written materials will be kept in a locked file and all electronic information will be password protected where access restricted to the investigator (s). After the study finished, all questionnaires, focus group discussion notes and similar materials will be destroyed. On the completion of this research. I will produce a summary discussion of my findings which will be distributed to you if you would like to receive it. The thesis will be submitted for marking to the School of Geography, Environment and Earth Sciences, Victoria University of Wellington, New Zealand, and subsequently deposited in the University Library.

If you have any questions or would like to receive further information about the project, please contact me at chidmasoms amysuw.ac.nz. or telephone -64-022 1346717 or +856 2059535837 , or you may contact my supervisor, Associate Professor Sara Kindon of the School of Geography, Environment and Earth Sciences, Victoria University of Wellington at Sara.Kindon@vuw.ac.nz or telephone

Somsanid CHIDMANY 


\section{Lao Version}

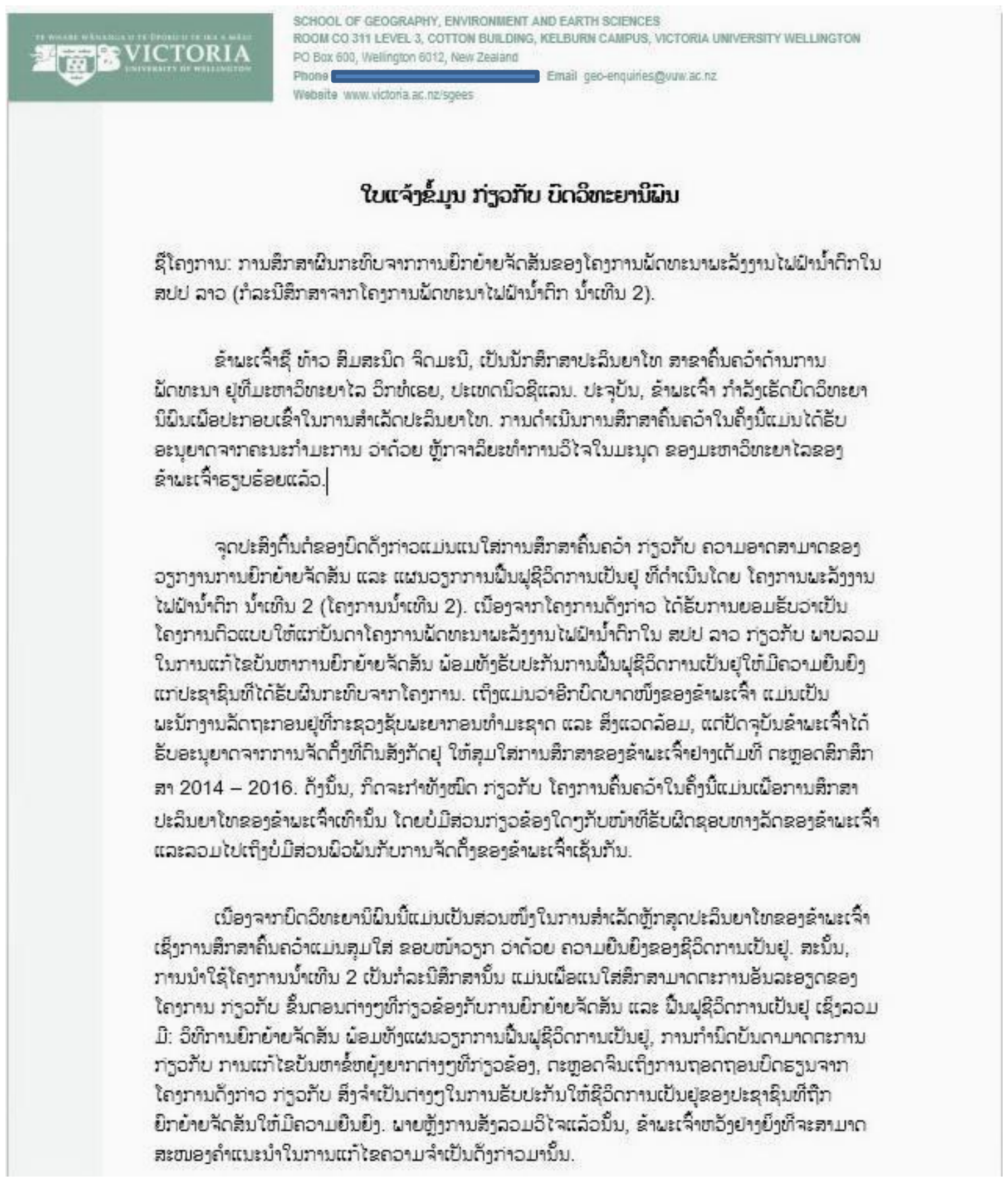




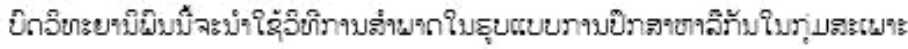

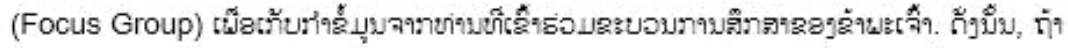

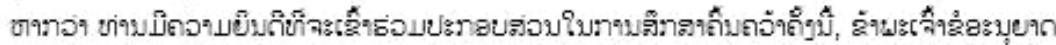

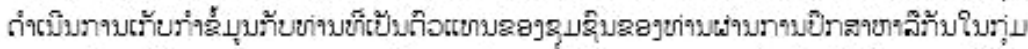

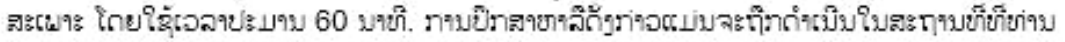

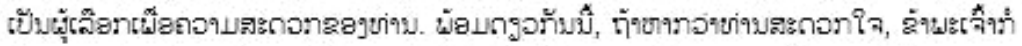

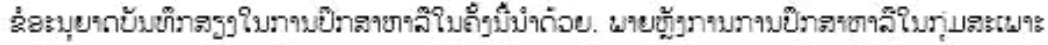

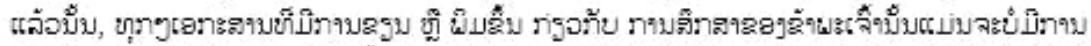

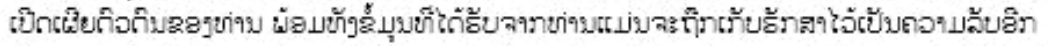

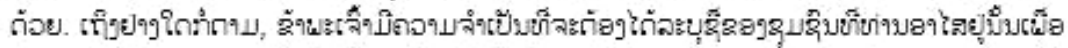

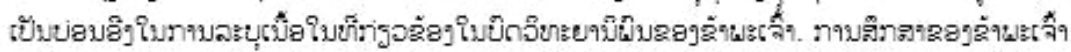

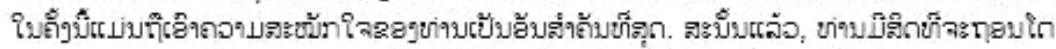

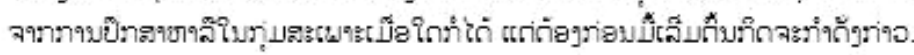

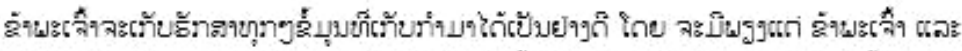

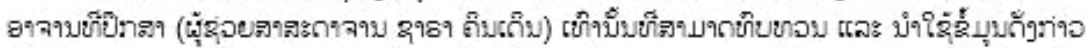

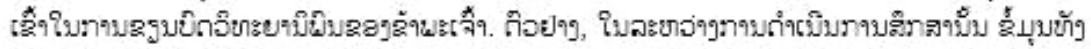

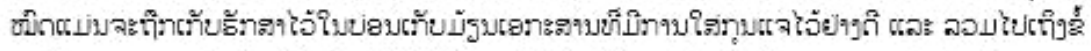

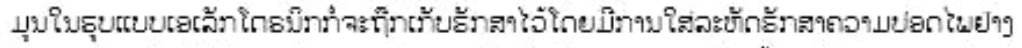

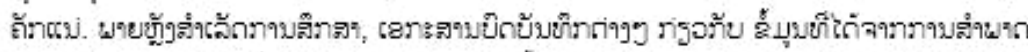

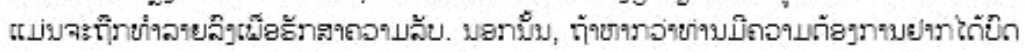

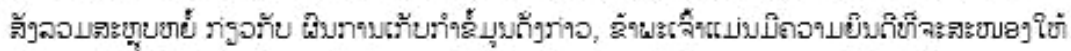

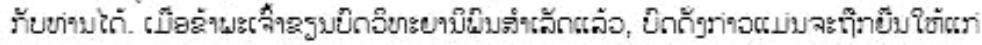

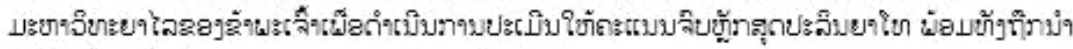

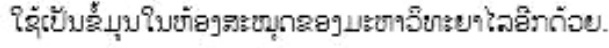

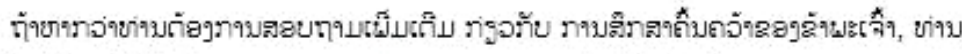

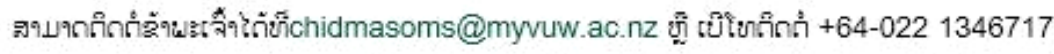

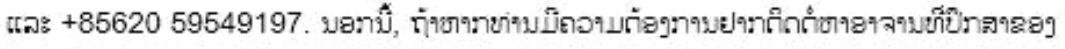

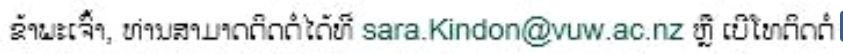

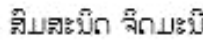




\section{Appendix 4: Participant Information Sheet for Semi-Structured Interviews}

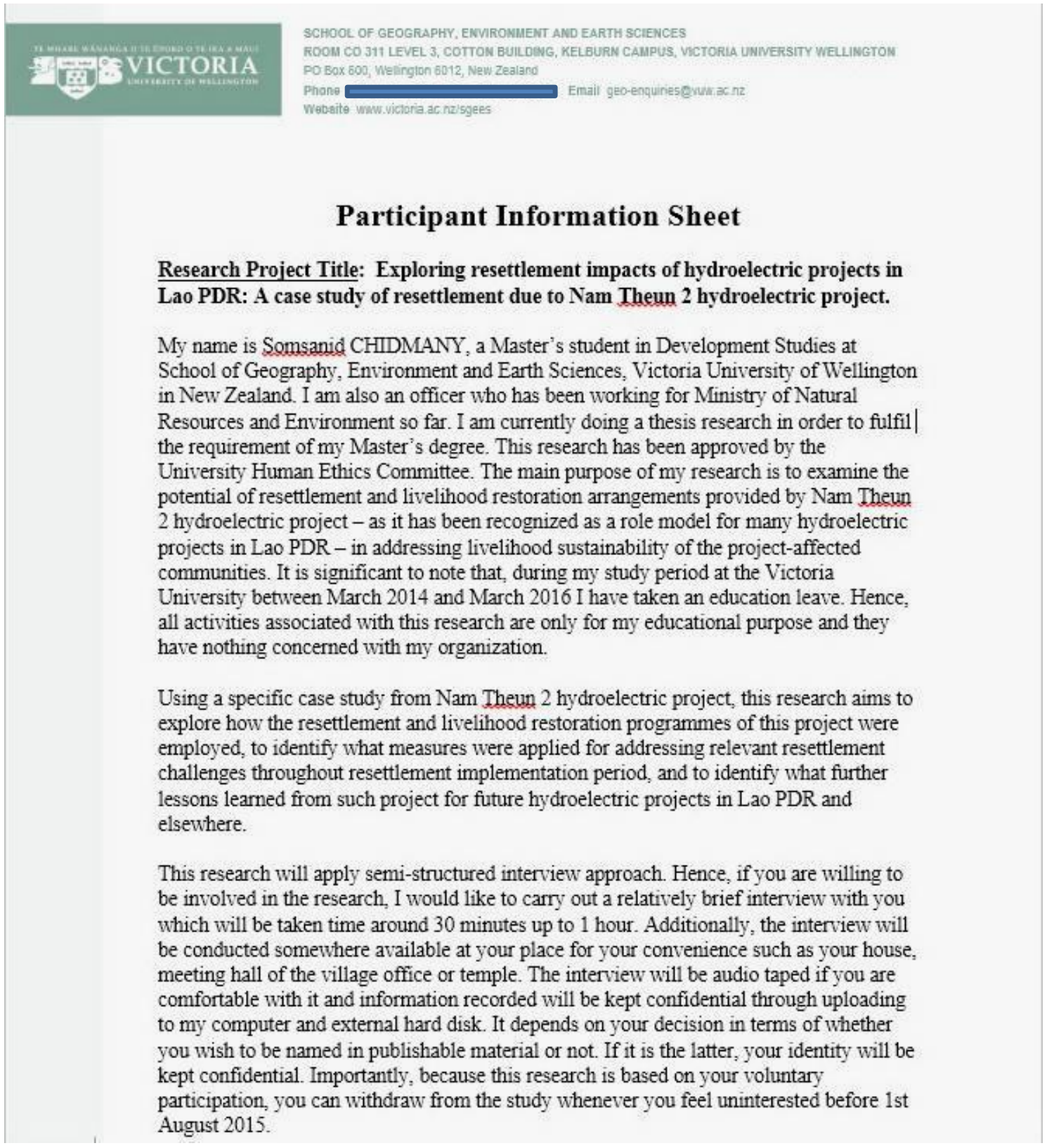


All materials collected will be kept confidential and will be viewed only by myself and my supervisor (AProf. Sara Kindon). For example, during the study, all written materials will be kept in a locked file and all electronic information will be password protected where access restricted to the investigator (s). After the study finished, all questionnaires, interview notes and similar materials will be destroyed. On the completion of this research, I will produce a summary discussion of my findings which will be distributed to you if you would like to receive it. The thesis will be submitted for marking to the School of Geography, Environment and Earth Sciences, Victoria University of Wellington, New Zealand, and subsequently deposited in the University Library.

If you have any questions or would like to receive further information about the project, please contact me at chidmasoms @myvuw.ac.nz. or telephone +64-022 1346717 or +856 2059535837 , or you may contact my supervisor, Associate Professor Sara Kindon of the School of Geography, Environment and Earth Sciences, Victoria University of Wellington at Sara.Kindon@vuw.ac.nz or telephone

Somsanid CHIDMANY 


\section{Lao Version}

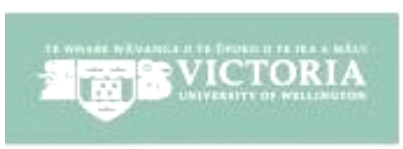

SCHOOL OF GEOGRAPHY, ENVIRONMENT AND EARTH SCIENCES

RDOH CO 311 LEVEL 3, COTTON BUILDING, KELEUAN CAMPUS, VICTORIA UNIVERSTY WELLNGTON

PO Box 50J, Velington 6012 , New Zesand

Phone

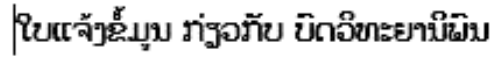

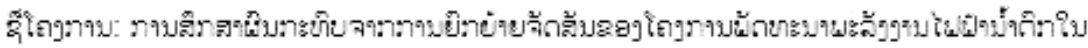

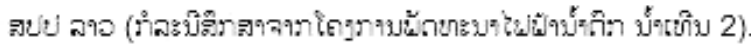

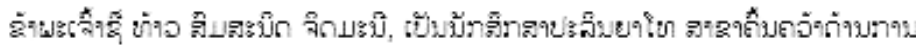

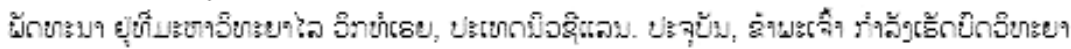

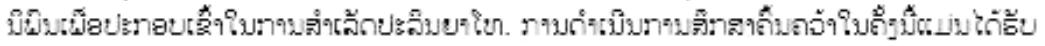

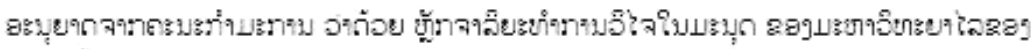

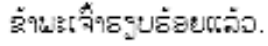

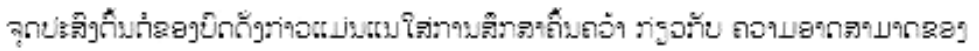

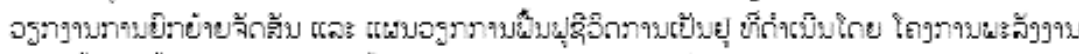

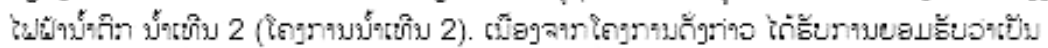

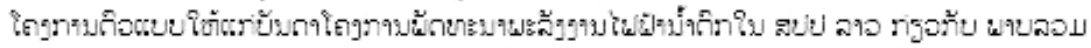

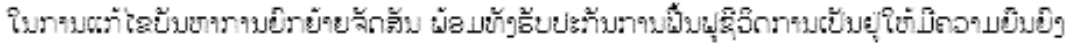

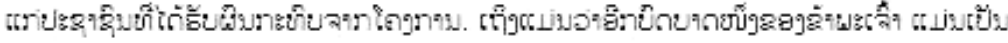

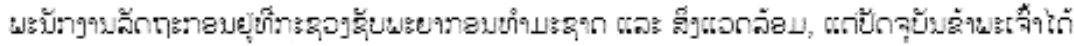

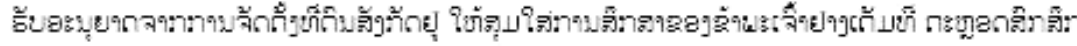

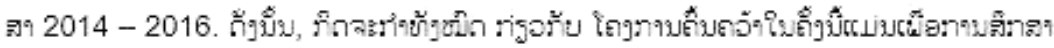

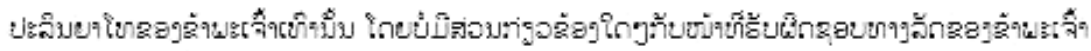

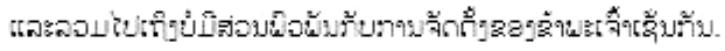

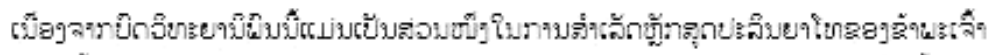

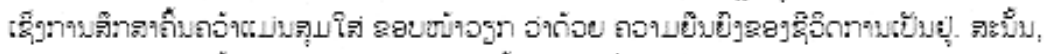

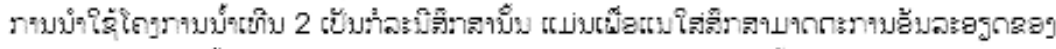

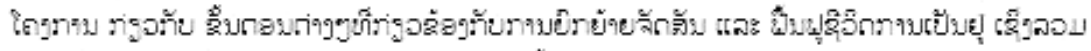

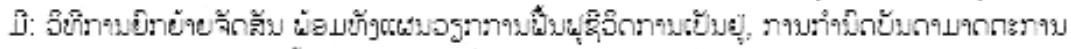

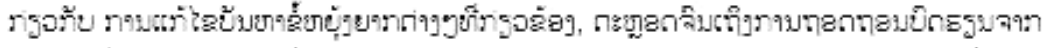

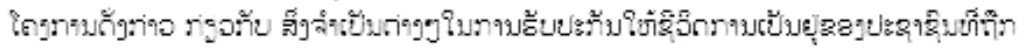

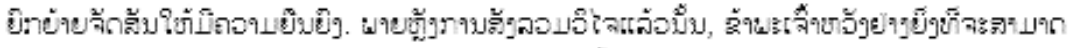

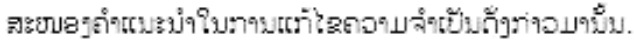




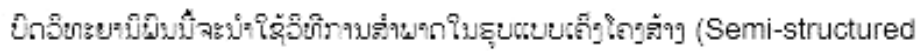

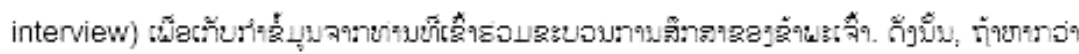

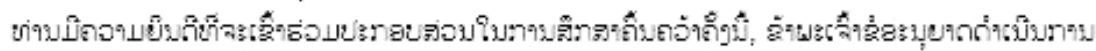

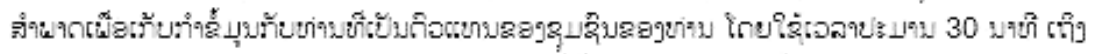

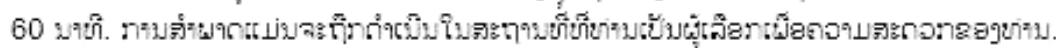

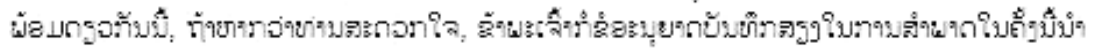

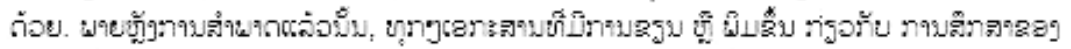

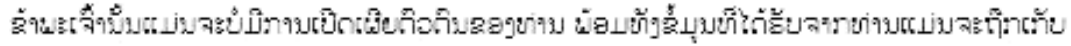

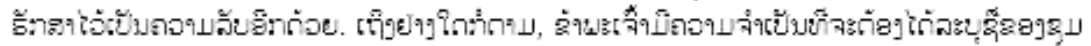

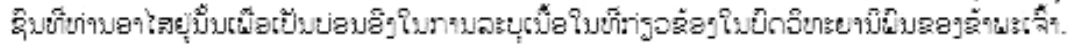

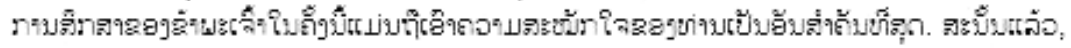

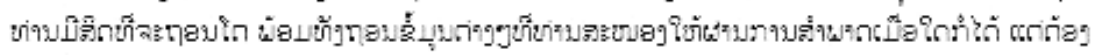
ทอมจัมชิ 1 คิงยา 2015.

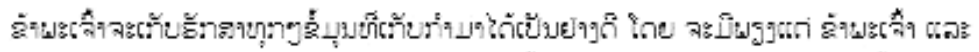

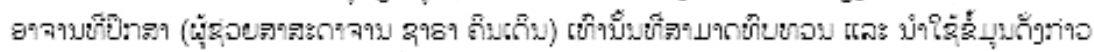

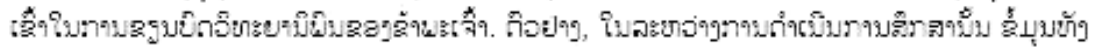

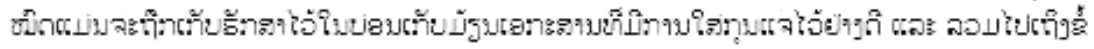

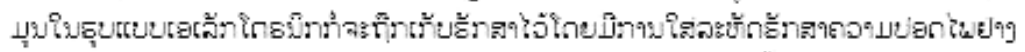

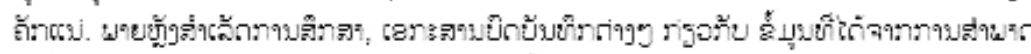

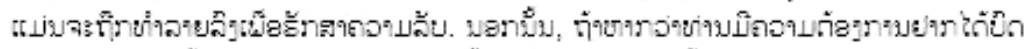

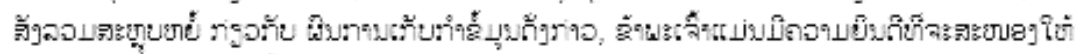

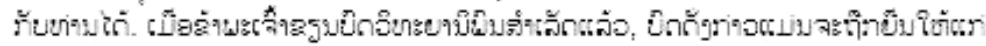

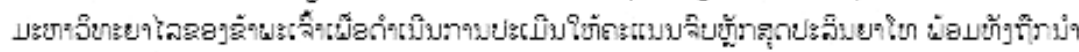

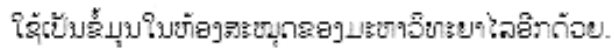

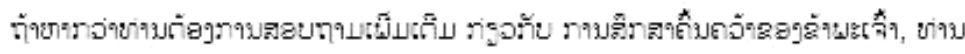

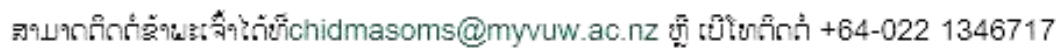

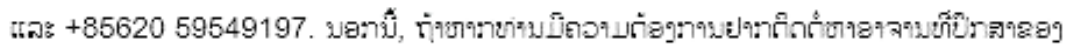

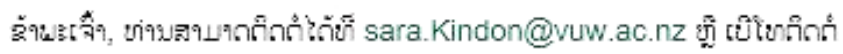

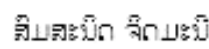




\section{Appendix 5: Participant Consent Form for Semi-Structured Interviews}

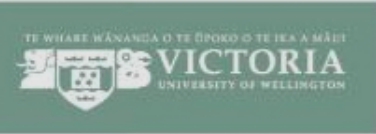

SCHOOL OF GEOGRAPHY, ENVIRONWENT AND EARTH SCIENCES

ROOM CO 311 LEVEL 3, COTTON BUILDING, KELBURN CAMPUS, VICTORIA UNIVERSITY WEUUNGTON

PO Box 600, Wellington 6012, New Zealand

Phone

Website www. victoria ac.nz/sgees

Email geo-enquiries Q

\section{Participant Consent Form}

Research Proiect Title: Exploring resettlement impacts of hydroelectric projects in Lao PDR: A case study of resettlement due to Nam Theun 2 hydroelectric project.

I have read and understood the information presented in the participant information sheet and have had any questions answered to my satisfaction. Besides, I understand that my participation is voluntary and I can withdraw at any time from the study before 1 st of August 2015 without having to give any reason. Moreover, I recognize that all information I provided in the interview of this research are considered as representing my organization or community. Given that, I understand that any information I provided will be kept confidential to the researcher and his supervisor. Also, I understand that the published results will not use my name, and that no opinions will be attributable to me in any way that will identify me. Finally, I understand that the data I provided will not be used for any other purposes or released to others.

I confirm that:

I would like to receive a summary of the results of this research when it is completed.

$\square \quad$ I agree to this interview being audio recorded.

।

Signed:

Name of participant:

Date: 


\section{Lao Version}

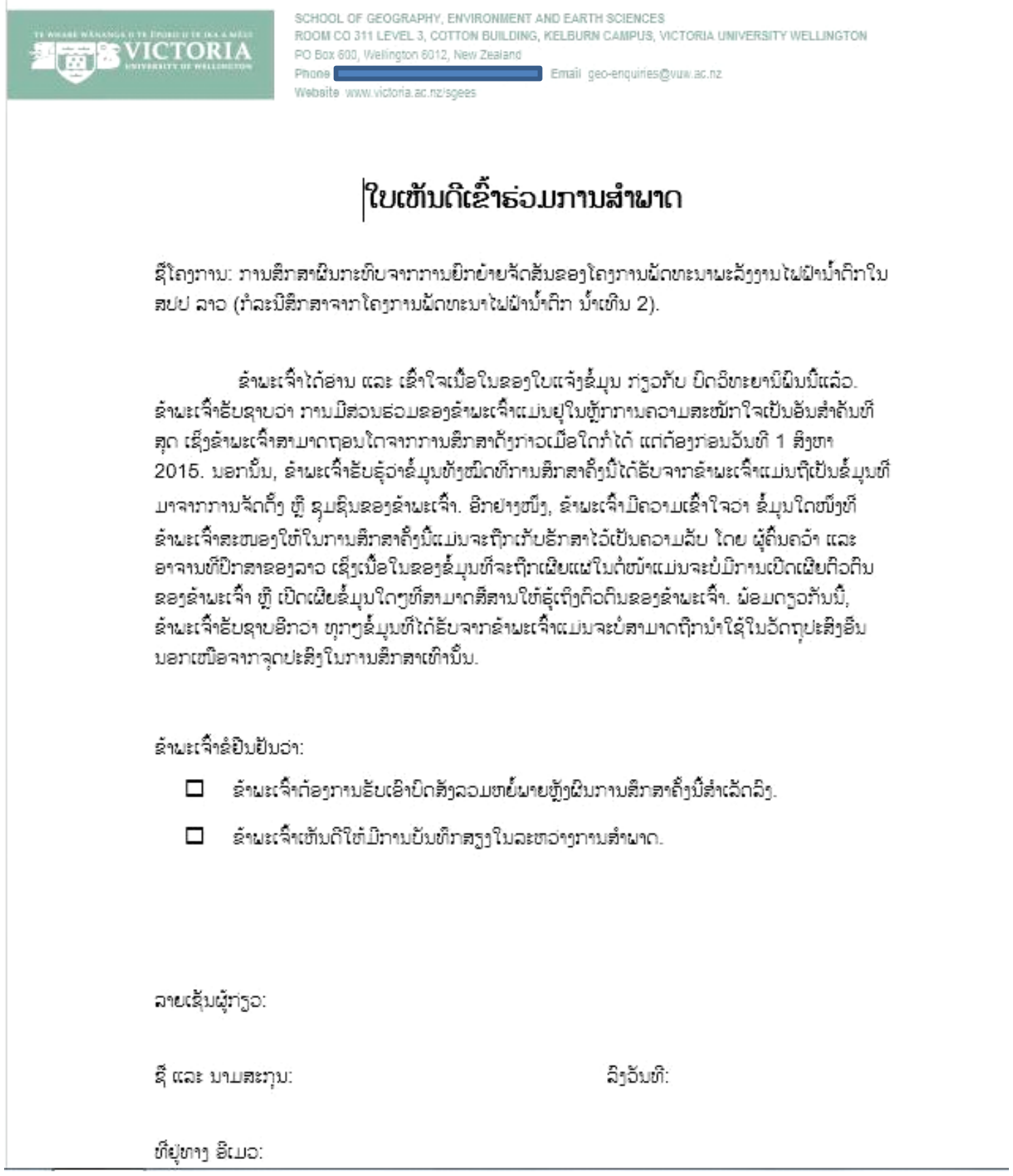




\section{Appendix 6: Consent Form for Focus Group Participants}
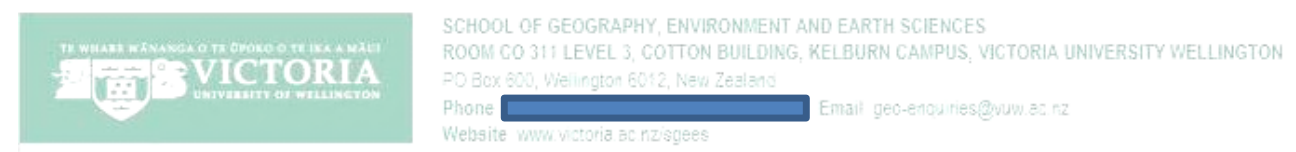

\section{Consent form for the focus group participants}

Research Project Title: Exploring Resettlement Impacts of Hydroelectric Projects in Lao PDR: A Case Study of Resettlement due to Nam Theun 2 Hydroelectric Project

I have read and understood the information presented in the participant information sheet and have had any questions answered to my satisfaction. Besides, I understand that any information I provided will be kept confidential to the researcher and their supervisor. In addition, I understand that the published results will not use my name, and that no opinions will be attributable to me in any way that will identify me. Finally, I understand that the data I provided will not be used for any other purposes or released to others.

I confirm that:

$\square \quad$ I agree to this focus group being audio recorded

Name:

Signature:

Date: 


\section{Lao Version}

\section{VIV VICTORIA}

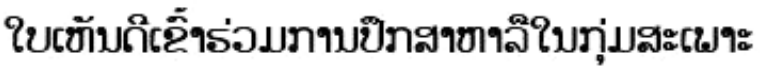

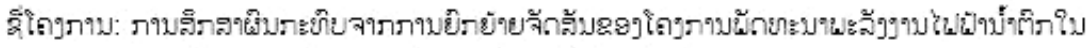

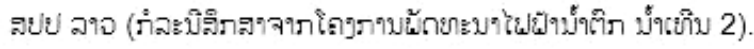

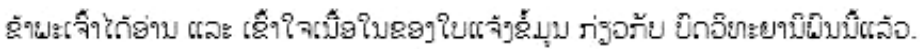

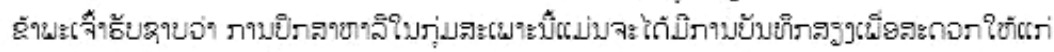

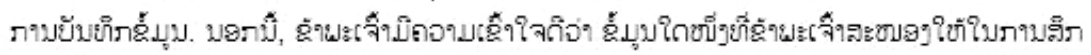

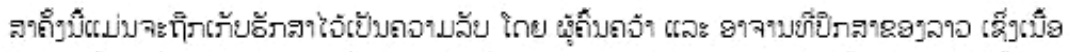

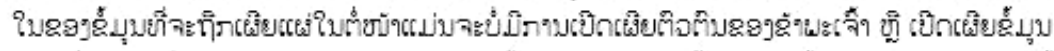

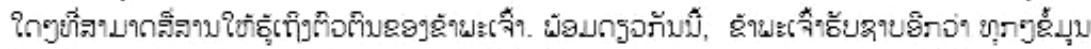

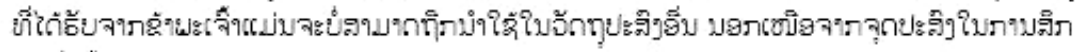
จาเข้าทบื้ม.

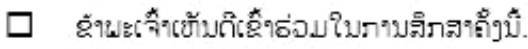

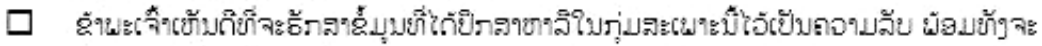

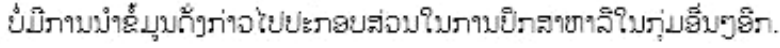

คื่ และ มาบระกุบ

ลายเฉัมผู้ร่รจ:

ล๊งจับยึ: 


\section{Appendix 7: An Invitation for Nam Theun 2 Power Company Limited to Participate in Semi-Structured Interview (Lao Language)}

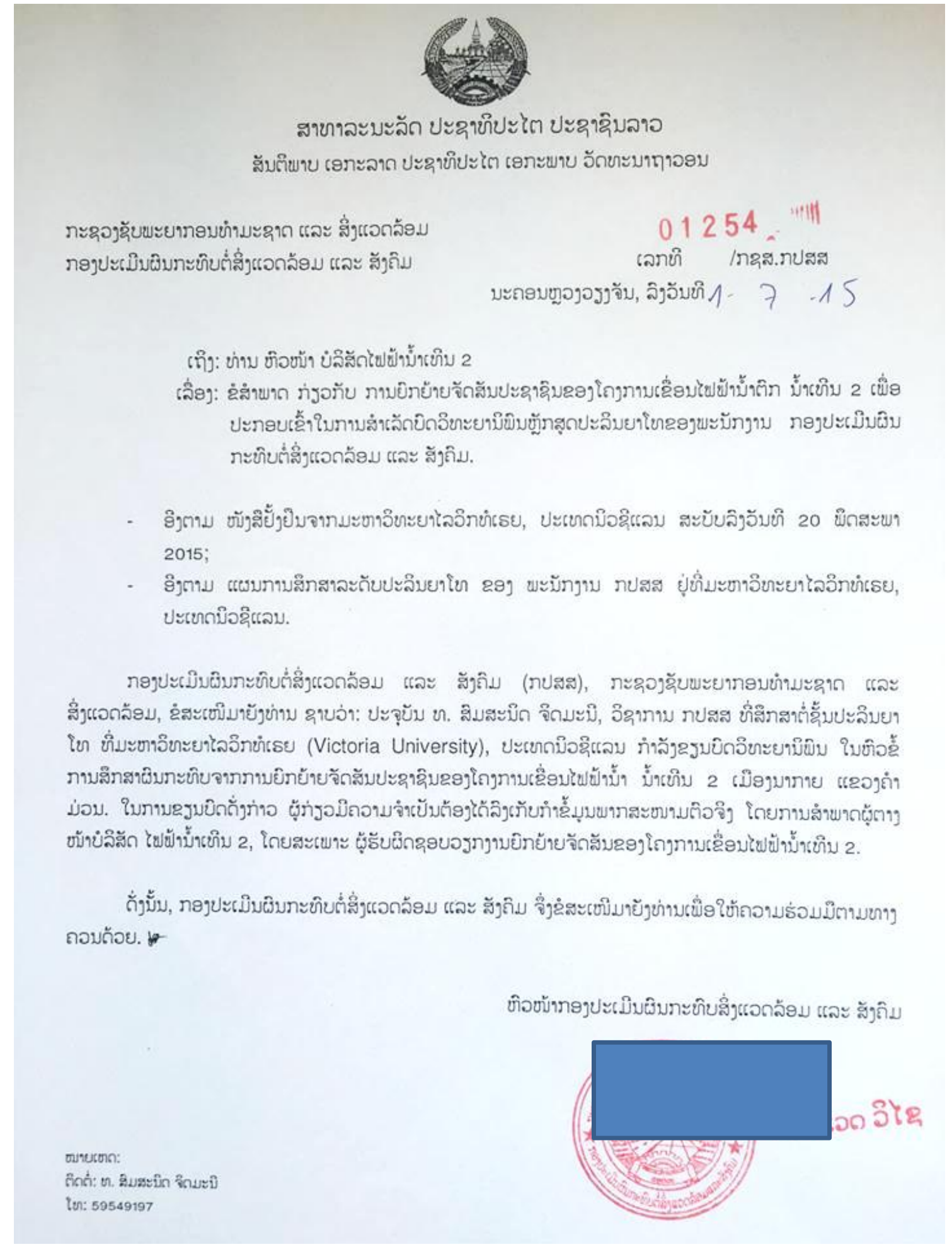




\section{Appendix 8: An Invitation for Department of Energy Business to Participate in Semi-Structured Interview (Lao Language)}

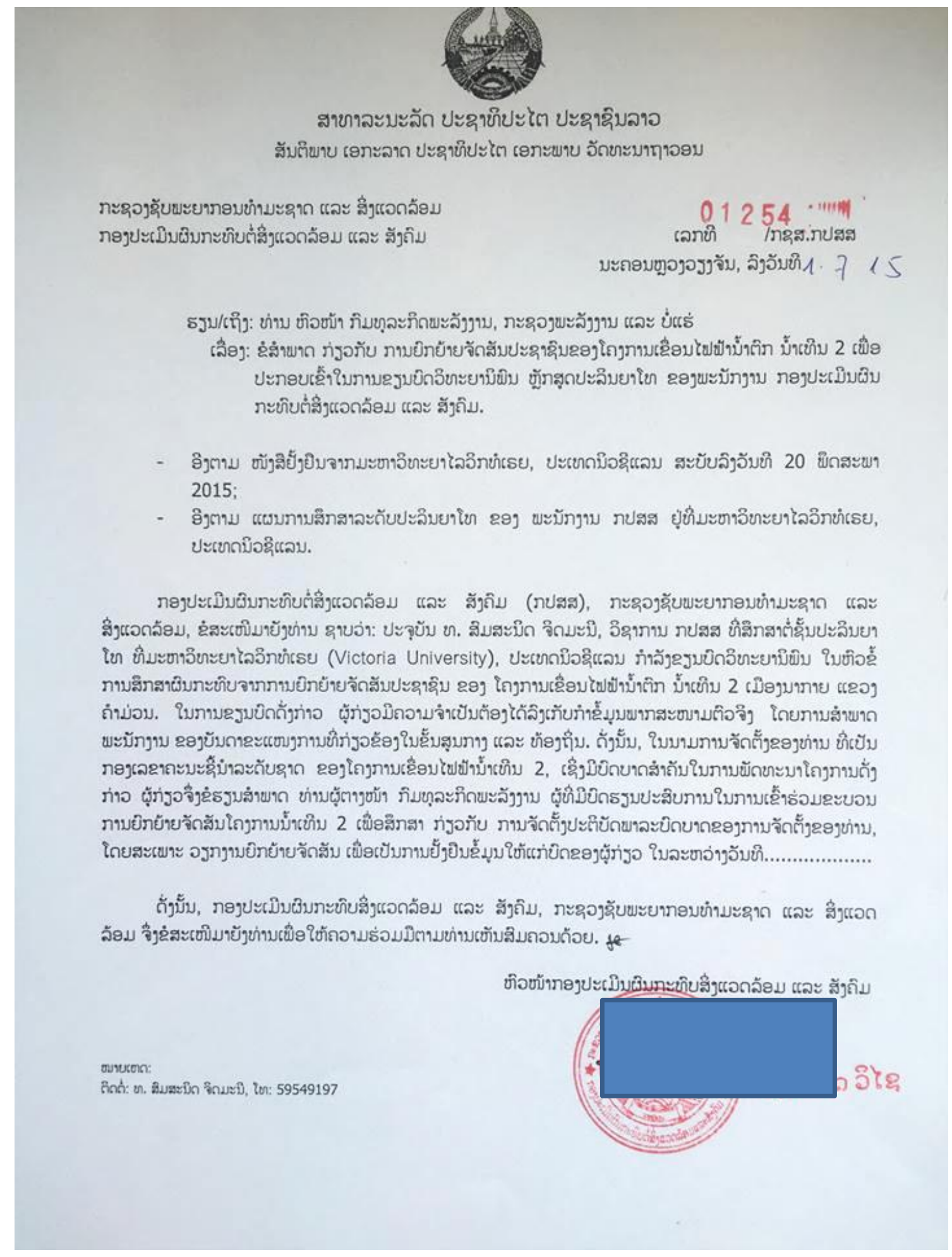


Appendix 9: Focus Group Activity Held in Phon-Sa-On Village

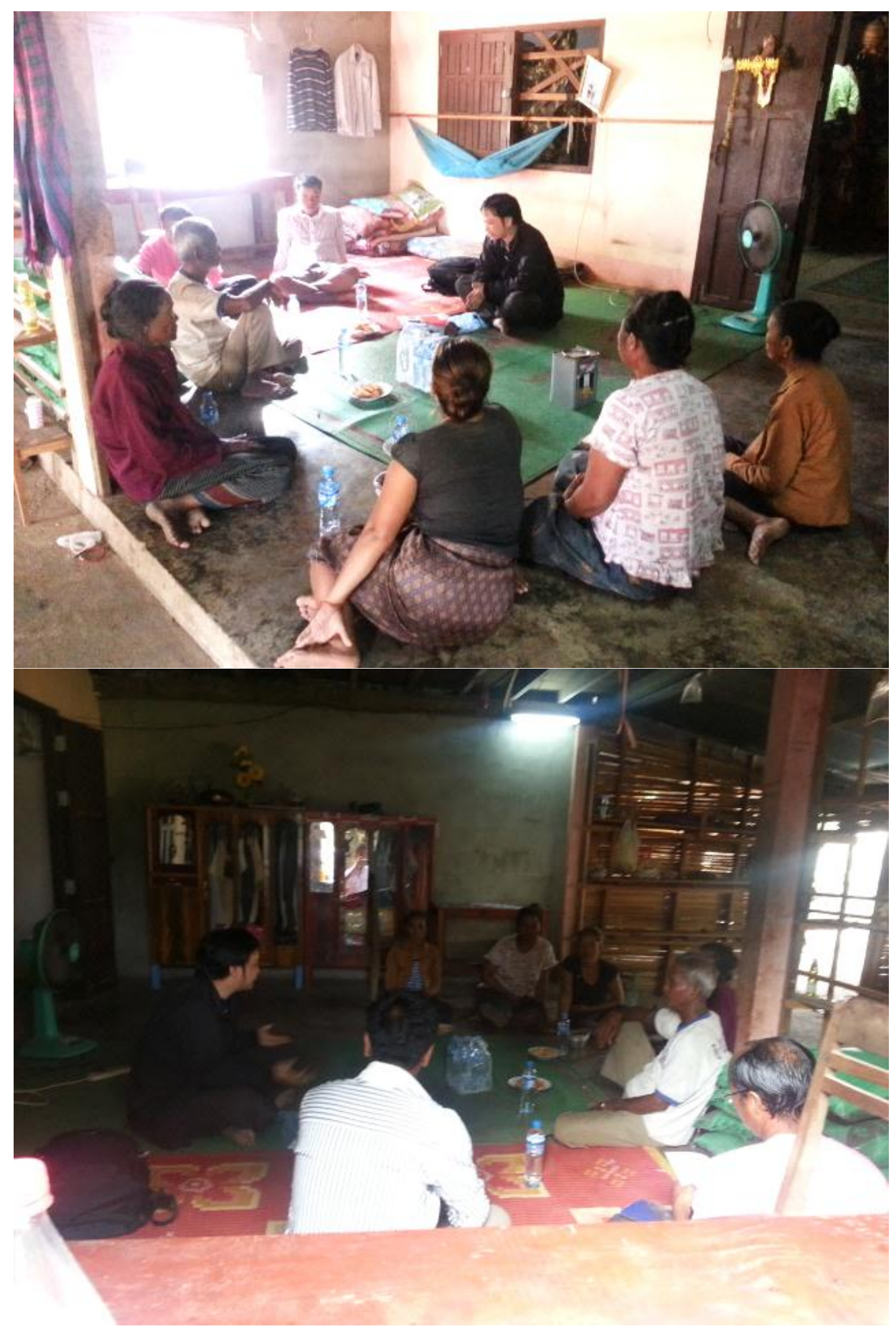


Appendix 10: Focus Group Activity Held in Nakai Village

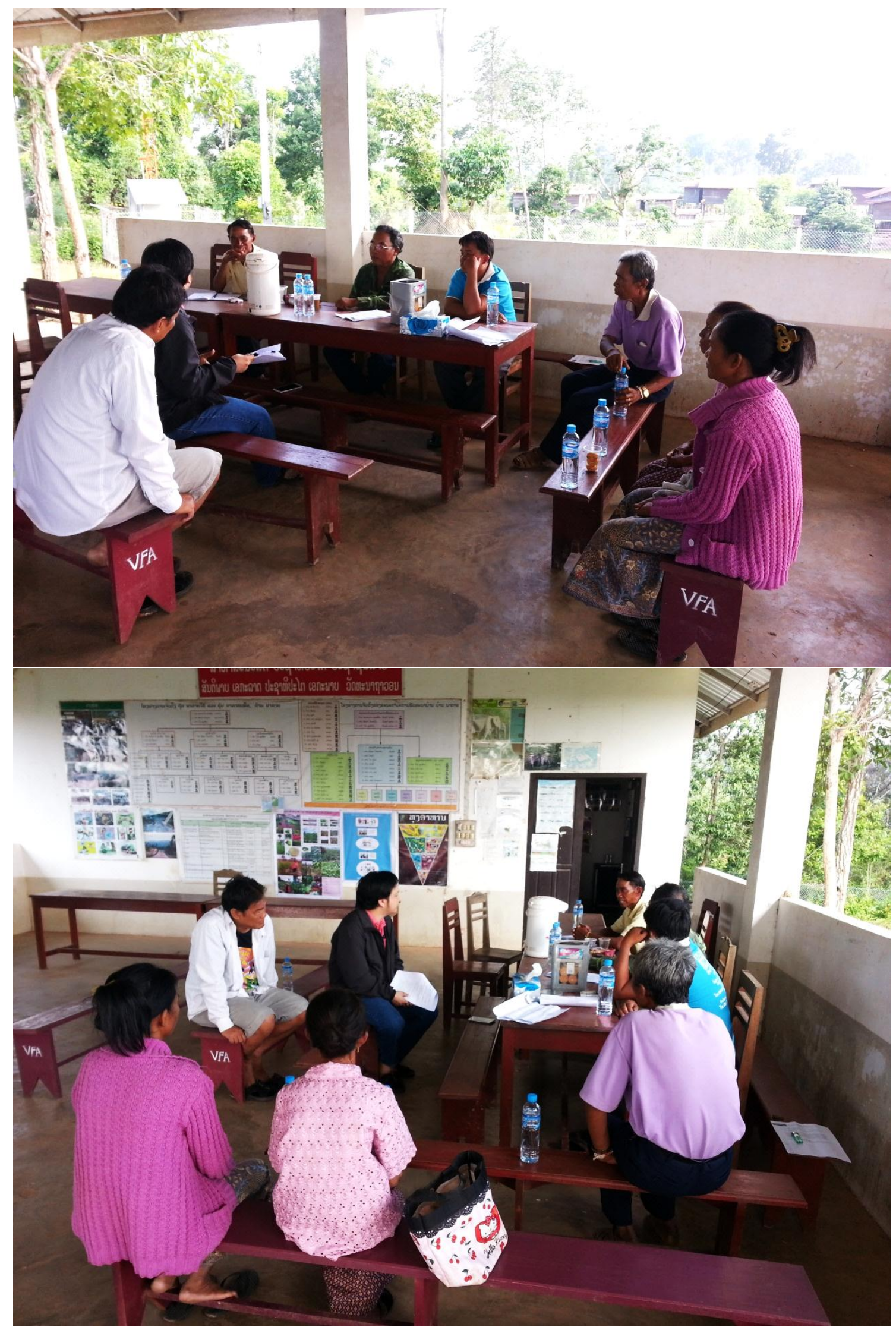


Appendix 11: Other Photos of Nakai and Phon-Sa-On villages
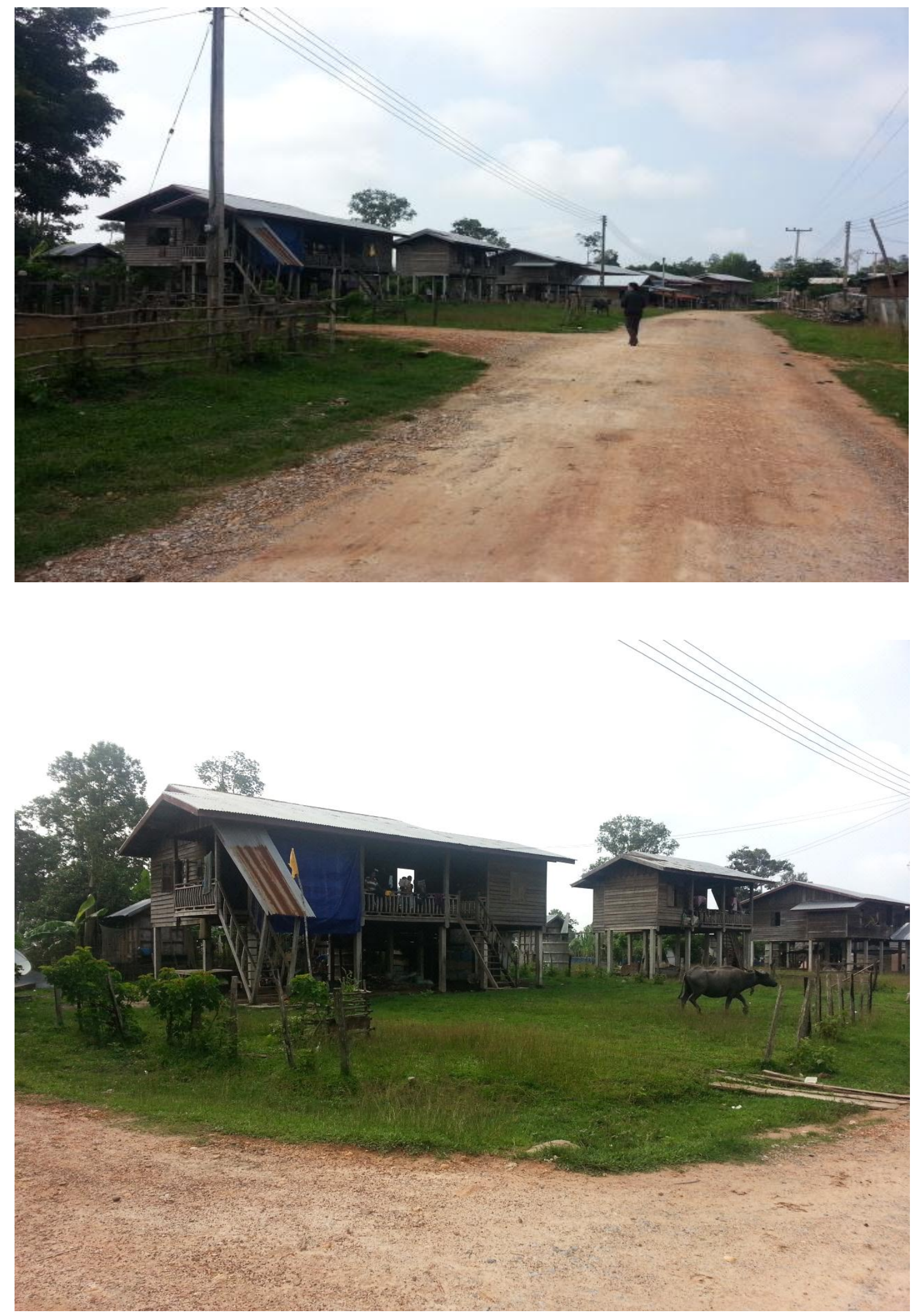

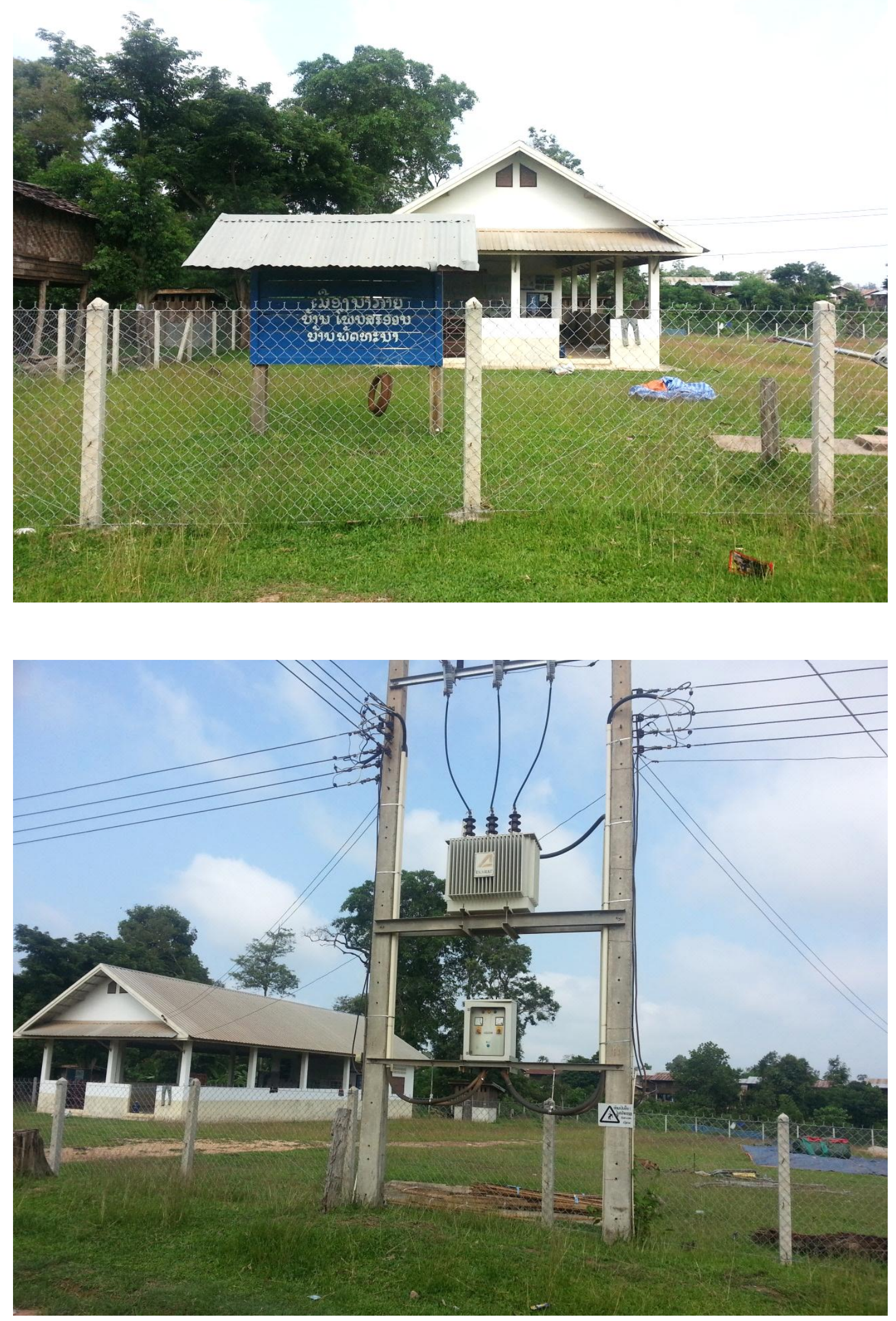


\section{References}

Anyan, F. (2013). The influence of power shifts in data collection and analysis stages: A focus on qualitative research interview. The Qualitative Report, 18(18), 1-9. Retrieved from http://search.proquest.com/docview/1505321395?accountid=14782

Aronson, J. (1995). A pragmatic view of thematic analysis. The qualitative report, 2(1), 1-3.

Aronsson, I. (2009). The paradox of local participation in forced displacement and resettlement caused by the development process 1 . Revista Romana De Sociologie, 20(1), 37-59. Retrieved from http://search.proquest.com.helicon.vuw.ac.nz/docview/197117346?accountid=1 4782

Asian Development Bank (2004). Summary environmental and social impact assessment. Nam Theun 2 hydroelectric project. Vientiane: Author.

Barutciski, M. (2006). International law and development-induced displacement and resettlement. Development Induced Displacement: Problems, Policies and People, 71-104.

Blaikie, N. (2003). Analyzing quantitative data: From description to explanation. Sage.

Braun, V., \& Clarke, V. (2006). Using thematic analysis in psychology. Qualitative research in psychology, 3(2), 77-101.

Bulgalski, N. \& Pred, D. (2013). Reforming the World Bank policy on involuntary resettlement. Submission to the World Bank safeguards review. USA: World Bank.

Cameron, R. (2011). Mixed methods research: the Five Ps framework. The Electronic Journal of Business Research Methods, 9(2), 96-108.

Cernea, M. M. (1988). Involuntary resettlement and development. Finance \& Development, 25(3), 44. Retrieved from http://search.profquest.com/docview/209411157?accountid=14782

Cernea, M. M. (1995). Understanding and preventing impoverishment from displacement: Reflections on the state of knowledge. Journal of Refugee Studies, 8(3), 245264.

Cernea, M. (1997). The risks and reconstruction model for resettling displaced populations. World Development, 25(10), 1569-1587. doi:10.1016/S0305-750X(97)00054-5 
Cernea, M. M. (1998). Impoverishtnent or Social Justice? A Model for Planning Resettlement. Oxford, New Delhi.

Cernea, M. M. (Ed.). (1999). The economics of involuntary resettlement: Questions and challenges. World Bank Publications.

Cernea, M. M. (2000). Risks, safeguards and reconstruction: a model for population displacement and resettlement. Economic and Political Weekly, 3659-3678.

Cernea, M. M. (2003). For a new economics of resettlement: A sociological critique of the compensation principle. International Social Science Journal, 55(175), 37-45.

Cernea, M. M., \& McDowell, C. (Eds.). (2000). Risks and reconstruction: Experiences of resettlers and refugees. World Bank Publications.

Chacko, E. (2004). Positionality and praxis: fieldwork experiences in rural India. Singapore Journal of Tropical Geography, 25(1), 51-63.

Chambers, R. (2012). Revolutions in development inquiry. Routledge.

Chiseri-Strater, E. (1996). Turning in upon ourselves: Positionality, subjectivity, and reflexivity in case study and ethnographic research. Ethics and representation in qualitative studies of literacy, 115-133.

Creak, S. (2011). LAOS: Celebrations and development debates. Southeast Asian Affairs, 107-128. Retrieved from http://search.proquest.com/docview/926197708?accountid=14782

Creswell, J. W. (2013). Research design: Qualitative, quantitative, and mixed methods approaches. Sage publications.

Creswell, J. W., \& Zhang, W. (2009). The application of mixed methods designs to trauma research. Journal of Traumatic Stress, 22(6), 612-621.

Croll, E. J. (1999). Involuntary resettlement in rural China: The local view. The China Quarterly, 158, 468-483.

Daas, P. J. H., \& Arends-Tóth, J. (2009). Secondary data collection. Methodology series, 9002.

Davidson, C., \& Tolich, M. (2003). Social science research in New Zealand: many paths to understanding. Auckland, N.Z: Pearson Education New Zealand.

Delang, C. O., \& Toro, M. (2011). Hydropower-induced displacement and resettlement in the Lao PDR. South East Asia Research, 19(3), 567-594. 
Department of energy business powering progress (n.d.). Back ground project overview. Retrieved from http://www.poweringprogress.org/index.php?option=com_content\&view=article $\underline{\text { \&id }=84 \& \text { Itemid }=77}$

Devi, N. B. (2009, May). Understanding the qualitative and quantitative methods in the context of content analuysis. In qualitative and quantitative methods in libraries. International conference organised by international federation of library associations (pp. 26-29).

de Wet, C. (2001). Economic development and population displacement: Can everybody win? Economic and Political Weekly 36(50): 4637-4646.

Downing, T. E. (2002). Avoiding new poverty: mining-induced displacement and resettlement (Vol. 52). International Institute for Environment and Development.

Downing, T.E. and Garcia-Downing, C. 2009. Routine and dissonant cultures: A theory about the psycho-socio-cultural disruptions of involuntary displacement and ways to mitigate them without inflicting even more damage. In Oliver-Smith, A. (Ed), Development and dispossession: The anthropology of displacement and resettlement, pp. 225-254. Santa Fe: School for Advanced Research Press.

Dwivedi, R. (2002). Models and Methods in Development-Induced Displacement (Review Article). Development and Change, 33(4), 709-732.

Eisenhardt, K. M.. (1989). Building Theories from Case Study Research. The Academy of Management Review, 14(4), 532-550. Retrieved from http://www.jstor.org.helicon.vuw.ac.nz/stable/258557

Erlanger, T. E., Sayasone, S., Krieger, G. R., Kaul, S., Sananikhom, P., Tanner, M., ... \& Utzinger, J. (2008). Baseline health situation of communities affected by the Nam Theun 2 hydroelectric project in central Lao PDR and indicators for monitoring. International journal of environmental health research, 18(3), 223-242.

Flyvbjerg, B. (2006). Five misunderstandings about case-study research. Qualitative inquiry, 12(2), 219-245.

Frega, R. (2014). Between pragmatism and critical theory: Social philosophy today. Human Studies, 37(1), 57-82. doi:http://dx.doi.org.helicon.vuw.ac.nz/10.1007/s10746013-9290-0

Fujikura, R., \& Nakayama, M. (2009). Lessons learned from the World Commission on Dams. International Environmental Agreements: Politics, Law and Economics, 9(2), 173-190. 
GOL Resettlement Principles. (n.d.). Retrieved from

http://www.poweringprogress.org/index.php?option=com_content\&view=article $\underline{\text { \&id=69\&Itemid=79 }}$

Goldman, M. (2001). The birth of a discipline: Producing authoritative green knowledge, World Bank-style. Ethnography, 2(2), 191-217.

Goodland, R. (2010). The World Bank versus the world commission on dams. Water Alternatives, 3(2), 384. Retrieved from http://search.proquest.com.helicon.vuw.ac.nz/docview/1151956897?accountid=1 4782

Gutman, P. S. (1994). Involuntary resettlement in hydropower projects. Annual Review of Energy and the Environment, 19(1), 189-210. doi:10.1146/annurev.energy.19.1.189

Hanna, K. S. (2000). The paradox of participation and the hidden role of information: A case study. Journal of the American Planning Association, 66(4), 398-410.

Hays, P. A. (2004). Case study research. Foundations for research: Methods of inquiry in education and the social sciences, 217-234.

Hennink, M. M. (2007). International focus group research: A handbook for the health and social sciences. Cambridge University Press.

Hirsch, P. (2002). Global Norms, Local Compliance and the Human Rights-Environment Nexus: A Case Study of the Nam Theun II Dam in Laos. Human rights and the environment: conflicts and norms in a globalizing world. London, Earthscan, 147-171.

Hsieh, H. F., \& Shannon, S. E. (2005). Three approaches to qualitative content analysis. Qualitative health research, 15(9), 1277-1288.

Huggins, G., \& Maasdop, K. (2010). Resettlement Policy Framework and Abbreviated Resettlement Action Plan-Nacala Dam. Durban, South Africa: June.

Imhof, A., \& Lawrence, S. (2005). An analysis of Nam Theun 2 compliance with World Commission on Dams strategic priorities. Joint paper for International Rivers Network/Environmental Defense, International Rivers Network. Retrieved from http://www. irn. org/programs/mekong/pdf/namtheun/NT2WCDExec Summary2005. Pdf. 
Jing, J. (1997). Rural resettlement: past lessons for the Three Gorges Project. The China Journal, 65-92.

Johnson, R. B., \& Onwuegbuzie, A. J. (2004). Mixed methods research: A research paradigm whose time has come. Educational researcher, 33(7), 14-26.

Jönsson, K. (2009). Laos in 2008: Hydropower and flooding (or business as usual). Asian Survey, 49(1), 200-205. doi:http://dx.doi.org/10.1525/as.2009.49.1.200

Jusi, S. (2011). Challenges in developing sustainable hydropower in Lao PDR. International Journal of Development Issues, 10(3), 251-267. doi:http://dx.doi.org.helicon.vuw.ac.nz/10.1108/14468951111165377

Kapoor, I. (2005). Participatory development, complicity and desire. Third World Quarterly, 26(8), 1203-1220.

Karnieli-Miller, O., Strier, R., \& Pessach, L. (2008; 2009). Power relations in qualitative research. Qualitative Health Research, 19(2), 279-289. doi:10.1177/1049732308329306

Koenig, D. (2001). Toward Local Development and Mitigating Impoverishment in Development-Induced Displacement and Resettlement. Prepared for ESCOR R7644 and the Research Programme on Development-Induced Displacement and Resettlement. Oxford: Refugee Studies Centre. University of Oxford.

Koenig, D. (2006). Enhancing local development in development-induced displacement and resettlement projects. Development-Induced Displacement: Problems, Policies and People, 18.

Krantz, L. (2001). The sustainable livelihood approach to poverty reduction. SIDA. Division for Policy and Socio-Economic Analysis.

Lawrence, S. (2009). The Nam Theun 2 controversy and its lessons for Laos. Contested waterscapes in the Mekong region: Hydropower, livelihoods and governance, 81114.

Leech, N. L., \& Onwuegbuzie, A. J. (2009). A typology of mixed methods research designs. Quality \& quantity, 43(2), 265-275.

Lintner, B. (2008). Laos: At the crossroads. Southeast Asian Affairs, 2008(2008), 171-183.

Longhurst, R. (2003). Semi-structured interviews and focus groups. Key methods in geography, 117-132. 
Li, J. G. (2008). A longitudinal study of corporate social disclosure in Chinese listed companies' annual reports: 2002 to 2006 (PhD thesis). Auckland University of Technology, New Zealand.

MacPherson, S. (2012). Education and sustainability: Learning across the diaspora, Indigenous, and minority divide. Routledge.

Mahapatra, L. K. (1999). Reconstruction Model on India's Resettlement Experiences. The economics of involuntary resettlement: Questions and challenges, 189-230.

Matthews, N. (2012). Water grabbing in the Mekong basin- An analysis of the winners and losers of Thailand's hydropower development in Lao PDR. Water Alternatives, $5(2), 392-411$.

Mathur, H. M. (2006). Resettling people displaced by development projects: Some critical management issues. Social Change, 36(1), 36-86.

McDonald, B. D. (2006). From compensation to development: involuntary resettlement in the People's Republic of China. ( $\mathrm{PhD}$ thesis). The University of Melbourne, Melbourne, Australia.

McDonald-Wilmsen, B., \& Webber, M. (2010). Dams and displacement: Raising the standards and broadening the research agenda. Water Alternatives, 3(2), 142-161.

McDonald, B., Webber, M., \& Yuefang, D. (2008). Involuntary resettlement as an opportunity for development: the case of urban resettlers of the Three Gorges Project, China. Journal of refugee studies, 21(1), 82-102.

McDowell, C. (1996). Understanding impoverishment: The consequences of developmentinduced displacement, Berghahn books.

McDowell, D., Scudder, T., Talbot, L. (2010). Sixteenth report of the international environmental and social panel of experts. Vientiane: Ministry of Industry and handicraft.

McDowell, D., Scudder, T., Talbot, L. (2014). Twenty second report of the international environmental and social panel of experts. Vientiane: Ministry of Industry and handicraft. 
McDowell, D., \& Talbot, L. (2014). Twenty third report of the international environmental and social panel of experts. Vientiane: Ministry of Industry and handicraft.

Middleton, C. (2012). Transborder environmental justice in regional energy trade in mainland south-east asia. Austrian Journal of South - East Asian Studies, 5(2), 292-315. Retrieved from http://search.proquest.com.helicon.vuw.ac.nz/docview/1312402693?accountid=1 $\underline{4782}$

Mikene, S., Gaizauskaite, I., \& Valaviciene, N. (2013). Qualitative interviewing: field-work realities. Socialinis Darbas, 12(1), 49-61. Retrieved from http://search.proquest.com.helicon.vuw.ac.nz/docview/1527435556? accountid $=14782$

Miller P.J., Hengst, J.A. \& Wang, S-H. (2003). Ethnographic methods: Applications from developmental cultural psychology. In P.M. Carnic, J.E. Rhodes \& L. Yardley(Eds.). Qualitative Research in Psychology: Expanding Perspectives in Methodology and Design (pp.219-242). Washington D.C.: American Psychological Association.

Ministry of Natural Resources and Environment. (n.d.). Standard environmental and social obligatons for hydropower projects [Technical guidelines]. Vientiane: Author.

Morgan, D. L. (1996). Focus groups. Annual review of sociology, 129-152.

Muggah, H. C. R. (2000). Conflict-induced Displacement and Involuntary Resettlement in Colombia: Putting Cernea's IRLR Model to the Test. Disasters, 24(3), 198-216.

Muqit, A. (2013). Identity and power relation in the discourse to the allies of America.

Psychology Research, 3(3), 129-141. Retrieved from http://search.proquest.com/docview/1465034771? accountid=14782

Murray, W. E., \& Overton, J. (2003). Designing development research. Development fieldwork a practical guide, London: Sage.

Nam Theun 2 hydroelectric project (2005). Summary of the concession agreement between the government of the Lao PDR and Nam Theun 2 power company limited. Vientiane: Nam Theun 2 power company Ltd. 
Nam Theun 2 hydroelectric project (n.d.). Nakai Resettlers' Reality: From the Past to the Future. Vientiane: Nam Theun 2 power company Ltd.

Nam Theun 2 hydropower project (2005). Social Development Plan: Executive summary. Vientiane: Nam Theun 2 power company Ltd.

Nam Theun 2: Independent Assessments. (n.d.). Retrieved from http://web.worldbank.org/WBSITE/EXTERNAL/COUNTRIES/EASTASIAPAC IFICEXT/LAOPRDEXTN/0,,contentMDK:21109084 pagePK:141137 piPK:14 1127 theSitePK:293684,00.html

Nam Theun 2 project (2005). Social Development Plan: "Volume 4-Chapter 1: Project Description”. Vientiane: Nam Theun 2 power company Ltd.

Nam Theun 2 project (2005a). Social Development Plan: "Volume 2-Chapter 2: Baseline Data-Nakai Plateau”. Vientiane: Nam Theun 2 power company Ltd.

Nam Theun 2 project (2005b). Social Development Plan: "Volume 2 - Chapter 10: Resettlement Site Selection, Land Use Planning and Land Tenure." Vientiane: Nam Theun 2 power company Ltd.

Nam Theun 2 project (2005c). Social Development Plan: "Volume 2 - Chapter 16:

Livelihood integration and income scenarios - transition to stability”. Vientiane: Nam Theun 2 power company Ltd.

Newman, I., \& Benz, C. R. (1998). Qualitative-quantitative research methodology: Exploring the interactive continuum. SIU Press.

Neumayer, E. (2003). Beyond income: convergence in living standards, big time. Structural Change and Economic Dynamics, 14(3), 275-296.

Neuendorf, K. A. (2002). The content analysis guidebook. Sage.

NT2 Concession Agreement (CA) (2005). NT2 Concession Agreement Volume 2A, Schedule No. 4 Part 1 (Vol. 2, pp. 1-132). Vientiane.

Oliver-Smith, A. (Ed.). (2009). Development \& dispossession: The crisis of forced displacement and resettlement. School for Advanced Research Press. 
Oliver-Smith, A., \& de Sherbinin, A. (2014). Resettlement in the twenty-first century. Forced Migration Review, (45), 23-25. Retrieved from http://search.proquest.com/docview/1503672925?accountid=14782

Ovenden, M. (2007). Nam Theun 2 Hydro Power Project-Resettlement Action Plan (Vol. 1: General Information, pp. 1-66). Vientiane: Nam Theun 2 power company Ltd.

Pearce, D. (1988). Economics, equity and sustainable development. Futures, 20(6), 598-605.

Phonepraseuth, V. (2012). From resettlement to sustainable livelihood development: The potential of resettlement and livelihood restoration arrangement to achieve livelihood sustainability. A case study of resettled communities on the Nakai plateau Nam Theun 2 hydropower project in Lao PDR (Unpublished Master's thesis). Massey University, New Zealand.

Pieterse, J. N. (1998). My paradigm or yours? Alternative development, post-development, reflexive development. Development and Change, 29(2), 343-373.

Pollard, A. (2009). Field of screams: difficulty and ethnographic fieldwork. Anthropology Matters, 11(2), 1-24.

Porter, I. C., \& Shivakumar, J. (Eds.). (2010). Doing a dam better: the Lao People's Democratic Republic and the story of Nam Theun 2. World Bank Publications.

Rew, A., Fisher, E., \& Pandey, B. (2006). Policy Practices in Development-induced Displacement. Development-induced displacement: Problems, policies, and people, $18,138$.

Rose, G. (1997). Situating knowledges: positionality, reflexivities and other tactics. Progress in human geography, 21(3), 305-320.

Sandelowski, M. (2000). Focus on research methods combining qualitative and quantitative sampling, data collection, and analysis techniques. Research in nursing \& health, $23,246-255$.

Santillo, D. (2007). Reclaiming the Definition of Sustainability (7 pp). Environmental Science and Pollution Research, 14(1), 60-66.

Satiroglu, I., \& Choi, N. (2015). Development-Induced Displacement and Resettlement. 
Scoones, I. (2009). Livelihoods perspectives and rural development. The Journal of Peasant Studies, 36(1), 171. doi:10.1080/03066150902820503

Singh, S. (2009). World Bank-directed Development? Negotiating Participation in the Nam Theun 2 Hydropower Project in Laos. Development and Change, 40(3), 487-507.

Singh, S. (2011). Bureaucratic migrants and the potential of prosperity in upland Laos. Journal of Southeast Asian Studies, 42(02), 211-231.

Smith, K. E. (2006). Problematising power relations in 'elite' interviews. Geoforum, 37(4), 643-653. doi:10.1016/j.geoforum.2005.11.002

Sørensen, H. T., Sabroe, S., \& Olsen, J. (1996). A framework for evaluation of secondary data sources for epidemiological research. International Journal of Epidemiology, $25(2), 435-442$.

Souksavath, B., \& Nakayama, M. (2013). Reconstruction of the livelihood of resettlers from the nam theun 2 hydropower project in laos. International Journal of Water Resources Development, 29(1), 71-86. doi:http://dx.doi.org/10.1080/07900627.2012.738792

Sultana, F. (2007). Reflexivity, positionality and participatory ethics: Negotiating fieldwork dilemmas in international research. ACME: An International E-Journal for Critical Geographies, 6(3), 374-385.

Tofail, M. M., \& Kaidab, N. (2015). Evaluating potential benefits of welfare packages for development-induced involuntary resettlement in bangladesh. Journal of Sustainable Development, 8(1), 203-217. Retrieved from http://search.proquest.com/docview/1658689713?accountid=14782

Tourangeau, R., \& Yan, T. (2007). Sensitive questions in surveys. Psychological bulletin, $133(5), 859$.

Victor, P. A. (1991). Indicators of sustainable development: some lessons from capital theory. Ecological economics, 4(3), 191-213.

Walker, Susan,B.A., B.Ed, Read, Susan, PhD, MA,R.N.M.H., CertEd(F.E.), \& Priest, Helena, PhD, MSc,B.A.Dip, NurseEd. (2013). Use of reflexivity in a mixed- 
methods study. Nurse Researcher, 20(3), 38-43. Retrieved from

http://search.proquest.com/docview/1285579159?accountid=14782

Wals, A. E., \& Jickling, B. (2002). "Sustainability" in higher education: from doublethink and newspeak to critical thinking and meaningful learning. International Journal of Sustainability in Higher Education, 3(3), 221-232.

Webber, M., \& McDonald, B. (2004). Involuntary resettlement, production and income: Evidence from Xiaolangdi, PRC. World Development, 32(4), 673-690.

Wilmsen, B., Webber, M., \& Yuefang, D. (2011). Development for whom? Rural to urban resettlement at the Three Gorges Dam, China. Asian Studies Review, 35(1), 21 42.

Wolnicki, M. (2012). Restoring pragmatism in American governance. International Journal of Social Economics, 39(7), 490-502. doi:http://dx.doi.org.helicon.vuw.ac.nz/10.1108/03068291211231678

World Bank (2015), Data: Lao PDR. Retrieved from http://data.worldbank.org/country/lao$\mathrm{pdr}$

Yin, R. K. (2013). Case study research: Design and methods. Sage publications. 